University of Louisville

ThinkIR: The University of Louisville's Institutional Repository

Electronic Theses and Dissertations

8-2009

\title{
Mitochondrial targeting of the pro-apoptotic protein Bax : Role of the Bax carboxy-terminal tail.
}

Stephanie Erin Brock 1980-

University of Louisville

Follow this and additional works at: https://ir.library.louisville.edu/etd

\section{Recommended Citation}

Brock, Stephanie Erin 1980-, "Mitochondrial targeting of the pro-apoptotic protein Bax : Role of the Bax carboxy-terminal tail." (2009). Electronic Theses and Dissertations. Paper 155.

https://doi.org/10.18297/etd/155

This Doctoral Dissertation is brought to you for free and open access by ThinkIR: The University of Louisville's Institutional Repository. It has been accepted for inclusion in Electronic Theses and Dissertations by an authorized administrator of ThinkIR: The University of Louisville's Institutional Repository. This title appears here courtesy of the author, who has retained all other copyrights. For more information, please contact thinkir@louisville.edu. 


\title{
MITOCHONDRIAL TARGETING OF THE PRO-APOPTOTIC PROTEIN BAX: \\ ROLE OF THE BAX CARBOXY-TERMINAL TAIL
}

By

Stephanie Erin Brock

B.S., University of Kentucky, 2002

\author{
A Dissertation \\ Submitted to the Faculty of the \\ University of Louisville School of Medicine \\ in Partial Fulfillment of the Requirements \\ for the Degree of \\ Doctor of Philosophy \\ Department of Biochemistry and Molecular Biology \\ University of Louisville \\ Louisville, Kentucky
}





\title{
MITOCHONDRIAL TARGETING OF THE PRO-APOPTOTIC PROTEIN BAX: \\ ROLE OF THE BAX CARBOXY-TERMINAL TAIL
}

\author{
By
}

Stephanie Erin Brock

B.S., University of Kentucky, 2002

A Dissertation Approved on

July 8, 2009

by the following Dissertation Committee

Dr. Binks Wattenberg

Dissertation Director

Dr. Paula Bates

Dr. Barbara Clark

Dr. Steven Ellis

Dr. Ronold Gregg 


\section{ACKNOWLEDGEMENTS}

I would like to express my profound gratitude to my mentor, Dr. Binks Wattenberg, for his never-ending encouragement, support, and patience. He has been an incredible scientific role-model and teacher. Without him this work would not have been possible. I am also extremely grateful to the members of my dissertation committee, Dr. Paula Bates, Dr. Barbara Clark, Dr. Steven Ellis, and Dr. Ronald Gregg for their time and support. I would like to thank the past and present members of our laboratory (Deanna Siow, Charles Anderson, Amy Massey, and Christine Simmons) who have made great contributions throughout my time as a graduate student. Their support and helpful discussions in the lab have been invaluable. Additionally, our friendships will always remain. I am very appreciative of the members of the University of Louisville Department of Biochemistry and Molecular Biology and the Brown Cancer Center Molecular Targets group for the immeasurable contribution to my growth as a scientist. Thanks is also owed to Marlene Steffen for all of her support. In addition to professional support, I have formed great friendships with these people. I must express my appreciation for the financial support of the American Heart Association predoctoral fellowship grant. Finally, I would like to express my immense appreciation and love for my family and my partner, Tiffany, for all of their support and unwavering love. I am the luckiest person in the world to have each of them in my life. Without them I would never be where I am today. 


\title{
ABSTRACT \\ MITOCHONDRIAL TARGETING OF THE PRO-APOPTOTIC PROTEIN BAX
}

\author{
Stephanie Erin Brock
}

July 08, 2009

Here, $I$ address the function of the carboxy-terminal hydrophobic helix of the pro-apoptotic protein Bax. There has been considerable controversy as to whether this sequence is required for the targeting and insertion of Bax into the mitochondrial outer membrane. The Bax carboxy-terminal tail is tucked into a hydrophobic pocket within the closed/inactive conformation of Bax. Apoptotic stimulation results in an opening of the Bax conformation, exposing a mitochondrial-targeting signal and subsequent insertion of Bax into the mitochondrial outer membrane. Here, I confirm that the Bax tail alone can specifically target and anchor a cytosolic passenger protein to the mitochondria. Surprisingly, however, I find that the carboxy-terminal tail is not responsible for the specific targeting of Bax to the mitochondria rather than other cellular membranes. Specifically, replacing the Bax tail with an ER-targeting tail-anchor had no effect on Bax mitochondrial targeting, in the context of full-length Bax. This contrasts to the targeting function of tail-anchor signals in other tailanchored proteins. In addition, I demonstrated that the Bax tail has a negative 
regulatory effect on Bax activation. Mutations that disrupt the interaction of the Bax tail with the hydrophobic pocket resulted in an open/active conformation of Bax and constitutive mitochondrial targeting. Deletion of the Bax tail also resulted in an open/active conformation of Bax, however the anchor-deleted form of Bax was not associated with mitochondria. This indicates a requirement of the Bax tail for mitochondrial translocation. By introducing charged residues into the tail sequence to block insertion of the sequence into the hydrophobic bilayer, I show that insertion of the Bax tail is required for Bax mitochondrial targeting. My data support a model whereby the Bax tail must be released from its hydrophobic pocket to initiate the change into an open/active conformation. The tail then functions as an anchor to stabilize Bax at the mitochondrion after the initial addressing step. 


\section{TABLE OF CONTENTS}

$\underline{\text { PAGE }}$

ACKNOWLEDGEMENTS

ABSTRACT

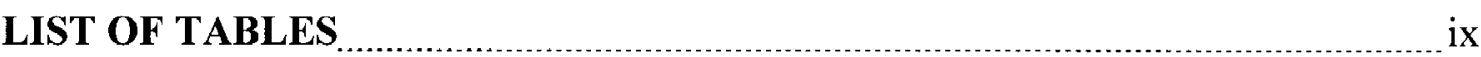

LIST OF FIGURES $\ldots \ldots$

CHAPTER I

INTRODUCTION

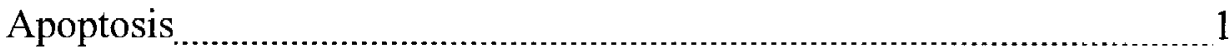

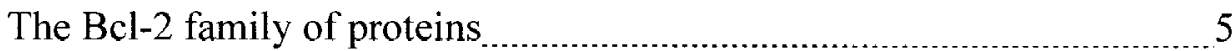

Role of Bax in apoptosis

Bax in disease states $\ldots$

Bax mitochondrial targeting and the C-terminal tail ............................ 24

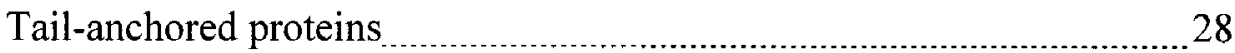

CHAPTER II

MATERIALS AND METHODS

CHAPTER III

RESULTS

The Bax carboxy-terminal tail is a bona fide mitochondrial- _ _ 44 targeting signal/anchor 
The targeting signal in the Bax tail does not play the primary

mitochondrial-addressing role in full-length Bax

Deletion of the N-terminal $\alpha$-helix1 of Bax disrupts mitochondrial targeting and results in constitutive ER-targeting

The Bax tail plays a role in regulating the membrane targeting of 60 Bax and the change into an open/active conformation of $\operatorname{Bax}$

Deletion of the Bax tail results in an open/active conformation of 66 Bax, yet Bax cannot target to the mitochondria without the tail

The constitutively-targeted $3 \times \mathrm{L}$ and $6 \times \mathrm{L}$ Bax mutants exhibit 72 enhanced apoptotic-inducing ability in comparison to wild-type and $\Delta \mathrm{C}$ Bax

Inhibiting insertion of the Bax tail disrupts Bax mitochondrial75 targeting

CHAPTER IV 80

DISCUSSION 80

CHAPTER V

RELATED PROJECT: HELIX FORMING PROPENSITIES OF 90

TAIL-ANCHOR PEPTIDES

Introduction 90

Materials and Methods 91

Results and Discussion 92 
REFERENCES

CURRICULUM VITAE 


\section{LIST OF TABLES}

1. Summary of tail-anchored proteins $\ldots$

2. Localization of artificial tail-anchor peptides 31

3. List of mutagenesis primers 38

4. Summary of conformation and localization of Bax constructs $\ldots$

5. Summary of alpha-helix content of artificial tail-anchor peptides _................ 101 


\section{LIST OF FIGURES}

$\begin{array}{ll}\text { FIGURE } & \text { PAGE }\end{array}$

1. Two main pathways to apoptosis $\ldots$

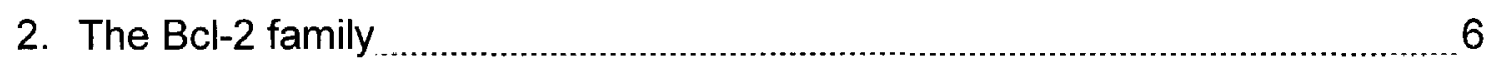

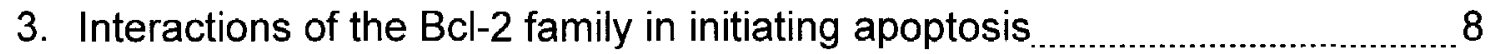

4. Localization and posttranslational modifications of $\mathrm{Bcl}-2$ proteins ................ 10

5. Structure of Bax

6. Known activators and inhibitors of Bax

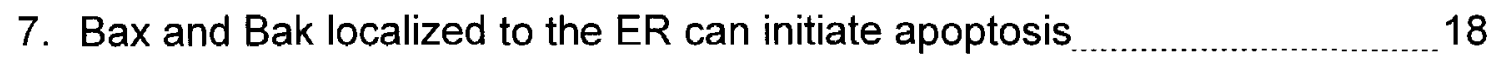

8. Bax/Bak control points of apoptosis at the ER and/or mitochondria $\ldots \ldots \ldots \ldots . . . .21$

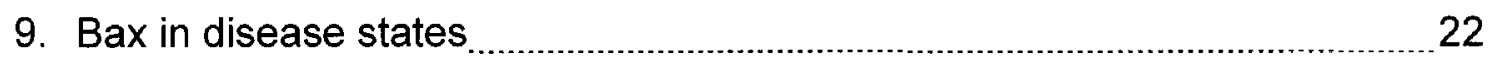

10. The orientation of the Bax C-terminal helix

11. Stages of targeting tail-anchored proteins to mitochondria

12. The Bax carboxy-terminus constitutes a mitochondrial-targeting signal $\ldots . . . .47$ that can be switched to an ER-targeting signal by increasing the overall hydrophobicity

13. The signals in the wild-type and mutated Bax tails result in membrane targeting and insertion of GFP

14. Increasing the hydrophobicity of the Bax signal/anchor in the context of 55 
full-length Bax does not alter Bax mitochondrial targeting

15. Deletion of the $\mathrm{N}$-terminal $\alpha$-helix1 of Bax results in a shift from 56 mitochondrial targeting to ER-targeting of Bax

16. Deletion of the $\mathrm{N}$-terminal $\alpha$-helix 1 of Bax results in constitutive 58 membrane targeting and insertion of full-length Bax

17. Mutations which increase the hydrophobicity of the Bax tail/anchor 62 result in constitutive membrane targeting and insertion of full-length Bax

18. The mutations made in the Bax tail result in an active conformation of 64 Bax

19. Deletion of the Bax tail results in an active conformation of Bax 68

20. Deletion of the Bax tail results in a cytosolic distribution independent 70 of apoptotic stimulus

21. In the absence of apoptotic stimulus, the constitutively-targeted $3 \times \mathrm{L}$ 73 and $6 \mathrm{xL}$ mutants of Bax exhibit enhanced apoptosis in comparison to BaxWT and Bax $\Delta \mathrm{C}$

22. Inhibiting insertion of the Bax tail by introducing charged residues 77 disrupts Bax mitochondrial-targeting

23. Model of Bax targeting to the mitochondria 88

24. The mitochondrially targeted MOA-tail peptide has a higher 94 propensity for TFE-induced $\alpha$-helix formation than the ER-targeted peptide L16

25. The mitochondrially targeted MOA-tail peptide has a higher propensity 99 
for $\alpha$-helix formation in the membrane mimetic DPC than the ERtargeted peptide L16 


\section{CHAPTER I}

\section{INTRODUCTION}

\section{Apoptosis}

Apoptosis is an important process whereby cells can induce their own demise. It is carried out by specific pathways in the cell that are tightly-regulated. This process of cell suicide was first described in 1842 by Carl Vogt, but wasn't coined "apoptosis" until 1972 by John Kerr Kerr JF, 1972. Programmed cell death is essential for the specific cell turnover in developmental processes as well as in tissue homeostasis. It is also important in the elimination of damaged or infected cells Strasser A, 2000. Cells undergoing apoptosis display very distinct characteristics. These include cell shrinkage, chromatin condensation, DNA fragmentation, membrane blebbing, and exposure of phosphatidyl serine on the outer leaflet of the plasma membrane. Apoptotic cell death is stimulated by two distinct pathways (Figure 1). One pathway is triggered by death receptors at the cell surface. The other pathway is initiated by cellular stress signals. Both pathways ultimately result in activation of proteases known as caspases. The death receptor pathway involves activation of death receptors including TNF, Fas and TRAIL receptors Ashkenazi A, ${ }^{1998}$. Stimulation by the respective death ligands triggers a signaling cascade within the cell. This leads to activation of caspases by triggering a specific proteolytic cleavage of the inactive procaspases to 


\section{FIGURE 1.}

\section{Stress patimuay}

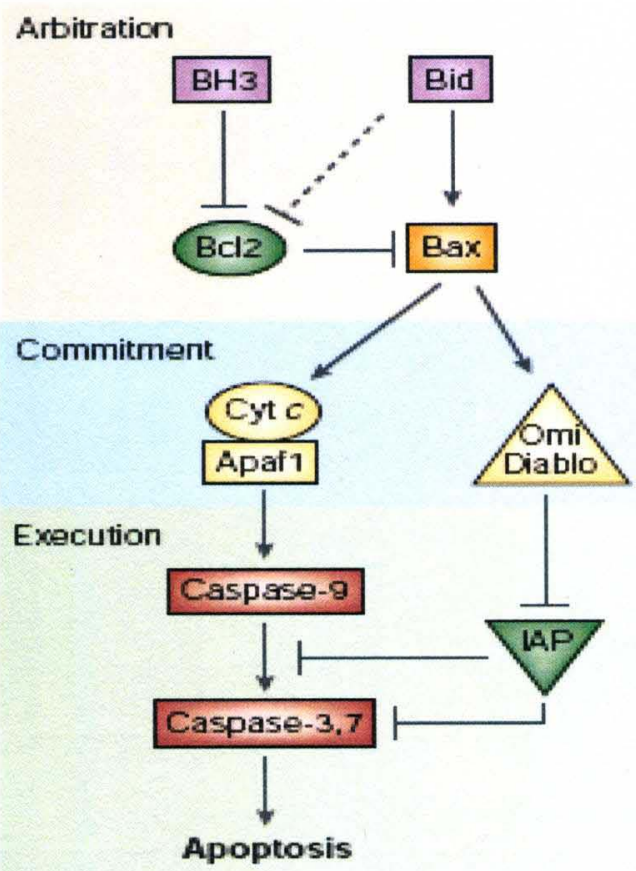

Death-receptor pattwo ay

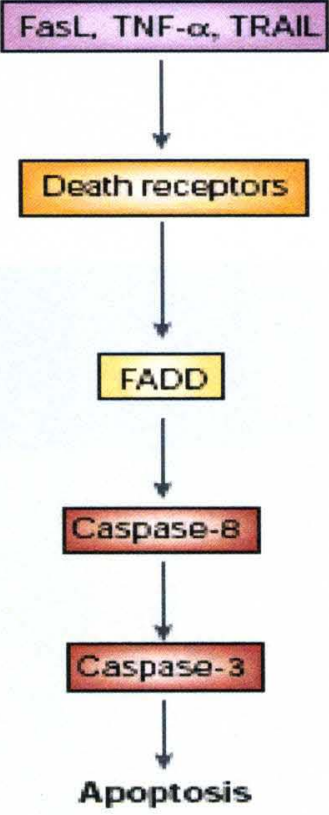

Cory S, 2002 
Figure 1. Two main pathways to apoptosis. Intracellular stress signals are mediated through the $\mathrm{Bcl} 2$ family, whereas the death-receptor pathway is activated by signals from other cells. Activity of caspase- 9 and caspase- 3 is restrained by inhibitor of apoptosis proteins (IAPs), but the IAPs can be countermanded by Diablo/Smac and Omi/HtrA2, which are released from damaged mitochondria. Apaf1, apoptotic protease-activating factor 1 ; cyt $c$, cytochrome $c$; FADD, Fas associated death-domain; FasL, Fas ligand; TNF- $\alpha$, tumournecrosis factor- $\alpha$; TRAIL, tumour-necrosis-factor-related apoptosisinducing ligand. 
produce active enzymes. These caspases then act as the executors of cell death. Caspase substrates include apoptotic proteins, inhibitors of apoptotic proteins, DNA repair enzymes, structural proteins, and negative regulators of endonucleases Strasser A, 2000 . The stress pathway is initiated by intrinsic stress signals (eg. DNA damage, oxidative stress, ER stress) or by outside signals (eg. growth factor withdrawal, irradiation, cytotoxins). Apoptosis is dependent on the mitochondria in this pathway ${ }^{\operatorname{lin} Z, 2005}$. The $\mathrm{Bcl}-2$ family of proteins deciphers and transfers these death signals to the mitochondria, inducing the release of apoptogenic factors (eg. Cytochrome c) from the mitochondria into the cytosol Green DR, 1998 . Cytochrome $c$ then interacts with Apaf-1 to form the apoptosome complex. The apoptosome cleaves pro-caspase- 9 to activate caspase- 9 , initiating the caspase activation cascade.

The apoptotic machinery must be kept in check, so that aberrant cell death does not occur Strasser A, 2000 . Inhibitors of apoptosis are found throughout both the death receptor and stress-signal pathways. Examples include the IAPs (inhibitors of apoptosis) that bind and inhibit caspases, and the anti-apoptotic members of the bcl-2 family (bcl-2, bcl-xL) that inhibit the pro-apoptotic bcl-2 members (bax, bak). The $\mathrm{Bcl}-2$ family will be described in greater detail in the next section. De-regulation of the apoptotic process is involved in a variety of disease states. When apoptosis is running un-checked, abnormal amounts of cell death occur. This can lead to neurodegeneration or cardiac disease. On the other hand, when apoptosis is not activated when cued, infected or damaged 
cells can accumulate. This can lead to states of tumorigenesis or autoimmune disease.

\section{The Bcl-2 family of proteins}

The $\mathrm{Bcl}-2$ protein was identified in 1984 where it was found to be aberrantly overexpressed in human B-cell lymphoma due to a chromosome

translocation Tsujmoto $Y, 1984$. Further studies showed that it was functioning in the inhibition of apoptosis in these cells. Following the identification of Bcl-2, various proteins containing homologous domains were discovered Adams JM, 1998. These are shown in Figure 2. These proteins contain conserved domains referred to as bcl-2 homology domains ( $\mathrm{BH} 1, \mathrm{BH} 2, \mathrm{BH} 3$ or $\mathrm{BH} 4)$. Most members of this family contain multiple homology domains, whereas some of these proteins contain only the $\mathrm{BH} 3$ domain. The $\mathrm{Bcl}-2$ protein family plays a central role in the stress-signal pathway of apoptosis ${ }^{C o r y} \mathrm{~S}, 2002$. Some of the Bcl-2 proteins induce apoptosis, while others inhibit apoptosis. The anti-apoptotic members all contain at least 3 of the $\mathrm{BH}$ domains, and include proteins such as $\mathrm{Bcl}-2, \mathrm{Bcl}-\mathrm{xL}$, and $\mathrm{Mcl}-1$. The pro-apoptotic members include multi-domain proteins (ie. Bax and Bak), as well as BH3-only proteins (ie. Bid and Bim). Various members of the Bcl-2 family can interact with themselves, as well as with other $\mathrm{Bcl}-2$ family members. These interactions are mediated via the $\mathrm{BH} 3$ domain Adams JM, 1998. These intricate interactions determine whether or not the cell will undergo apoptosis (Figure 3). The anti-apoptotic $\mathrm{Bcl}-2$ proteins can heterodimerize with the pro-apoptotic $\mathrm{Bcl}-2$ proteins, thereby inhibiting apoptotic activation. The $\mathrm{BH}$-only proteins serve as 
FIGURE 2.

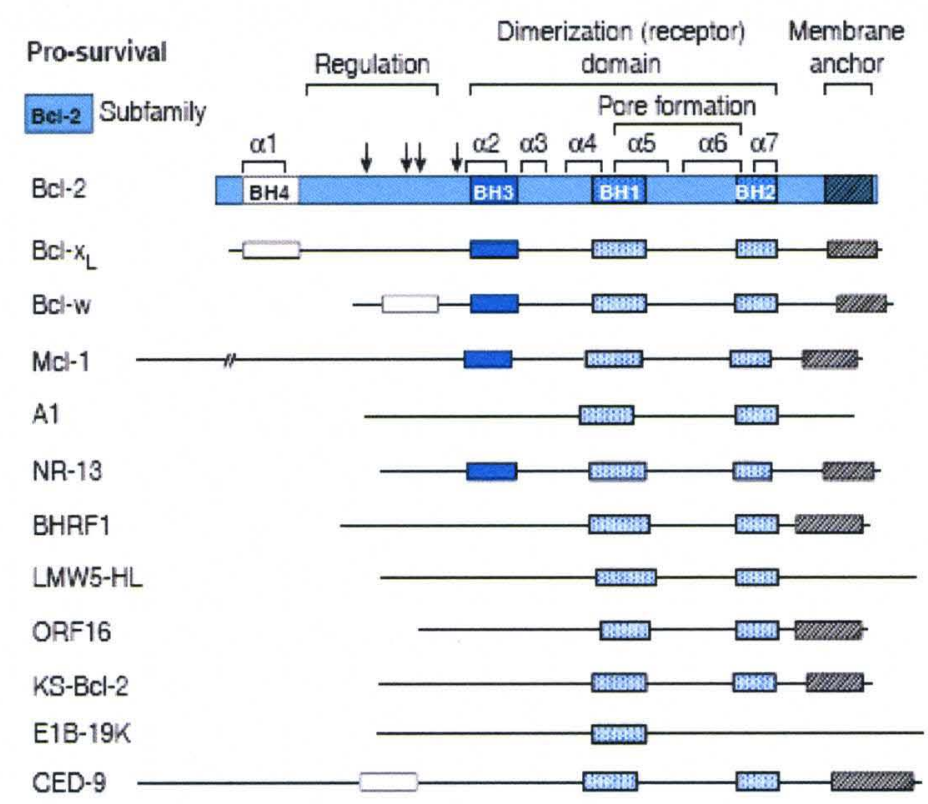

Pro-apoptosis

Bex Subfamily

Bax

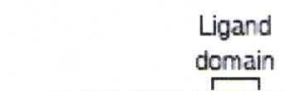

Bak

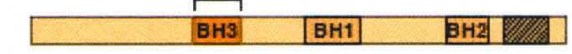

Bok

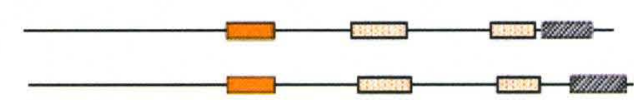

BH3 Subfamily

Bik

Blk

$\mathrm{Hrk}$

BNIP3

Bim.

Bad

Bid

EGL-1

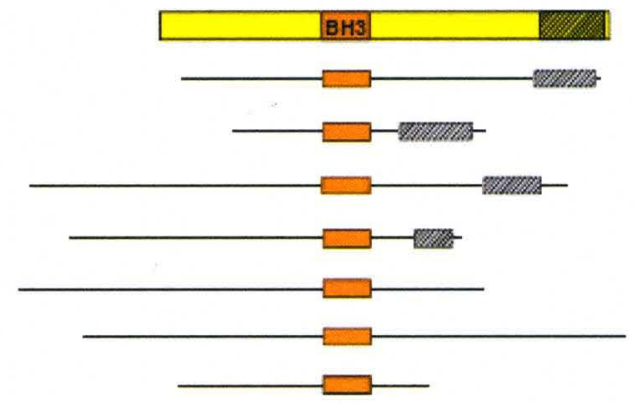

Adams JM, 1998 
Figure 2. The Bcl-2 family. Three subfamilies are indicated: The $\mathrm{Bcl}-2$ cohort promotes cell survival, whereas the Bax and $\mathrm{BH} 3$ cohorts facilitate apoptosis. $\mathrm{BH} 1$ to $\mathrm{BH} 4$ are conserved sequence motifs. The Bax subfamily resembles the Bcl-2 subfamily but lacks a functional BH4 domain. Except for the $\mathrm{BH} 3$ domain, the $\mathrm{BH} 3$ subfamily is unrelated to $\mathrm{Bcl}-2$. All proteins compared are mammalian (usually human), except for NR-13 (chicken), CED-9, and EGL-1 (C. elegans), and the viral proteins BHRF1, LMW5-HL, ORF16, KS Bcl-2, and E1B- 19K. 
FIGURE 3.

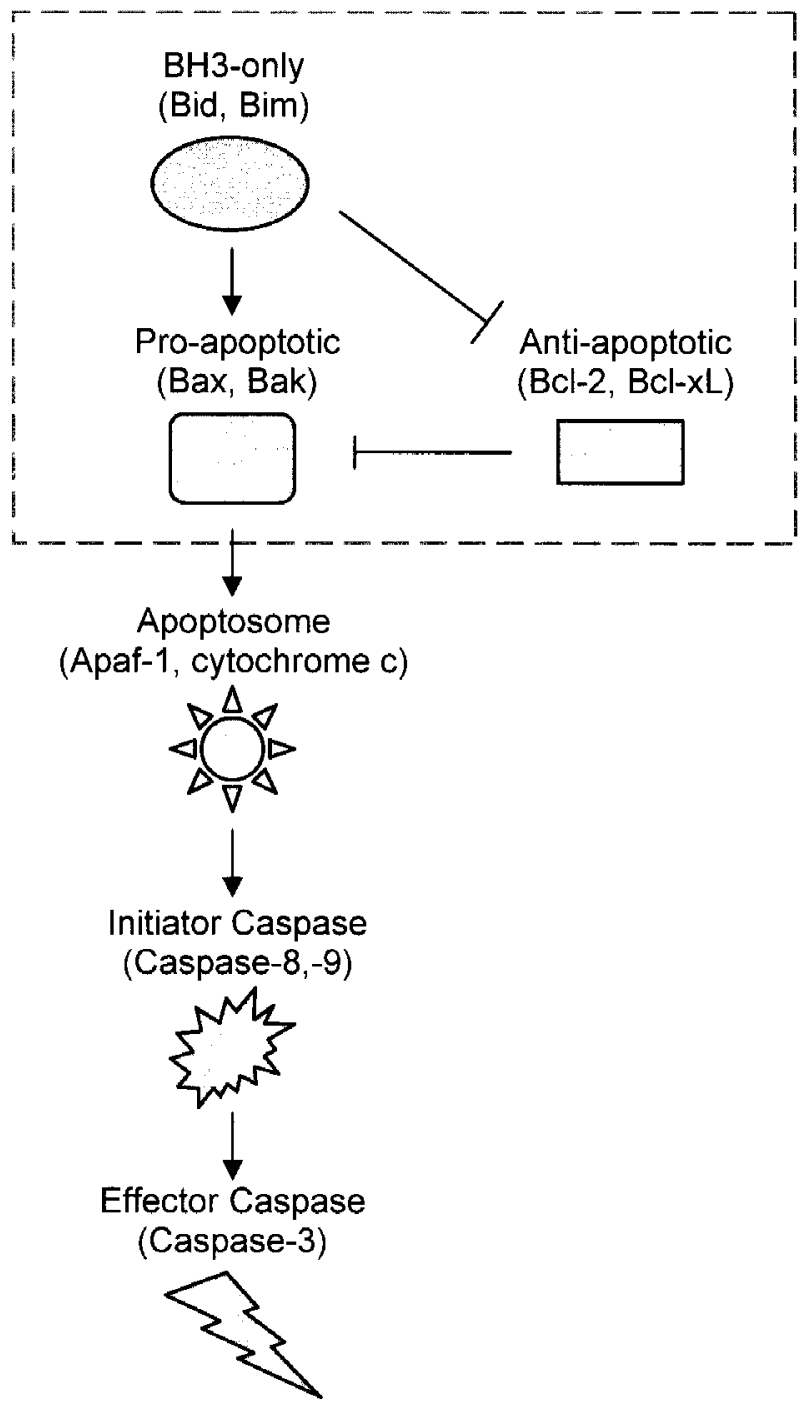

Figure 3. Interactions of the $\mathrm{Bcl}-2$ family in initiating apoptosis. 
activators of the pro-apoptotic $\mathrm{Bcl}-2$ proteins by direct interaction or indirectly by interacting with and inhibiting the anti-apoptotic $\mathrm{Bcl}-2$ proteins.

Proteins within this family are localized primarily at the mitochondria, but also to some extent at the endoplasmic reticulum (Figure 4). While some $\mathrm{Bcl}-2$ family proteins are constitutively localized to their respective membranes, some require conformational changes or posttranslational modifications to translocate to membranes Schinzel A, 2004. Posttranslational modifications include phosphorylation/dephosphorylation, proteolytic cleavage, release from inhibiting proteins, or dissociation from intracellular structures.

\section{Role of Bax in apoptosis}

Bax was discovered by Dr. Stanley Korsmeyer's group in the early 1990's Oltvai ZN, 1993 . In Korsmeyer's study, Bax was identified due to its interaction with $\mathrm{Bcl}-2$. Although Bax is similar in structure to $\mathrm{Bcl}-2$, Bax was found to work in opposition to $\mathrm{Bcl}-2$ and promote apoptosis. Bax and its closely-related $\mathrm{Bcl}-2$ family member, Bak, play a redundant role in triggering apoptosis. The presence

of one or the other is essential for the intrinsic apoptotic pathway Cheng EH, 2001; Wei MC, 2001; Zong $W X, 2001$. Mutation or deletion of Bax results in a small impairment of the apoptotic-inducing ability of cells, whereas disruption of Bak function does not exhibit any effects on apoptosis. However, inactivation of both Bax and Bak conveys resistance to various apoptotic stress stimuli in a variety of cell lines. Exogenous expression of Bax can rescue this effect. 


\section{FIGURE 4.}

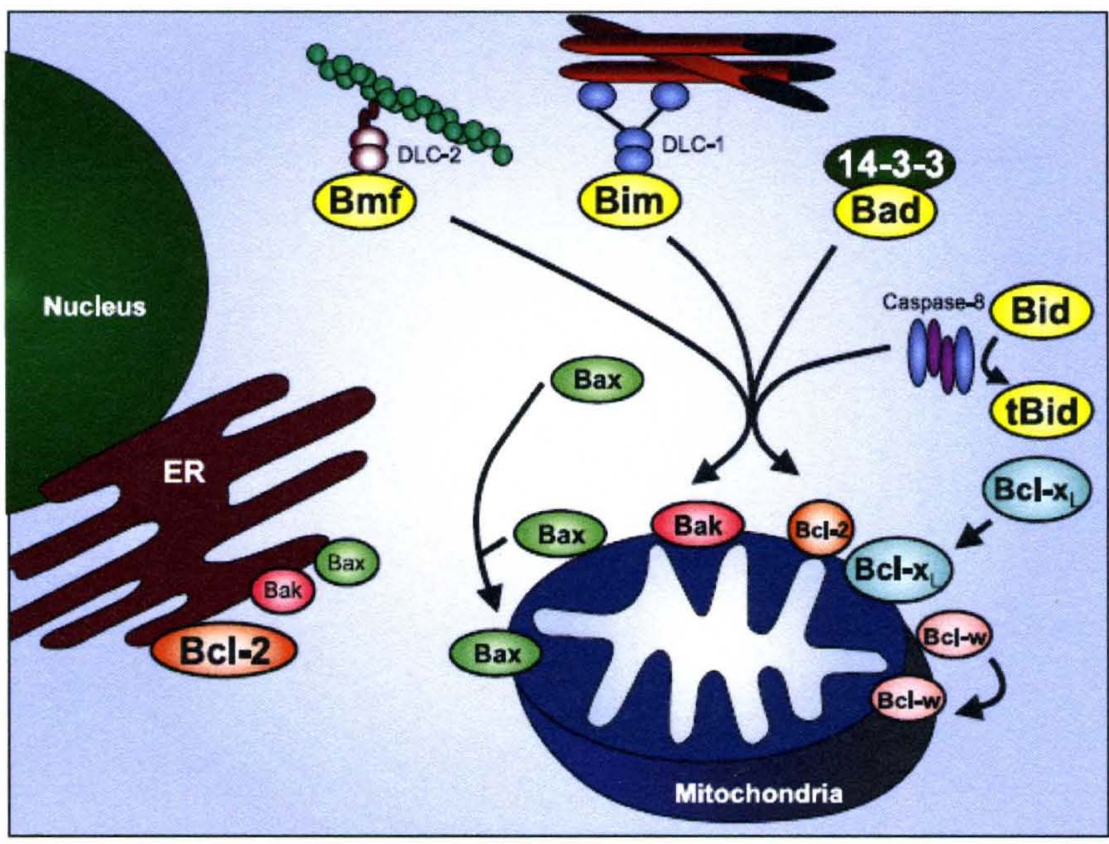

Schinzel A, 2004 
Figure 4. Localization and posttranslational modifications of $\mathrm{Bcl}-2$ proteins. Posttranslational modification is required for the translocation of certain multidomain and $\mathrm{BH} 3$-only $\mathrm{Bcl}-2$ family members, whilst some proteins are directly targeted to and inserted into the mitochondrial outer membrane (MOM) and/or the ER membrane (Bak, Bcl-xL and Bcl-2). In response to an apoptotic stimulus, $\mathrm{BH} 3-$ only proteins (yellow) translocate to interact with multidomain $\mathrm{Bcl}-$ 2 family members on the MOM. Bim and Bmf dissociate from cytoskeletal structures, Bad from 14-3-3 and Bid is proteolytically cleaved. Bax and Bcl-w undergo a conformational change, which allows them to translocate and/or insert into the MOM. 
In the normal state of cells, Bax is found as a soluble monomer within the cytosol. This conformation of Bax consists of a bundle of $9 \alpha$-helices (Figure 5) Suzuki M, 2000. The C-terminal tail (a-helix9) of Bax is tucked within a hydrophobic pocket. Within this pocket, the Bax tail functions to hide two important domains, the $\mathrm{BH} 3$ domain and $\alpha$-helices 5 and 6 . The $\mathrm{BH} 3$ domain is essential for Bax activity due to its requirement for oligomerization. Helices 5 and 6 are considered to be the "pore-forming domain" of Bax Annis MG, 2005. Upon apoptotic induction, Bax translocates to a mitochondrial-bound form Hsu YT, 1997; Wolter KG, 1997; Goping IS, 1998; Hsu YT, 1998; Nechushtan A, 1999; Hou Q, 2005. Translocation is due to a conformational change of Bax, resulting in a more open structure and exposure of a mitochondrial-targeting signal. This open conformation of Bax can be detected using a conformation-specific antibody (termed 6a7) that binds to an $\mathrm{N}$ terminal epitope. This epitope is normally hidden in the closed conformation of Bax Hsu YT, 1998, Hsu YT, 1997, Yethon JA, 2003. The mitochondrial-bound form of Bax consists of insertion of the putative "pore-forming domain" $\alpha$-helices 5 and 6 , and the C-terminal tail $\alpha$-helix9 Annis MG, 2005. This was determined by chemically labeling residues within the potential transmembrane sequences of $\alpha$-helices 5 , 6, and 9. A membrane-impermeant modifying agent was then used to probe for the chemical labels. Insertion within the bilayer protected against modification of the chemical labels. At the mitochondrial outer membrane (MOM), Bax homooligomerizes and stimulates the release of apoptotic factors such as cytochrome c from the mitochondria Antonsson B, 2000; Antonsson B, 2001; Annis MG, 2005; Sharpe JC, 2004; Jurgensmeier JM, 1998 . Cytochrome $c$ then interacts with Apaf-1 in the cytosol, initiating 


\section{FIGURE 5.}

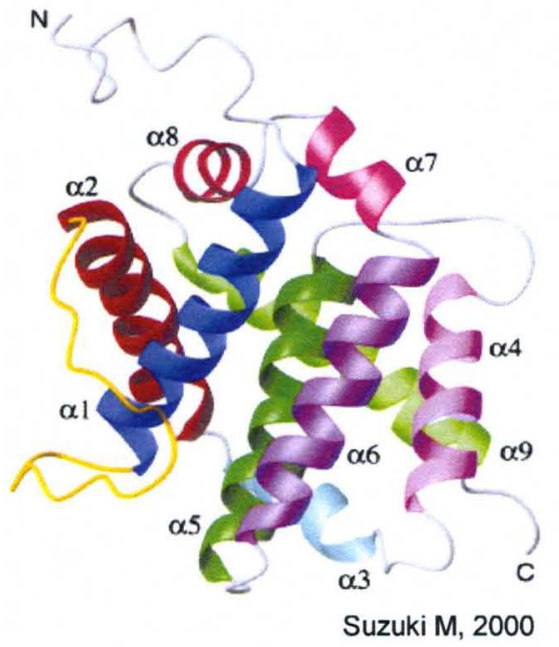


Figure 5. Structure of Bax. A ribbon representation of an averaged minimized NMR structure for the closed conformation of Bax. Helices are distinguished by different colors. Residues S16- A35, A54-D71, M74-A81, R89-M99, G108-C126, P130 E146, L149-D154, W158-Y164, W170-W188 make up helices a1, a2, a3, a4, a5, a6, a7, a8, a9, respectively. $\alpha$-helix9 is designated by lime green. 
the formation of the oligomeric apoptosome complex. The apoptosome complex promotes activation of caspases in the cell, resulting in cell death.

Bax has been widely studied, yet the details of its activation remain unclear. Addition of an apoptotic cytosolic extract can induce Bax translocation to mitochondria in vitro. This supports the notion that soluble cytosolic factors can activate Bax Goping IS, 1998; Nomura M, 1999. Many apoptotic stimuli that induce Bax activation have been identified, yet the mechanisms that lead to this activation remain to be elucidated. One generally accepted model is that the $\mathrm{BH}$-only $\mathrm{Bcl}-$ 2 family members, such as Bid and Bim, interact directly with Bax, leading to Bax activation Kuwana T, 2005; Eskes R, 2000; Desagher S, 1999; Marani M, 2002; Roucou X, 2002 . However, other activation mechanisms, and control of Bax activation, appear to operate as

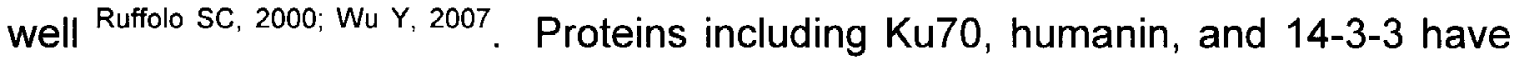
been identified to interact with Bax and inhibit Bax translocation and activation Sawada M, 2003; Guo B, 2003; Nomura M, 2003. Anti-apoptotic Bcl-2 family proteins such as $\mathrm{Bcl}-2$ and $\mathrm{Bcl}-\mathrm{xL}$ also act to prevent Bax conformational change, translocation, oligomerization and activity Jurgensmeier JM, 1998; Finucane DM, 1999; Murphy KM, 2000; Yi X, 2003; Antonsson B, 2001; Dlugosz PJ, 2006; Billen LP, 2008 . Therefore, activation of Bax could be partly due to disruption of these inhibitory interactions. Known activators and inhibitors of Bax are displayed in Figure 6. Bax inserted at the membrane can also act to recruit cytosolic Bax to the mitochondria. This autoactivation leads to a positive feedback loop after initial Bax targeting Billen LP, 2008.

Bax action at the MOM is also incompletely understood. One model describes a Bax interaction with pre-existing MOM channels that is responsible 


\section{FIGURE 6.}

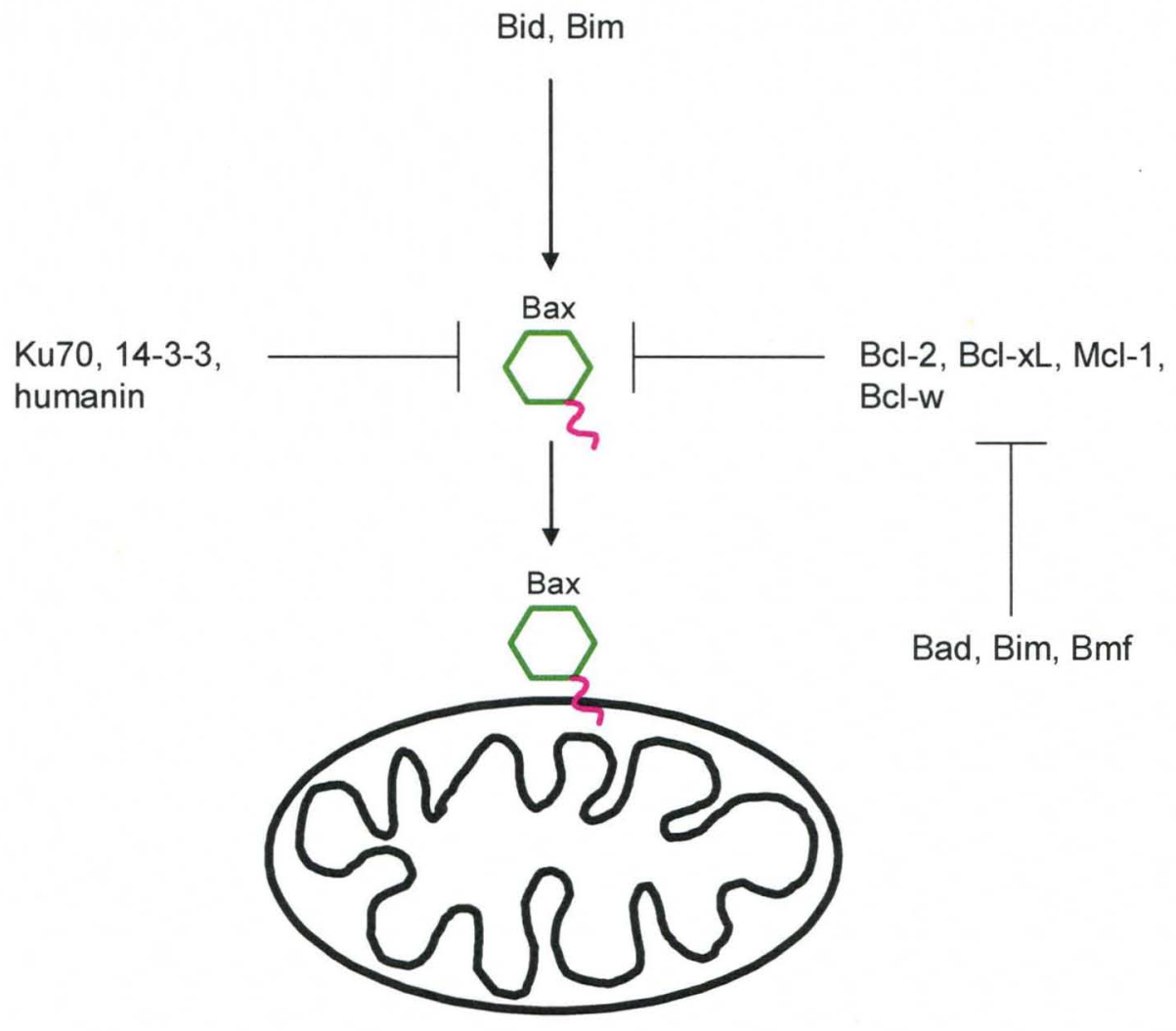

Figure 6. Known activators and inhibitors of Bax. 
for the release of apoptotic factors. Specifically, Bax has been shown to interact with the voltage-dependent anion channel (VDAC or porin) and the adenine nucleotide translocator (ANT). These two channels comprise the permeability transition pore (PTP) of the mitochondria Marzo I, 1998; Narita M, 1998; Brenner C, 2000; Capano M, 2002, Belzacq AS, 2003. According to this model, Bax cooperates with these channels to allow for passage of apoptotic components through the pores. However, the detection of these Bax interactions with the PTP have been challenged Eskes R, 1998; Finucane DM, 1999; Antonsson B, 2001; Mikhailov V, 2001 . Specific blocking of the PTP does not inhibit Bax-induced release of cytochrome $c$ in vitro Eskes R, 1998. These results support a second model in which Bax oligomerization alone leads to direct pore formation allowing for release of these factors. During apoptosis, Bax is found in an oligomeric state at the MOM. This oligomerization is mediated by the $\mathrm{BH} 3$ domain of Bax Antonsson B, 2001; Zha H, 1996; Wang K, 1998 . In vitro studies have shown that Bax oligomers can form pores in artificial membranes Adams JM, 1998; Antonsson B, 1997; Schlesinger PH, 1997; Antonsson B, 2000; Saito M, 2000. Bax oligomers can also mediate the release of cytochrome $\mathrm{c}$ from isolated mitochondria, whereas monomeric Bax cannot. In addition, a glycoprotein, clusterin, specifically blocks Bax oligomerization, subsequently inhibiting Bax-induced apoptosis Zhang H, 2005 . These data indicate that Bax oligomerization is essential for the release of apoptotic factors from the mitochondria.

For the most part, Bax specifically translocates to the mitochondria. However, a small portion of Bax can also localize to the endoplasmic reticulum (ER) to mediate apoptosis (Figure 7). ER stress agents can induce translocation 


\section{FIGURE 7.}

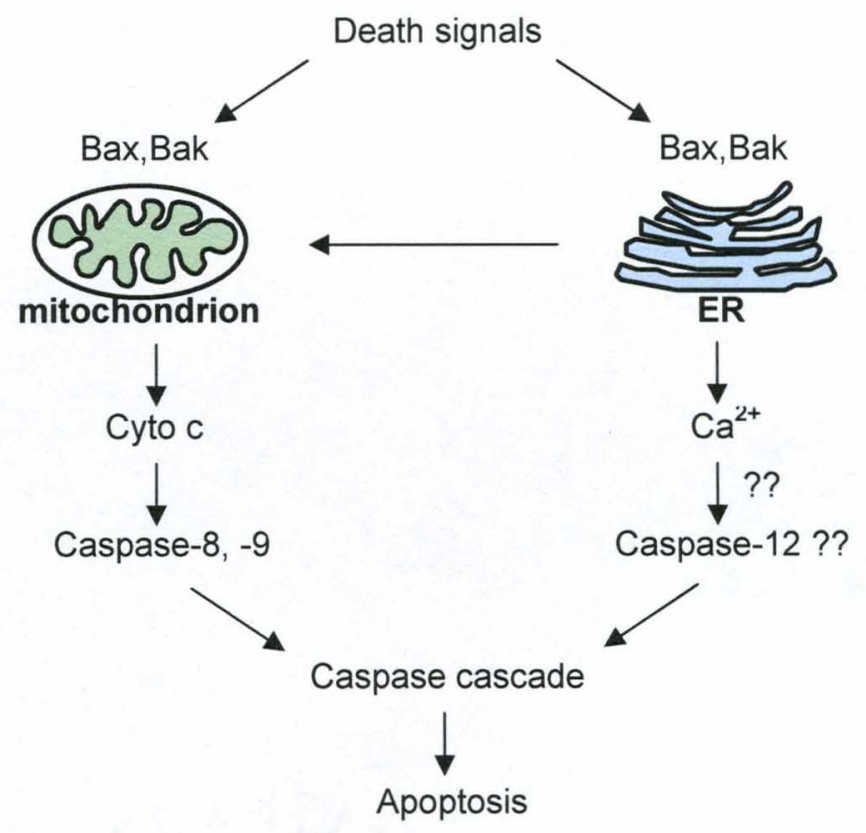


Figure 7. Bax and Bak localized to the ER can initiate apoptosis. In addition to their mitochondrial localization and activity, Bax and Bak also reside at the ER. Upon ER stress treatment, Bax and Bak can initiate apoptosis from the ER. 
and oligomerization of Bax at the ER. This subsequently induces caspase 12 cleavage and apoptosis Zong WX, 2003; Adams JM, 1998. Studies have shown that Bax can regulate $\mathrm{Ca}^{2+}$ storage of the ER. This can then increase the $\mathrm{Ca}^{2+}$ uptake into the mitochondria, thereby triggering apoptosis Nutt LK, 2002; Nutt LK, 2002; Scorrano L, 2003; Oakes SA, 2005. A direct interaction of Bax with the ER transmembrane protein, IRE1 $\alpha$, has also been detected. IRE1 $\alpha$ mediates the unfolded protein response (UPR) of the ER Hetz C, 2006. Therefore, it seems that depending on the upstream apoptotic stimulus, Bax can translocate to the mitochondria or the ER to induce apoptosis (Figure 8) Scorrano L, 2003.

\section{Bax in disease states}

Because Bax is a key determinant in cell death, Bax inactivation or overactivation has been implicated in a variety of disease states (Figure 9). Impairment of Bax-induced apoptosis can lead to autoimmune disease or oncogenesis. Bax conditional deletion results in an increased number of $B$ cells and results in severe autoimmune disease in adult mice Takeuchi 0, 2005. The role of Bax in tumorigenesis has been studied to a much greater extent. Analysis of Bax expression and Bax function in a variety of different cancer cells indicates that Bax possesses tumor-suppressor function. Bax expression was shown to be downregulated in hepatocellular carcinomas as well as in breast cancer Beerheide W, 2000; Bargou RC, 1995. Frameshift mutations, missense mutations, and/or single amino-acid substitutions have been detected in colorectal cancers, gastrointestinal cancers, hematopoietic malignancies, stomach cancers, and 


\section{FIGURE 8.}

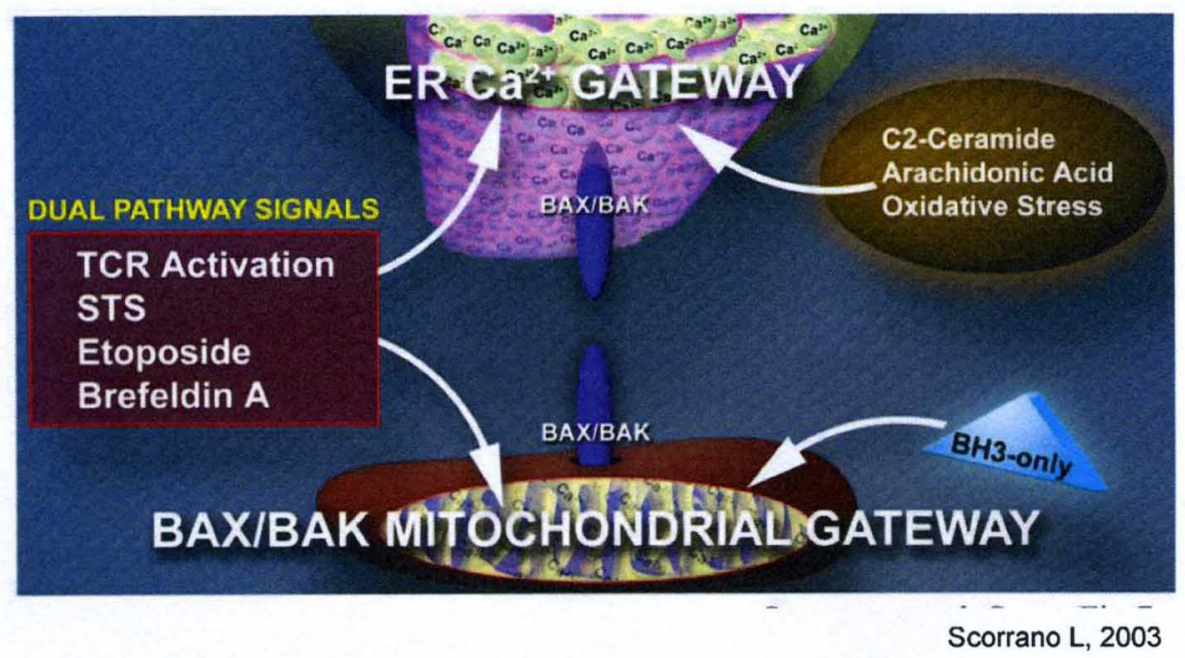

Figure 8. Schematic representation of BAX/BAK control points of apoptosis at level of ER $\mathrm{Ca}^{2+}$ or mitochondria and categories of stimuli that demonstrate a requirement for each or display dual use of the pathways. 


\section{FIGURE 9.}
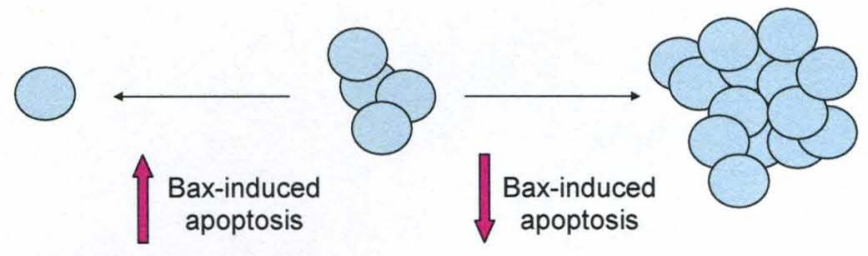

Neurodegeneration

Cardiac disease

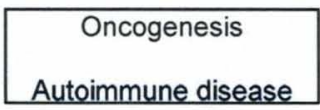

Figure 9. Bax in disease states. 
endometrial cancers Rampino N, 1997; Gil J, 1999; Yamamoto H, 1997; Meijerink JP, 1998; Ouyang H, 1998 . Cells deficient in Bax expression, including epithelial cancer cells and colon carcinoma cells, displayed resistance to multiple apoptotic-inducing stimuli and anti-cancer agents Zhang L, 2000; LeBlanc H, 2002; Theodorakis P, 2002. Additionally, Bax deficiency in mice displayed increased tumor growth and decreased apoptotic ability Yin C, 1997 . These results designate Bax as a possible therapeutic target in oncogenesis. Initial studies have produced promising results of the therapeutic potential of Bax. Exogenous overexpression of Bax increased apoptotic induction sensitivity in breast and pancreatic cancer Sakakura C, 1996; Wagener C, 1996; Xu ZW, 2002. Furthermore, overexpression of Bax using adenoviral delivery or tetracycline-dependent expression resulted in increased apoptosis and tumor regression in prostate cancer, lung cancer, and breast cancer mouse models Lix, 2001; Kagawa S, 2000; Lowe SL, 2001

Aberrant amplification of Bax-induced apoptosis can cause neurodegenerative or cardiac disease states. Increased levels of Bax have been found in a variety of neurological disorders including Alzheimer's disease, Parkinson's disease, and Huntington's disease. Studies have shown that Alzheimer's disease is associated with overexpressed levels of Bax, resulting in increased neurodegeneration Paradis E, 1996; Su JH, 1997; Tortosa A, 1998 . In a transgenic mouse model of Huntington's disease, Bax was overexpressed in affected areas of the brain and correlated with increased levels of apoptosis compared to

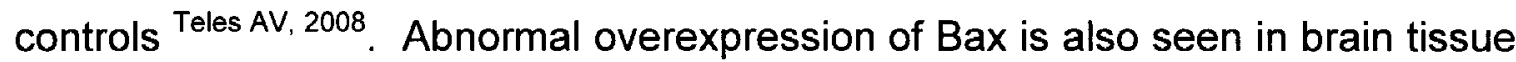
of deceased Parkinson's disease patients compared to tissue from control 
patients Vila M, 2001. It should be noted that it is difficult to distinguish cause and effect of Bax overexpression and nuerodegeneration in these studies. However, deletion of Bax increases resistance to neural cell death in a Parkinson's disease model, suggesting that Bax could be a therapeutic target in neurodegenerative disorders Vila M, 2001; Perier C, 2007. Bax is also a potential therapeutic target for heart disease Haunstetter A, 1998; Haunstetter A, 2000. Activation and translocation of Bax is detected during cardiac ischemia/reperfusion Lundberg KC, 2004; Hou Q, 2005; Capano M, 2006; Gupta S, 2005. Furthermore, absence of Bax results in increased resistance to ischemia/reperfusion in mouse hearts Hochhauser E, 2003. In Bax homozygous knockout mice (-I-), significant protective effects with ischemia/reperfusion treatment, as well as resistance to myocardial infarction, were detected compared to Bax homozygous wild-type mice (+/+) Hochhauser E, 2007; Hochhauser E, 2003.

\section{Bax mitochondrial targeting and the C-terminal tail}

The principle action of $\mathrm{Bax}$ is at the mitochondrial membrane. The mechanisms that target Bax to the mitochondria remain a matter of controversy. In particular, there is disagreement about the role of a hydrophobic alpha helix (a-helix9) at the carboxy-terminus of Bax in Bax targeting and activation. The Bax tail is tucked in a hydrophobic pocket within the inactive/closed conformation of Bax (Figure 10) Suzuki M, 2000; Cartron PF, 2005; Arokum H, 2004. Upon Bax activation, a conformational change results in release of the tail from the pocket. This exposes the previously hidden $\mathrm{BH} 3$ domain and transmembrane $a$-helices 5 and 6 . This conformational change also results in 
FIGURE 10.

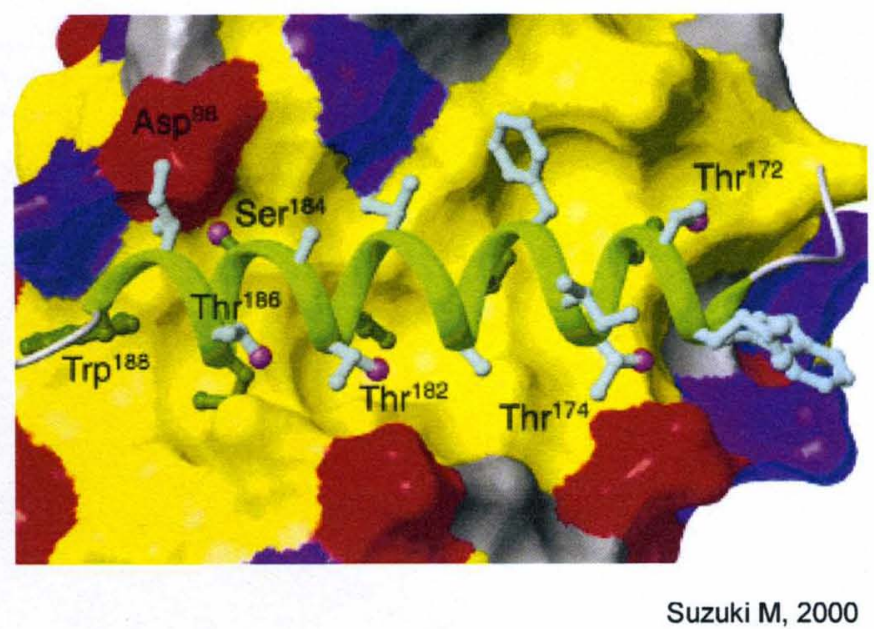


Figure 10. The Orientation of the C-terminal Helix. A close-up view of the Bax C-terminal helix and the hydrophobic pocket is shown. The side chains of the residues in the $C$ terminal helix are represented by balls and sticks. Magenta balls represent oxygen atom in threonines and serine. A surface representation of the pocket is colored red, purple, and yellow to represent negative, positive, and hydrophobic residues, respectively. 
exposure of a mitochondrial-targeting signal. In one model, upon release from the hydrophobic groove, the Bax tail serves as the mitochondrial-targeting signal. This is similar to the function of the C-terminal hydrophobic tail-anchors of $\mathrm{Bcl}-2$, $\mathrm{Bcl}-\mathrm{xL}$, and other so-called tail-anchored proteins that will be described in the next section Nguyen M, 1993; Kaufmann T, 2003; Borgese N, 2003. In support of this model, the Bax C-terminal tail alone is sufficient to target a passenger protein to the mitochondria Goping IS, 1998; Schinzel A, 2004. This model is also corroborated with tail mutation and deletion studies in full-length Bax Schinzel A, 2004; Wolter KG, 1997; Nechushtan A, 1999. These studies indicate that the Bax tail can regulate Bax targeting and is required for Bax mitochondrial localization. Mutation of a single residue (S184) within the Bax tail has significant effects on Bax translocation Nechushtan A, 1999. Deletion of this residue or substitution of this serine with a valine results in constitutive targeting of Bax to the mitochondria. On the contrary, substitution with a charged amino acid (lysine, glutamic acid, aspartic acid) inhibits translocation of Bax. Phosphorylation at this serine residue has also been detected Gardai SJ, 2004; Xin M, 2005. This phosphorylation is believed to be an important physiological regulator of Bax targeting. Specifically, Akt-mediated phosphorylation at S184 inhibits Bax translocation and Bax-mediated apoptosis. Mutation of this serine to a non-phoshorylatable residue abrogates this inhibition. These findings indicate that the Bax tail alone can regulate Bax targeting. Complete deletion of the tail $(\operatorname{Bax} \Delta \mathrm{C})$ inhibits mitochondrial localization and abrogates apoptotic activity of Bax Schinzel A, 2004; Wolter KG, 1997 . Upon addition of an apoptotic stimulus, the apoptotic-inducing ability of $\operatorname{Bax} \Delta \mathrm{C}$ is comparable to that 
of vector alone. These results imply that the Bax tail is essential for Bax targeting and function.

This model has been challenged by reports that the C-terminal tail of Bax is dispensible for targeting to the mitochondria and subsequent Bax function Cartron PF, 2003; Cartron PF, 2005; Tremblais K, 1999 . In addition, contradictory findings show that the Bax tail alone cannot target a passenger protein to the mitochondria Cartron PF, 2003 . This supports an alternative model in which a mitochondrialtargeting signal is present in Bax outside of the C-terminal tail domain. There have been reports suggesting a potential mitochondrial-targeting signal within $\alpha-$ helix1 in the N-terminal portion of Bax Cartron PF, 2003; Cartron PF, 2005; Bellot G, 2007. This $\mathrm{N}$-terminal targeting signal can localize a cytosolic passenger protein to the mitochondria. This domain was also shown to interact with the wellcharacterized mitochondrial import receptor Tom22 and the import channel Tom 40 Bellot $G, 2007$. Deletion of $\alpha$-helix1 was shown to abrogate Bax mitochondrial targeting Cartron PF, 2003. In addition, an $\alpha$-helix1 peptide could compete for binding of Bax to mitochondria in vitro.

\section{Tail-anchored proteins}

Tail-anchored proteins consist of an $\mathrm{N}$-terminal cytosolic globular domain that is tethered to an intracellular membrane by a C-terminal hydrophobic transmembrane domain, or tail-anchor Wattenberg BW, 2001; Borgese N, 2003; Habib SJ, 2003; Borgese $\mathrm{N},{ }^{2003}$. There are a variety of proteins considered to be tail-anchored proteins that have been identified and characterized (Table 1). A bioinformatic 


\section{TABLE 1.}

\begin{tabular}{|c|c|c|}
\hline Tail-anchored protein & Function & Located \\
\hline \multicolumn{3}{|l|}{ 1. Localisation proteins } \\
\hline $\begin{array}{l}\text { Vamp synaptobrevin family, } \\
\text { syntaxin family }\end{array}$ & $\begin{array}{l}\text { SNAREs, mediating events of vesicle } \\
\text { targeting and fusion }\end{array}$ & $\begin{array}{l}\text { Organelles and vesicles of endomembrane } \\
\text { system (endoplasmic reticulum) }\end{array}$ \\
\hline Vamp-1B & Unknown & Mitochondrial outer membrane \\
\hline Sec61B, Sec61y & $\begin{array}{l}\text { Protein translocation across endoplasmic } \\
\text { reticulum }\end{array}$ & Endoplasmic reticulum \\
\hline Ramp-4 & $\begin{array}{l}\text { Co-translational protein glycosylation, } \\
\text { ribosome-binding }\end{array}$ & Endoplasmic reticulum \\
\hline Sec 12 & Sar1p binding & Endoplasmic reticulum \\
\hline SRPR $\alpha$ & $\begin{array}{l}\text { Docking receptor for signal recognition } \\
\text { particle }\end{array}$ & Endoplasmic reticulum \\
\hline Tom5, Tom6, Tom7, Tom22 & $\begin{array}{l}\text { Binding translocation of mitochondrial } \\
\text { precursor proteins }\end{array}$ & Mitochondrial outer membrane \\
\hline OMP25 & Binding of inositol 5-phosphatase & Mitochondrial outer membrane \\
\hline Fis 1:Mdv2: Mdal & Dynamin recruitment protein & Mitochondrial outer membrane \\
\hline Kar1 & $\begin{array}{l}\text { Cdc3l binding and binding to spindle pole } \\
\text { body }\end{array}$ & $\begin{array}{l}\text { Outer nuclear envelope (endoplasmic } \\
\text { reticulumi }\end{array}$ \\
\hline \multicolumn{3}{|c|}{ 2. Enzymes and motabolic cofactors } \\
\hline $\begin{array}{l}\text { Dolicolphosphate mannose } \\
\text { synthase }\end{array}$ & $\begin{array}{l}\text { Transfer of mannose residues onto lipid } \\
\text { anchor }\end{array}$ & Endoplasmic reticulum \\
\hline Crtochrome $b_{\mathrm{s}}$ & Electron transfer & Endoplasmic reticulum \\
\hline OM cytochrome $b_{5}$ & Electron transfer & Mitochondrial outer membrane \\
\hline Heme oxygenase & Electron transfer & Endoplasmic reticulum \\
\hline Cytochrome P450 & Electron transfer & Endoplasmic reticulum \\
\hline Aldehyde dehydrogenase & Oxidation of small metabolites and drugs & Endoplasmic reticulum \\
\hline Monoamine oxidases & Oxidation of small metabolites and drugs & Mitochondrial outer membrane \\
\hline $\begin{array}{l}\text { Carnitine palmitovl } \\
\text { transferase | }\end{array}$ & Transfer of long-chain fatty acids & Mitochondrial outer membrane \\
\hline $\begin{array}{l}\text { Pig-A } \\
\text { Ubc6 }\end{array}$ & $\begin{array}{l}\text { Glycosylphosphoinositide anchor synthesis } \\
\text { Conjugation of ubiquitin to substrates }\end{array}$ & $\begin{array}{l}\text { Endoplasmic reticulum Golgi } \\
\text { Endoplasmic reticulum }\end{array}$ \\
\hline \multicolumn{3}{|l|}{ 3. Bel-2 family } \\
\hline Bax & Pro-apoptotic function & Mitochondrial outer membrane \\
\hline $\begin{array}{l}\text { Bok, Bcl-X } X_{s}, \text { Bak, Bik, Hrk, } \\
\text { Blk, Birm }\end{array}$ & Pro-apoptotic function & Unknown \\
\hline $\mathrm{Bcl}-\mathrm{W}, \mathrm{Mcl}-1, \mathrm{Boo}$ & Anti-apoptotic function & Unknown \\
\hline $\mathrm{Bcl}-2, \mathrm{Bcl} \mathrm{X}_{\mathrm{L}}$ & Anti-apoptotic function & $\begin{array}{l}\text { Mitochondrial outer membrane and } \\
\text { endoplasmic reticulum }\end{array}$ \\
\hline
\end{tabular}

Since the biochemical activity of the Bcl-2 family of proteins has not vet been defined, there may in fact be only two categories. There is already much evidence suggesting that the Bcl-2 family of proteins acts by localising each other and other proteins to modulate cell death signals: they might then fall into the first category. Note that the endoplasmic reticulum is continuous with the other membranes of the secretory system and that tail-anchored proteins, as best illustrated by the SNARES, can be destined for locations throughout this endomembrane system. The sorting mechanism involved in this redistribution is not known: however, localisation within the endomembrane system depends on both the transmembrane and the cytoplasmic sequences.

Wattenberg BW, 2001 
study predicts that there are over 400 such proteins encoded in the human genome Wattenberg $\mathrm{BW}, 2007$. The $\mathrm{C}$-terminal transmembrane domain serves two essential functions in the localization of tail-anchored proteins Wattenberg BW, 2001; Habib $\mathrm{S} J$, 2003; Borgese $\mathrm{N}, 2003$. First, the transmembrane domain and its flanking residues contain the sole targeting signal for specific membrane targeting. The tail alone contains sufficient information to specifically target a passenger protein to a destination membrane. Second, the C-terminal tail serves as an anchor to tether the protein to the membrane. Therefore, this signal-anchor is absolutely required for the correct targeting and insertion of these proteins. Tail-anchored proteins localize primarily to the endoplasmic reticulum or the mitochondria, and to a lesser extent at peroxisomal membranes Borgese N, 2003 . Initial targeting to the ER can be followed by transport to a variety of other cellular sites by vesicular trafficking. Some proteins are localized exclusively at a single membrane. Others, such as $\mathrm{Bcl}-2$, are more broadly distributed. The targeting signal within the C-terminal tail that differentiates between membranes does not consist of specific amino acid sequences. Instead, distinctive structural characteristics of the tail allow for differential targeting (Table 2). These characteristics include hydrophobicity, polarity, charged flanking-residues, and spacing of residues Borgese N, 2001; Horie C, 2002; Isenmann S, 1998; Habib SJ, 2003; Borgese N, 2007; Wattenberg BW, 2007. ER-targeted tail-anchored proteins contain relatively hydrophobic transmembrane sequences. Alternatively, mitochondrial-targeted tail-anchored proteins contain less hydrophobic 


\section{TABLE 2.}

Table 2 List of constructs and summary of results

\begin{tabular}{|c|c|c|}
\hline Construct & Tail-sequence & $\begin{array}{l}\text { Mitochondrial } \\
\text { targeting }\end{array}$ \\
\hline GFP-MOA Tail & EGFP_LGMDELYKSGSGSKIIGFSTSVTALGFVLYKKKLLPKS & +++ \\
\hline GHP-L $L_{16}$ & eGFP-LGMDELYKSGSGSKLLLLLLLLLLLLLLLLKKKLLPKS & $\begin{array}{l}\text {-(endoplasmic } \\
\text { reticulum) }\end{array}$ \\
\hline GFP-G3S5S7TYGil2 & EGFP_LGMDELYKSGSGSKLLGLSLSLTLLGLLLLKKKLLPKS & +++ \\
\hline GFP-G3S5S7G12 & eGPP—LGMDELYYKSGSCISKLLGLSLSLLLLGLLLLKKKLLPKS & +++ \\
\hline GHP-G3S7T9G12 & eGHP-LGMDELYKSGSGSKLLGLLLSLTLLGLLLLKKKLLPKS & ++ \\
\hline GFP-G3S7G12 & eGFP-LGMDEL YKSGSGSKLLGLLLSLLLLGLLLLKKKLLPKS & $\begin{array}{l}\text {-(endoplasmic } \\
\text { reticulum) }\end{array}$ \\
\hline KAKLLPRS & EGPP-LGMDEL YKSGSGSKLLGLSLSLTLLGLLLLKAKLLPKS & ++ \\
\hline KAAAKA & EGFP-LGMDELYKSGSGSKLLGLSLSLTLLGLLLLKAAAKA & ++ \\
\hline KAAK & eGFP-LGMDEL YKSGSGSKLLGLSLSLTLLGLLLLKAAK & ++ \\
\hline KAKA & eGFP-LGMDELYKSGSGSKLLGLSLSLTLLGLLLLKAKA & ++ \\
\hline KK & eGFP-LGMDEL YKSGSGSKLLGLSLSLTLLGLLLLKK & $\begin{array}{l}+/ \text {-(endoplasmic } \\
\text { reticulum) }\end{array}$ \\
\hline
\end{tabular}

Shown are the names given to constructs (column 1 the sequence of the sequence of $C$-terminus of each construct and a surnmary of localization experiments for each construct. In bold type are positively charged residues. Underlined is the presumptive transmembrane sequence 
transmembrane domains due to the presence of polar residues or due to containing shorter transmembrane segments. The mitochondrial-targeting tail anchors also contain positively-charged residues that flank the transmembrane sequence. Because the C-terminal sequence is the final portion of the protein to exit the ribosome during translation, targeting to the destination membrane is post-translational. Due to the hydrophobic nature of the tail-anchor, the tail is most likely bound by a cytosolic factor, such as a molecular chaperone, upon release from the ribosome (Figure 11) Lan L, 2000; Wattenberg BW, 2001. In the case of Bax, the protein itself acts as its own chaperone, whereby the C-terminal tail folds into a hydrophobic pocket within Bax Suzuki M, 2000. It has not yet been established whether a proteinaceous component directly acts as a receptor for tail-anchored proteins at the membrane Kim P, 1997; Stefanovic S, 2007; Anting U, 2005; Wattenberg BW, 2001 . Some studies have shown that pre-treating membranes with proteases abolishes targeting, while others have shown that this pre-treatment has no effect. In addition, potential membrane receptors have been identified. The requirement for a protein receptor at the membrane remains a matter of controversy. 


\section{FIGURE 11.}

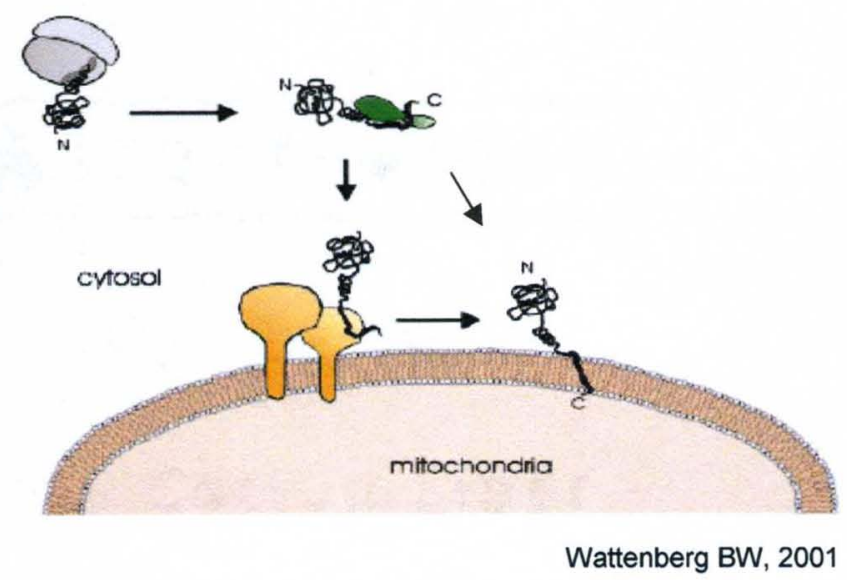


Figure 11. Stages of targeting tail-anchored proteins to mitochondria.

Nascent tail-anchored proteins can fold co-translationally in the cytoplasm and, to keep the polypeptide soluble in the cytosol, the hydrophobic tail-segments might interact with factors such as molecular chaperones (green). The identity of the soluble factor(s) is not known, but they might include general molecular chaperones such as HSP70, which are involved in the targeting of other protein precursors to the endoplasmic reticulum and mitochondria. Facilitation of tailanchor insertion into the membrane may or may not involve the TOM complex. 
Localization of Bax to the mitochondria is an essential step in Baxmediated apoptosis. However, the mechanisms that facilitate this translocation are not well-understood. It has generally been accepted that Bax is a tail-anchored protein. According to this view the C-terminal transmembrane domain facilitates targeting and anchoring of Bax to the mitochondria. However, contradictory results have made the role of the Bax tail in mitochondrial targeting a matter of debate. In light of these observations, I aim to elucidate the function of the C-terminal tail of Bax in mitochondrial translocation. 


\section{CHAPTER II}

\section{MATERIALS AND METHODS}

\section{Cell culture}

Mouse embryonic fibroblasts (MEFs) and Hela cells were grown in Dulbecco's modified Eagle's medium (DMEM) with 10\% heat-inactivated fetal bovine serum (FBS), 20mM HEPES buffer $(\mathrm{pH} 7.4), 2 \mathrm{mM}$ glutamine, $100 \mathrm{U} / \mathrm{mL}$ penicillin, and $100 \mu \mathrm{g} / \mathrm{mL}$ streptomycin. The MEFs used were generated from Bax/Bak knockout mouse embryos and were generously provided by $\mathrm{Dr}$. Chi $\mathrm{Li}$ (University of Louisville). Hela cells were purchased through the American Type Tissue Collection. All cells were incubated at $37^{\circ} \mathrm{C}$ in $5 \% \mathrm{CO}_{2}$ for culturing.

\section{Construct generation}

Baxa in the vector pcDNA3 was a gift from Dr. Richard Youle (National Institute of Health). Bax was amplified from this vector using PCR and was subcloned into pIRES-neo3 using EcoR1 and Not1 restriction enzymes. eGFP was then cloned into the $\mathrm{N}$-terminal flanking region of Bax using Nhe1 and EcoR1 restriction enzymes to generate pIRES-eGFP-Baxa. The carboxyterminal tail portion (residues 166-192) of Bax-WT was amplified from the pIRESeGFP-Bax construct using the following primers: 5' primer 5'- CCC CGG ATC CGG GAC GCC CAC GT -3' and 3' primer 5'- CCC CTC TAG ATC AGC CCA 
TCT TCT TCC AGA TGG -3'. The amplified fragment was then cloned into pcDNA3-eGFP using BamH1 and Xba1 to generate pcDNA3-eGFP-Bax-tail. The shortened version of the WT-tail construct (residues 169-192) was generated using the QuikChange site-directed mutagenesis kit (Stratagene) to delete residues 166-169 from pcDNA3-eGFP-tail (WT). The forward mutagenesis primer used was 5'-GCT GTA CAA GTC TGG TTC TGG ATC CAC GTG GCA GAC CGT GAC C -3'. The carboxy-terminal tail deleted form of Bax was generated by amplification from pIRES-eGFP-Baxa using the following primers: 5' primer 5'- GGG GGA ATT CGC CAC CAT GGA CTA CAA GGA CGA CGA CGA CAA AGA CGG GTC CGG GGA GCA -3' and 3' primer 5'- CCC CGC GGC CGC TCA GGG CGT CCC AAA GTA G-3'. The amplified product was then cloned back into pIRES-eGFP-Baxa using EcoR1 and Not1 restriction enzymes, thereby replacing Baxa. The resulting construct was pIRES-eGFPBax $\triangle C$. Amino acid substitutions for the Bax tail mutants were created using the QuikChange site-directed mutagenesis kit (Stratagene) according to the manufacturer's protocol. The template and the $5^{\prime}$ to $3^{\prime}$ primers used for each mutant are listed in Table 3. Some mutants required a two-step sequential mutagenesis. Each mutant was generated as a full-length Bax construct as well as a GFP-Bax-tail construct. The amino-terminal deleted forms of Bax were generated by amplification from pIRES-eGFP-Bax $\alpha$ (wild-type, $3 \times \mathrm{L}$, or $6 \mathrm{xL}$ ) using the following primers: 5' primer 5'- GGG GGA ATT CGC CAC CAT GGA CTA CAA GGA CGA CGA CGA CAA AGG AGG GGA GGC ACC CGA G -3' and 3' primer 5'- CCC CGC GGC CGC TCA GCC CAT CTT CTT CCA G -3'. The 


\section{TABLE 3.}

Table 3 List of mutagenesis primers

\begin{tabular}{|c|c|c|}
\hline Bax mutant & Template & 5'-3' Primer sequence \\
\hline $3 \times L$ & Bax WT & $\begin{array}{l}\text { 1st round: CGCCCACGTGGCAGCTCGTGCTCATCTTTGTGGCGGG } \\
\text { 2nd round: GTGCTCACCGCCTCACTCCTCATCTGGAAGAAGATGGGC }\end{array}$ \\
\hline $6 \times L$ & $B \operatorname{ax} 3 \times L$ & $\begin{array}{l}\text { 1st round: GCTCGTGCTCATCTTTGTGGCGCTAGTGCTCACCGCCTC } \\
\text { 2nd round: GCTCATCTTTGTGGCGCTAGTGCTCCTCGCCTTGCT }\end{array}$ \\
\hline T186K & Bax WT & GTGCTCACCGCCTCACTCAAGATCTGGAAGAAGATGGGC \\
\hline G179K & Bax WT & GAAGGTGACCATCTTTGTGGCGAAAGTGCTCACCGCCTC \\
\hline S184K & Bax WT & GCGGGAGTGCTCACCGCCAAACTCACCATCTGGAAGAAG \\
\hline S184D & Bax WT & GGCGGGAGTGCTCACCGCCGATCTCACCATCTGGAAGAAG \\
\hline S184E & Bax WT & GGCGGGAGTGCTCACCGCCGAACTCACCATCTGGAAGAAG \\
\hline V180K,L185K & $B a x W T$ & $\begin{array}{l}\text { 1st round: GACCATCTTTGTGGCGGGAAAGCTCACCGCCTCACTCACCATC } \\
\text { 2nd round: GCGGAAAGCTCACCGCCTCAAAGACCATCTGGAAGAAGATGGGC }\end{array}$ \\
\hline
\end{tabular}

Shown are a list of the names given to the Bax tail mutants. The template construct used for each of the mutants is listed as well as the 5' to 3 ' primer sequences used. Underlined nucleotides indicate mutated sites. 
amplified product was then cloned back into pIRES-eGFP-Bax $\alpha$ using EcoR1 and Not1 restriction enzymes, thereby replacing Bax $\alpha$. The resulting constructs were pIRES-eGFP-Bax $\Delta N$ (wild-type, $3 \times \mathrm{L}$, or $6 \mathrm{xL}$ ). All constructs were confirmed by sequencing.

\section{Antibodies}

Polyclonal anti-GFP (\#A11122) and polyclonal anti-PARP (214/215) cleavage site (\#44698G) were from Invitrogen. Polyclonal anti-Calnexin (\#SPA860) was from Stressgen. Monoclonal anti-Bax (6a7) (\#556467) and monoclonal anti-Cytochrome c (\#556433) were from BD Biosciences. Polyclonal anti-LDH-A (N14) (\#sc-27230) and horseradish peroxidase conjugated bovine anti-goat (\#sc2350) were from Santa Cruz. Polyclonal anti-Tom 20 was produced by this laboratory in rabbits using GST-Tom20 as an antigen. Polyclonal anti-cleaved caspase-3 (Asp175) (\#9661) was from Cell Signaling Technology. Horseradish peroxidase conjugated goat anti-rabbit (\#31460) and horseradish peroxidase conjugated goat anti-mouse (\#31430) were from Pierce.

\section{Confocal microscopy}

MEF (bax-/bak-) cells were grown on fibronectin-coated, $12 \mathrm{~mm}$ round coverslips (Fisherbrand) within the wells of a 24-well plate. Cells were plated at $7 \times 10^{4}$ cells/well for FuGENE transfection and $9 \times 10^{4}$ cells/well for LipoFectamine transfection. Transfection was done $24 \mathrm{~h}$ later using $1 \mu \mathrm{g}$ DNA/2 $\mu \mathrm{L}$ FuGENE (Roche Diagnostics) or $0.8 \mu \mathrm{g}$ DNA/2 $\mu \mathrm{L}$ Lipofectamine2000 
(Invitrogen) per well, following the protocol of the manufacturer. Indicated cells were treated with $10 \mathrm{~J} / \mathrm{m}^{2}$ ultraviolet (UV) light $24 \mathrm{~h}$ after transfection. $1 \mathrm{~h}$ after UV treatment, cells were washed in PBS, fixed in fresh 4\% paraformaldehyde for 10 min at RT, and permeabilized using PBS/0.1\% Triton X-100. Primary antibody incubation with the indicated antibodies (dilutions: $\alpha$-Tom20 1:200, $\alpha$-calnexin 1:1000, $\alpha-6 a 71: 200$ ) in PBS/0.1\% Triton X-100/3\% BSA was done for $1 \mathrm{~h}$ at RT, followed by a PBS/0.1\% Triton X-100 wash. Secondary incubation was done in PBS/0.1\% Triton X-100/3\% BSA for $1 \mathrm{~h}$ at RT using Red-Alexa 594-goat antirabbit or Red Alexa 594-goat anti-mouse secondary antibody from Molecular Probes (dilution: 1:500). Cells were then washed with PBS/0.1\% Triton X-100 and mounted in fluorescent slide mounting medium from Dako. Fluorescence was analyzed under oil immersion using a $60 \mathrm{X}$ objective of an Olympus BX51WI confocal microscope. Images are presented as Z-stacks.

\section{Subcellular fractionation}

MEF (bax-/bak-) or Hela cells were plated in $60 \mathrm{~mm}$ dishes at $1 \times 10^{6}$ cells/dish. Transfection was done using $8 \mu \mathrm{g}$ DNA/20 $\mu \mathrm{L}$ Lipofectamine2000 according to the manufacturer's protocol. At 24 hours post-transfection, designated cells were treated with $8 \mathrm{~J} / \mathrm{m}^{2}$ UV light. $4 \mathrm{~h}$ after UV treatment, cells were harvested by trypsinization and washed with PBS. The pelleted cells were brought up in $0.5 \mathrm{~mL}$ MS buffer $(210 \mathrm{mM}$ mannitol, $70 \mathrm{mM}$ sucrose, $5 \mathrm{mM}$ Tris, $1 \mathrm{mM}$ EDTA, $\mathrm{pH} 7.5)+$ complete protease inhibitor (Roche Diagnostics) and broken with 5 back and forth strokes of a ball-bearing homogenizer as previously 


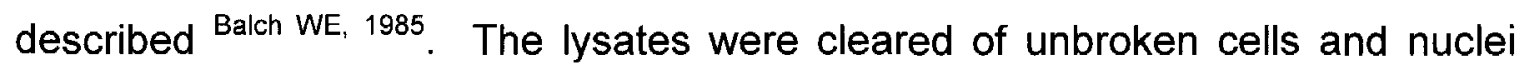
with a $600 \mathrm{rpm}$ centrifugation step for $10 \mathrm{~min}$ in a swing-bucket centrifuge (Sorvall Legend RT). Membrane was separated from cytosol by centrifugation of the cleared lysate for $20 \mathrm{~min}$ at $100,000 \mathrm{rpm}$ in a TLA 100.2 rotor using an ultracentrifuge (Beckman Optimax, Beckman-Coulter). The supernatant was removed and saved as the cytosolic fraction. For the membrane fraction, the pellet was resuspended in $75 \mu \mathrm{L}$ MS buffer + complete protease inhibitor and was subjected to 10 passages through a 26-gauge needle. For alkaline extraction, the pellet was instead resuspended in $75 \mu \mathrm{L} \mathrm{Na} \mathrm{CO}_{3}(0.1 \mathrm{M}, \mathrm{pH} 11.5)$ for $30 \mathrm{~min}$ at $4^{\circ} \mathrm{C}$ with gentle agitation. The alkaline treated sample was then centrifuged as above in a Beckman Optimax ultra-centrifuge. The supernatant was saved as the alkaline-sensitive fraction. The pellet was resuspended in $75 \mu \mathrm{L}$ MS buffer + complete protease inhibitor and was denoted as the alkaline-resistant fraction. Protein concentration was assessed using Coomassie plus Bradford protein assay reagent (Pierce). Ten micrograms of each protein fraction was separated by electrophoresis on poly-acrylamide gels, and then transferred onto PVDF membranes. After transfer, the membranes were incubated in blocking buffer (PBS/0.1\% Triton-X 100/5\% milk) for $1 \mathrm{hr}$. After washing in wash buffer (PBS/0.1\% Triton-X 100), the membranes were incubated with the indicated primary antibodies in wash buffer for $1 \mathrm{~h}$. The membranes were washed in wash buffer and then incubated in horseradish peroxidase-conjugated secondary antibody in wash buffer for $1 \mathrm{~h}$. After the final washes in wash buffer, ECL-plus 
reagent (Pierce) was added to the membrane and exposure to film was used to visualize bound antibody.

\section{Immunoprecipitation}

MEF (bax-/bak-) cells were plated in T75 flasks at $4 \times 10^{6}$ cells/flask, and transfected with Lipofectamine2000 using $16 \mu \mathrm{g}$ DNA/40 $\mu \mathrm{L}$ Lipofectamine the next day. At $24 \mathrm{~h}$ post-transfection, cells were trypsinized, and two T75 flasks were pooled for each construct transfected. The cells were washed with PBS and resuspended in $2 \mathrm{~mL}$ MS buffer + complete protease inhibitor. The cells were lysed by 3 back and forth strokes with a ball-bearing homogenizer. The lysates were cleared with a $15 \mathrm{~min}$ spin at $600 \mathrm{rpm}$ in a swinging-bucket centrifuge. The resultant supernatant was separated into a membrane and cytosol fraction as described in the subcellular fractionation section. The membrane fraction was resuspended in $0.5 \mathrm{~mL}$ CHAPS buffer (10mM HEPES, $150 \mathrm{mM} \mathrm{NaCl}, 1 \%$ CHAPS, $\mathrm{pH} 7.4)+$ complete protease inhibitor and was passed 10 times through a 26-gauge needle. The cytosolic fraction was concentrated to $500 \mu \mathrm{L}$ using Amicon Ultra centrifugal filter devices (Millipore), and $\mathrm{NaCl}$ and CHAPS were added to a final concentration of $150 \mathrm{mM}$ and $1 \%$, respectively. One milligram of each membrane or cytosol fraction was incubated with $2 \mu \mathrm{g} \mathrm{Bax} \mathrm{(6a7)} \mathrm{antibody} \mathrm{in} 500 \mu \mathrm{L}$ total volume. Each sample was rotated for $24 \mathrm{~h}$ at $4^{\circ} \mathrm{C}$. Forty microliters of protein A/G Plus agarose beads (Santa Cruz) were then added to each sample and rotated for an additional $2 \mathrm{~h}$ at $4^{\circ} \mathrm{C}$. The supernatant was removed and saved as the non-binding fraction. The beads 
were washed 3 times with CHAPS buffer using centrifugation in an Eppendorf $5415 \mathrm{R}$ microcentrifuge at $2500 \mathrm{rpm}$ for $1 \mathrm{~min}$. The beads were then resuspended in $50 \mu \mathrm{L} 1 \mathrm{X}$ SDS Loading Buffer $(60 \mathrm{mM}$ Tris pH6.8, $2 \%$ SDS, $10 \%$ glycerol, $0.02 \%$ Bromophenol Blue, $10 \% \beta$-mercaptoethanol) and boiled. The beads were pelleted and the resulting supernatant, in addition to $20 \mu \mathrm{g}$ of protein of each corresponding non-binding fraction, was analyzed by Western analysis. Western analysis was performed as described in the subcellular fractionation section.

\section{Assay for apoptotic markers}

Hela cells were plated at $2 \times 10^{5}$ cells/well in a 12-well plate. Transfection was performed $24 \mathrm{~h}$ after plating with $1.6 \mu \mathrm{g}$ DNA $/ 4 \mu \mathrm{L}$ Lipofectamine2000. Cells were harvested by trypsinization at $24 \mathrm{~h}$ post-transfection. Following the washes, the cells were resuspended in $75 \mu \mathrm{L}$ extraction buffer $(50 \mathrm{mM}$ Tris, $150 \mathrm{mM} \mathrm{NaCl}$, $0.1 \%$ Triton $\mathrm{X}-100, \mathrm{pH} 7.4)+$ complete protease inhibitor and lysed by passaging 10 times through a 26-gauge needle. The lysates were cleared by spinning at $13,000 \mathrm{rpm}$ for $15 \mathrm{~min}$ in a Galaxy 14D microcentrifuge (VWR). Twenty micrograms of protein were analyzed with Western analysis as described in the subcellular fractionation section. Probing of PARP cleavage and caspase-3 cleavage was used as an indicator of apoptosis. 


\section{CHAPTER III}

\section{RESULTS}

The Bax carboxy-terminal tail is a bona fide mitochondrial-targeting signal/anchor. Increasing the hydrophobicity of the sequence converts the Bax signal to an ER targeting signal. The function of $\alpha$-helix9 within the tail of Bax has recently been the subject of controversy. To determine the targeting ability of $\alpha$-helix9, the tail portion of Bax (residues166-192) was fused to the Cterminus of GFP (Figure 12A). Confocal fluorescence was used to measure the localization of this construct within mouse embryonic fibroblasts lacking Bax and Bak (MEF bax-/bak-). In my hands it is quite clear that a-helix9 is a strong and specific MOM targeting signal (Figure 12B). GFP alone displays a diffuse/cytosolic localization (data not shown).

To address whether the Bax tail serves a specific mitochondrial-targeting function, I sought to introduce mutations that would alter mitochondrial targeting. Initially, I explored the effect of these mutations on targeting GFP to the MOM. Studies from this and other laboratories have established that ER-targeted tailanchored proteins have relatively hydrophobic tails. In contrast, the tails of mitochondrially-targeted tail-anchored proteins are less hydrophobic and have

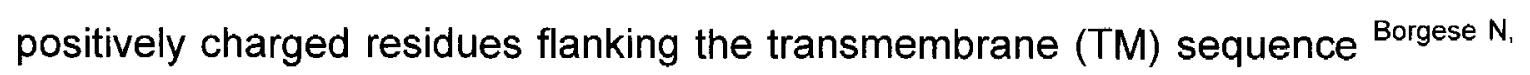
2007; Horie C, 2002; Isenmann S, 1998; Wattenberg BW, 2007. Using these general properties as a 
guide, I explored the targeting function of the Bax C-terminus. Because the Bax tail resembles a classic mitochondrial signal, I tested whether increasing the overall hydrophobicity of the Bax tail could shift targeting from the mitochondria to the ER. I specifically mutated polar residues within the Bax tail into hydrophobic leucines (Figure 12A). The $3 \times \mathrm{L}$ tail contains three substituted leucines, while the $6 \mathrm{xL}$ tail is even more hydrophobic with six substituted leucines. As shown in Figure 12B, the 3xL tail co-localized with the mitochondrial marker. This indicates that the degree of hydrophobicity is not enough to drive targeting to the ER. On the other hand, the more hydrophobic $6 \times \mathrm{L}$ tail targets GFP to the ER, as seen by the overlay of GFP with calnexin. These results confirm that the information in the Bax tail is sufficient for targeting a cytosolic protein to the mitochondria. Further, this mitochondrial-targeting signal can be switched to an ER-targeting signal by increasing the overall hydrophobicity of the tail.

I then established the degree of membrane targeting and insertion of these constructs biochemically. The GFP-tail constructs were transfected into MEF (bax-/bak-) cells, and the cells were fractionated into lysate, cytosol, and membrane portions. The wild-type, $3 \times \mathrm{L}$, and $6 \times \mathrm{L}$ tails all result in constitutive membrane targeting (Figure 13A). Moreover, the membrane-associated constructs were embedded in the membrane as assessed by resistance to extraction by sodium carbonate (Figure 13B). This reiterates the finding that the Bax tail contains all the information needed for the targeting and anchoring into membrane. My results contrast with those of Vallette's group, who reported that 
the tail of Bax alone cannot target a cytosolic protein to membrane Cartron PF, 2003 . The Bax tail used by that group was three residues shorter than the tail I have fused to GFP in my study. I therefore generated a GFP-fused construct with the exact portion of the Bax tail (residues 169-192) used in the previous studies. This construct localized to mitochondria as assessed by fluorescence microscopy (data not shown). In addition, the shortened tail was predominantly membrane associated (Figure 13C), although a slight increase in cytosolic localization was observed in comparison to the longer Bax tail in Figure 12A. 


\section{FIGURE 12.}

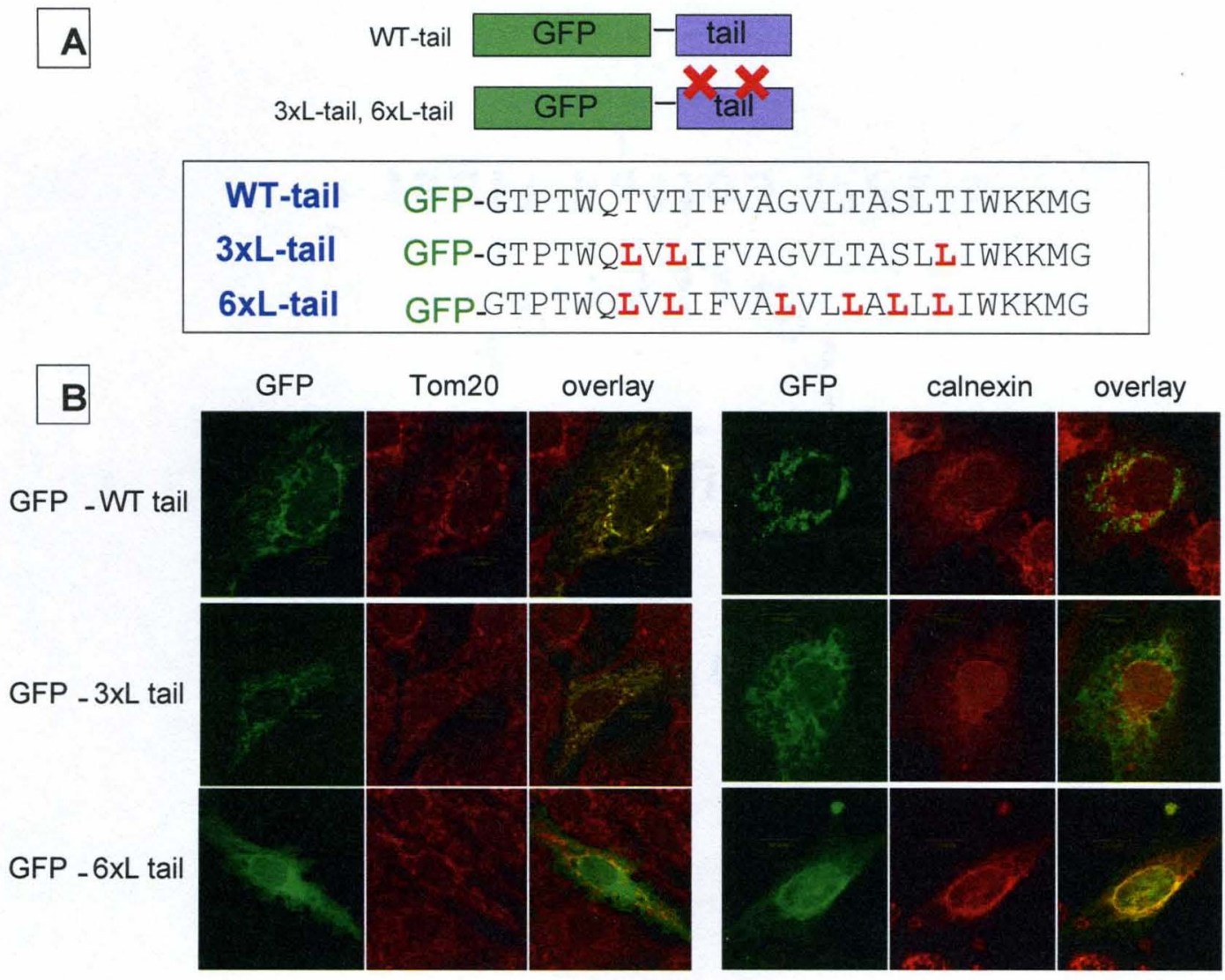


Figure 12. The Bax carboxy-terminus constitutes a mitochondrial-targeting signal that can be switched to an ER-targeting signal by increasing the overall hydrophobicity. (A) Site-directed mutagenesis was used to introduce hydrophobic residues within the Bax tail. The tails alone (residues 166-192) were fused to the C-terminal end of GFP. The tail sequences of wild-type Bax and the Bax mutants are shown. The mutated residues are shown in red. (B) The GFPBax tail constructs were transfected into mouse embryonic fibroblasts lacking Bax and Bak (MEF bax-/bak-). Confocal microscopy was then used to visualize the localization of these constructs. An anti-Tom20 antibody and an anti-calnexin antibody were used as a mitochondrial and ER markers, respectively. 
FIGURE 13.

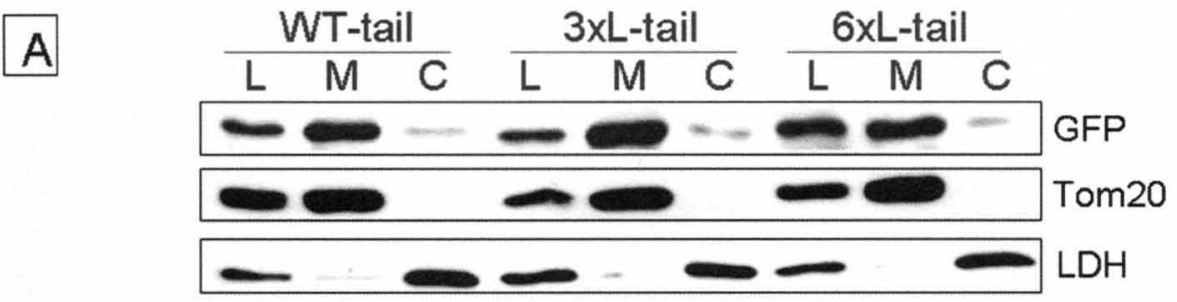

B

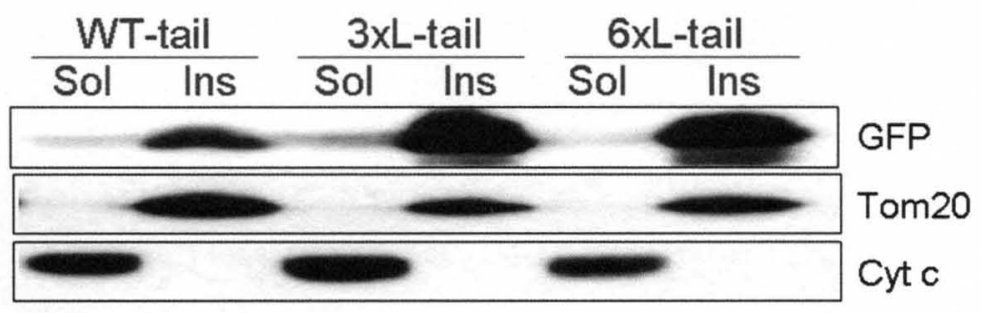

C

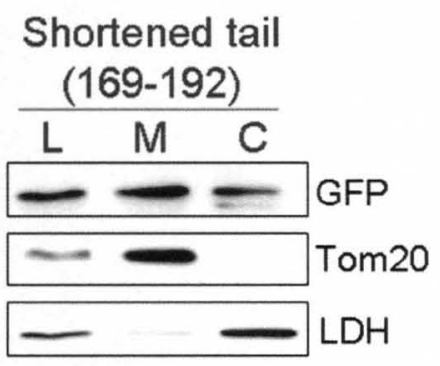


Figure 13. The signals in the wild-type and mutated Bax tails result in membrane targeting and insertion of GFP. (A) The GFP-Bax tail constructs were transfected into MEF (bax-/bak-) cells as in Figure 12. Subcellular fractionation was used to isolate lysate, membrane, and cytosol fractions from these cells. Western analysis was then used to analyze the localization of the Bax tail constructs within these fractions. Tom20 and lactate dehydrogenase (LDH) were used as a membrane marker and cytosolic marker, respectively. Llysate, M-membrane, C-cytosol. (B) Membrane fractions from (A) were treated with $0.1 \mathrm{M} \mathrm{Na} \mathrm{Na}_{2}(\mathrm{pH}$ 11.5) and separated into pelletable and supernatant fractions to test for stable membrane insertion. Appearance of the construct in the pellet fraction indicates stable membrane insertion. Tom20 (membrane inserted) and cytochrome c (soluble) were used as controls. Attattached, Ins-inserted. (C) A shorter version of the wild-type Bax tail containing residues $169-192$, previously examined by Cartron et al, was tested for its ability to target a passenger protein to membrane fractions. Subcellular fractionation and Western analysis were used as in (A). 
The targeting signal in the Bax tail does not play the primary mitochondrial-addressing role in full-length Bax. Having confirmed that the Bax tail can specifically target a cytosolic passenger protein to the mitochondria, I tested this targeting function within the context of full-length Bax. GFP was fused to the $\mathrm{N}$-terminus of full-length Bax (Figure 14A), and the localization of this construct was assessed using confocal microscopy. Previous studies have shown that fused GFP has no effect on the function of Bax Schinzel A, 2004; Nechushtan A, 1999; Wolter KG, 1997 . Under normal conditions, Bax exhibits a diffuse pattern in the cytosol (Figure 14B). Using ultraviolet light (UV) treatment as an apoptotic inducer, Bax then translocated to the mitochondria. This is shown by the colocalization with the mitochondrial marker Tom20. The same $3 \times L$ and $6 \times \mathrm{L}$ tail mutations depicted in Figure 12A were then introduced into the full-length Bax construct to determine if this could shift targeting of Bax from the mitochondria to the ER (Figure 14A). As expected, the $3 \times \mathrm{L}$ mutant resulted in mitochondrial targeting (Figure 14B). Surprisingly, the 6xL mutant also displayed mitochondrial targeting, in contrast to the ER-targeting exhibited with the $6 \times \mathrm{L}$ tail fused to GFP as depicted in Figure 12B. Because Bax6xL localized to the mitochondria despite the ER-targeting signal within the tail, this suggests that the targeting of full-length Bax does not depend on the information within the tail. 


\section{FIGURE 14.}

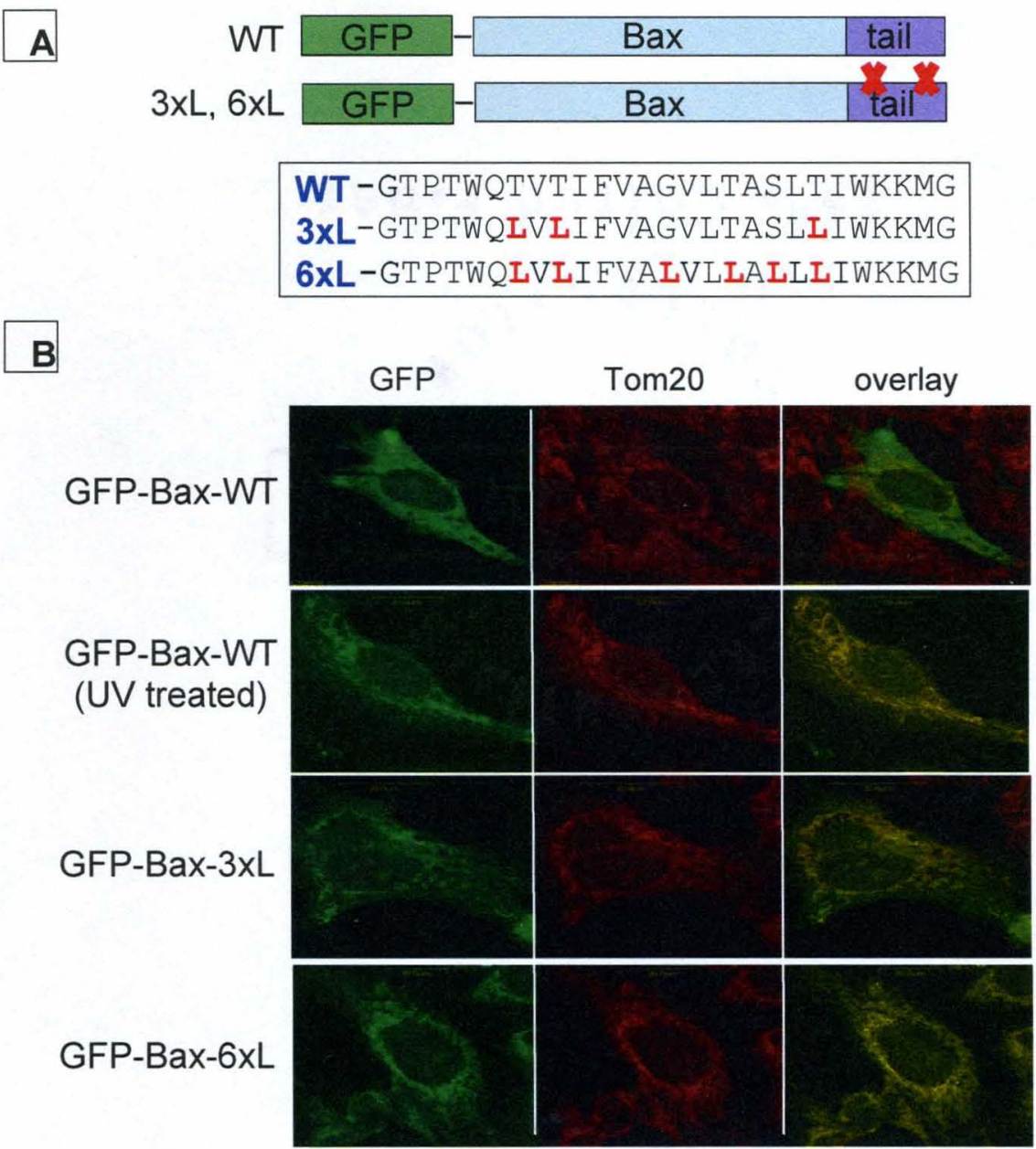


Figure 14. Increasing the hydrophobicity of the Bax signal/anchor in the context of full-length Bax does not alter Bax mitochondrial targeting. (A) Mutations increasing the hydrophobicity of the Bax signal/anchor, corresponding to those depicted in Figures 12 and 13, were introduced into a full-length Bax construct. GFP was fused to the amino-terminus of this construct. The tail sequences of wild-type Bax and the Bax mutants are shown. The mutated residues are shown in red. (B) The GFP-fused Bax constructs were transfected into MEF (bax-/bak-) cells. Wild-type transfected cells were subjected to UV treatment as described in materials and methods. Confocal microscopy was then used to visualize the localization of these constructs. An anti-Tom20 antibody was used as a mitochondrial marker. 
Deletion of the $\mathrm{N}$-terminal $\alpha$-helix1 of Bax disrupts mitochondrial targeting and results in constitutive ER-targeting. Vallette's group has identified a potential mitochondrial-addressing signal within the $\mathrm{N}$-terminal $\alpha$ helix1 of Bax Cartron PF, 2003; Cartron PF, 2005; Bellot G, 2007. This finding is in accordance with my results that indicate that the Bax C-terminal tail is not the primary addressing signal for Bax mitochondrial targeting. Thus, I wanted to investigate the requirement of the Bax $\mathrm{N}$-terminal domain for mitochondrial-targeting. I also wanted to determine if the Bax tail could control Bax targeting in the absence of the $\mathrm{N}$-terminus. I therefore deleted the entire $\mathrm{N}$-terminus $(\Delta \mathrm{N})$ containing $\alpha$ helix1 (residues 1-37) from wild-type Bax, as well as the $3 \times \mathrm{L}$ and $6 \mathrm{xL}$ Bax tail mutants (Figure 15A). Localization of the GFP-fused Bax $\Delta N$ constructs was visualized in MEF (bax-/bak-) cells by confocal microscopy. As shown in Figure 15B, deletion of the $\mathrm{N}$-terminal domain of Bax inhibits mitochondrial targeting and results in predominantly ER targeting regardless of the signal within the tail. This indicates that the $\mathrm{N}$-terminal domain is required for correct mitochondrial targeting, and that the Bax tail does not function as a targeting signal even in the absence of the $\mathrm{N}$-terminal domain.

I also determined the degree of membrane targeting and insertion of these constructs biochemically. Each Bax $\Delta \mathrm{N}$ construct was transfected into MEF (bax/bak-) cells. The transfected cells were then fractionated into lysate, membrane, and cytosol fractions. Deletion of the $\mathrm{N}$-terminus of Bax wild-type, $3 \times \mathrm{L}$, and $6 \times \mathrm{L}$ results in constitutive membrane targeting of each construct (Figure 16A). Moreover, each of these Bax $\Delta \mathrm{N}$ constructs is inserted within the membrane, as 
assessed by alkaline resistance (Figure 16B). These results suggest that deletion of the $\mathrm{N}$-terminal domain disrupts the regulation of Bax that keeps it in an inactive state within the cytosol. 


\section{FIGURE 15.}
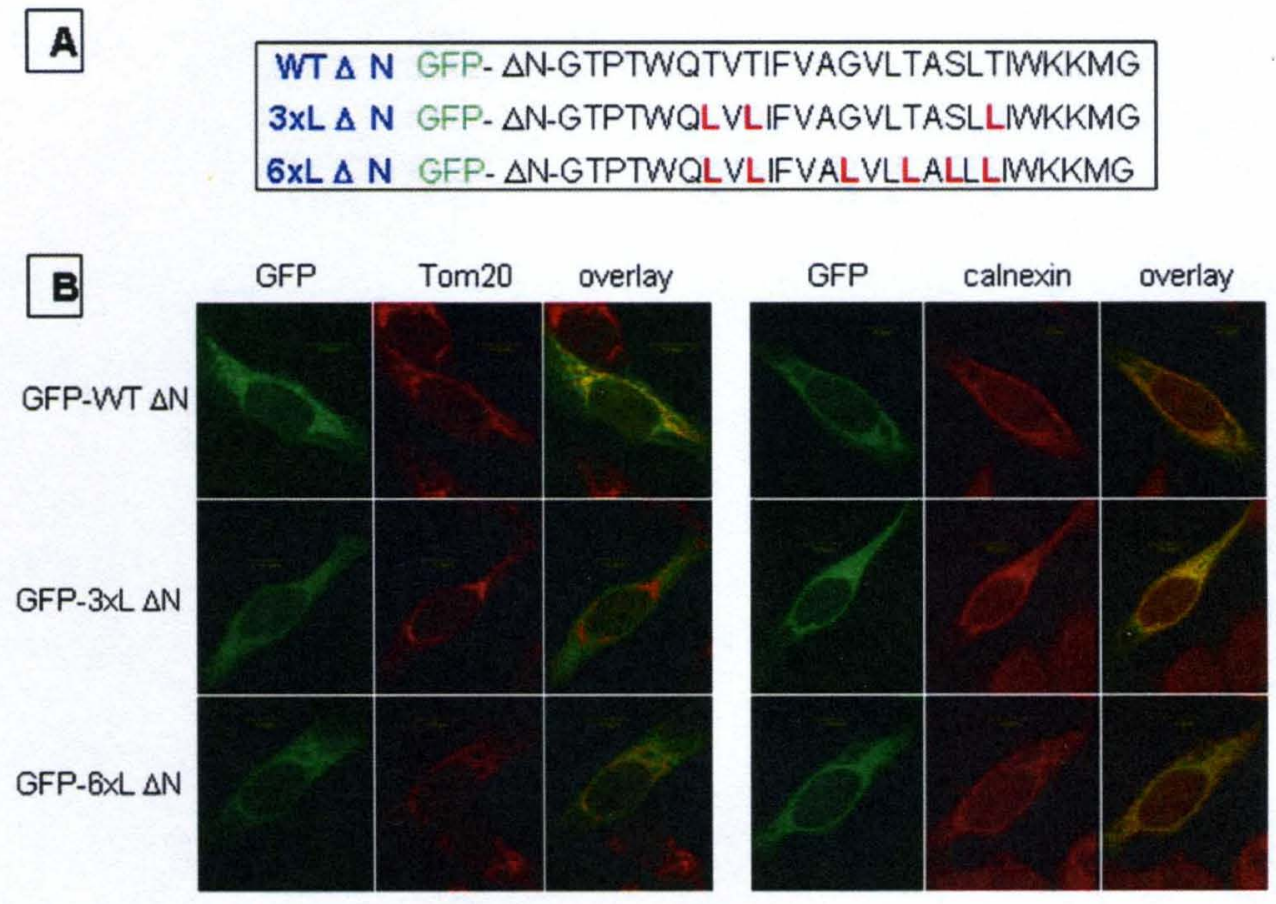
Figure 15. Deletion of the $\mathbf{N}$-terminal $\alpha$-helix1 of Bax results in a shift from mitochondrial targeting to ER-targeting of Bax. (A) The amino-terminal residues $1-37$, including $\alpha$-helix 1 , were deleted from the full-length wild-type, $3 \times L$, and 6xL Bax constructs. These proteins were expressed as GFP-fusion proteins where GFP was fused to the N-terminus of each Bax construct. (B) The GFPfused $\operatorname{Bax} \Delta N$ constructs were transfected into MEF (bax-/bak-) cells. Confocal microscopy was then used to visualize the localization of these constructs. An anti-Tom20 antibody and an anti-calnexin antibody were used as a mitochondrial and ER marker, respectively. 
FIGURE 16.

A

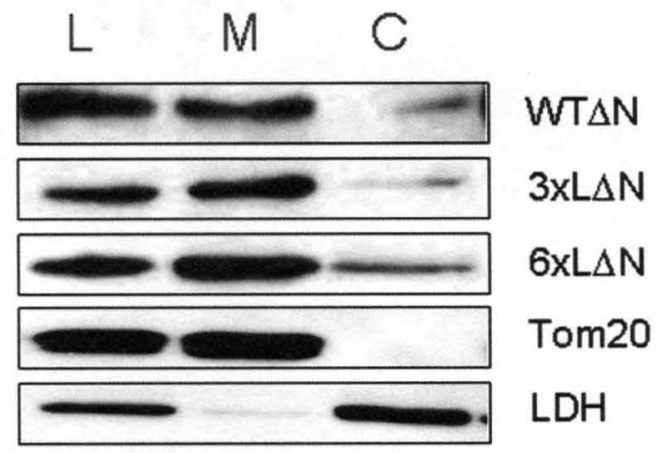

B

$\frac{W T \Delta N}{\operatorname{lns} \text { Sol }} \frac{3 \times L \Delta N}{\operatorname{lns} \text { Sol }} \frac{6 x L \Delta N}{\operatorname{lns} \text { Sol }}$

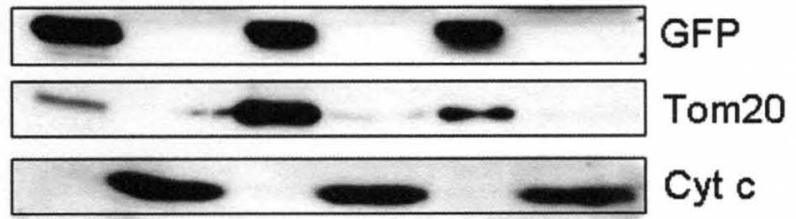


Figure 16. Deletion of the N-terminal $\alpha$-helix1 of Bax results in constitutive membrane targeting and insertion of full-length Bax. (A) The GFP-fused, fulllength $\operatorname{Bax} \Delta N$ constructs used in Figure 15 were tested. These constructs were transfected into MEF (bax-/bak-). Subcellular fractionation was performed in order to obtain lysate, membrane, and cytosol fractions. Localization of the Bax constructs within these fractions was determined using Western analysis. Llysate, $\mathrm{M}$-membrane, $\mathrm{C}$-cytosol. (B) Membrane fractions from the MEF (bax/bak-) cells from (A) were treated with $0.1 \mathrm{M} \mathrm{Na} \mathrm{CO}_{3}(\mathrm{pH}$ 11.5) to observe insertion properties of the Bax mutant constructs as described in Figure 13B. 
The Bax tail plays a role in regulating the membrane targeting of Bax and the change into an open/active conformation of Bax. Some studies have indicated that the Bax tail functions as a regulator of Bax activation Suzuki M, 2000; Arokium $\mathrm{H}, 2004$. As shown in Figure $14 \mathrm{~B}$, the $3 \times \mathrm{L}$ and $6 \mathrm{xL}$ full-length $\mathrm{Bax}$ mutants constitutively target to the mitochondria in the absence of an apoptotic inducer. Subcellular fractionation of $3 \times \mathrm{L}$ and $6 \mathrm{xL}$ transfected cells displays a constitutive membrane distribution of these mutants in both MEF (bax-/bak-) and Hela cells (Figure 17A), in agreement with the confocal microscopy results. For reasons that are not clear, somewhat more cytosolic Bax is observed in Hela cells than in MEF cells. Alkaline extraction shows that the $3 x \mathrm{~L}$ and $6 \mathrm{xL}$ Bax mutants are integrated into the membrane (Figure 17B). Conversely, wild-type Bax is found predominantly in the cytosolic fraction (Figure 17A). These results indicate that the mutations made within the tail disrupt a negative regulatory effect that the tail has on Bax targeting.

To further investigate this effect, I therefore assessed the conformational state of these Bax constructs. Previous results have demonstrated that Bax is in a closed conformation when inactive, and when activated Bax changes into a more open conformation, exposing a targeting signal. I wanted to determine if the $3 \times \mathrm{L}$ and $6 \mathrm{xL}$ mutations result in an open/active conformation of Bax, thereby allowing for constitutive targeting. GFP-fused full-length wild-type, $3 \times \mathrm{L}$, and $6 \mathrm{xL}$ Bax were transfected into MEF (bax-/bak-) cells. A Bax antibody (6a7) that specifically recognizes Bax in the open/active conformation was used to evaluate the conformation of these constructs Hsu YT, 1998; Hsu YT, 1997; Yethon JA, 2003. I 
confirmed, by confocal microscopy, that wild-type Bax is not recognized by the $6 a 7$ antibody unless it is treated with UV (Figure 18A). Conversely, the $3 \times \mathrm{L}$ and $6 \times \mathrm{L}$ Bax mutants are in an open/active conformation in the absence of UV treatment, as probed by staining with the $6 a 7$ antibody. I then tested whether this conformational change is a stable property induced by these mutations, or is a result of membrane binding. Cytosol and membrane fractions were prepared from transfected cells and immunoprecipitated with the $6 a 7$ antibody. The immunoprecipitates were then analyzed by immunoblotting to GFP. Although the $3 \times \mathrm{L}$ and $6 \times \mathrm{L}$ mutants are predominantly in the membrane fraction, a small amount of these proteins are found within the cytosol and can be measured using this method. Wild-type Bax does not immunoprecipitate with the $6 a 7$ antibody and is found in the non-binding fraction as expected (Figure 18B). $3 \times \mathrm{L}$ and $6 \mathrm{xL}$ solubilized from the membrane fractions are immunoprecipitated with 6a7, in agreement with the confocal microscopy results. Cytosolic $6 x \mathrm{~L}$ is immunoprecipitated from the cytosolic fraction. This illustrates that the $6 \mathrm{xL}$ mutation leads to the conformational activation of Bax directly and independently of membrane integration. In contrast, the cytosolic $3 \times \mathrm{L}$ mutant was not $6 \mathrm{a} 7$ reactive. This may indicate that the activation of Bax by the $3 \times \mathrm{L}$ mutation is more transient than that induced by $6 \times \mathrm{L}$. 


\section{FIGURE 17.}

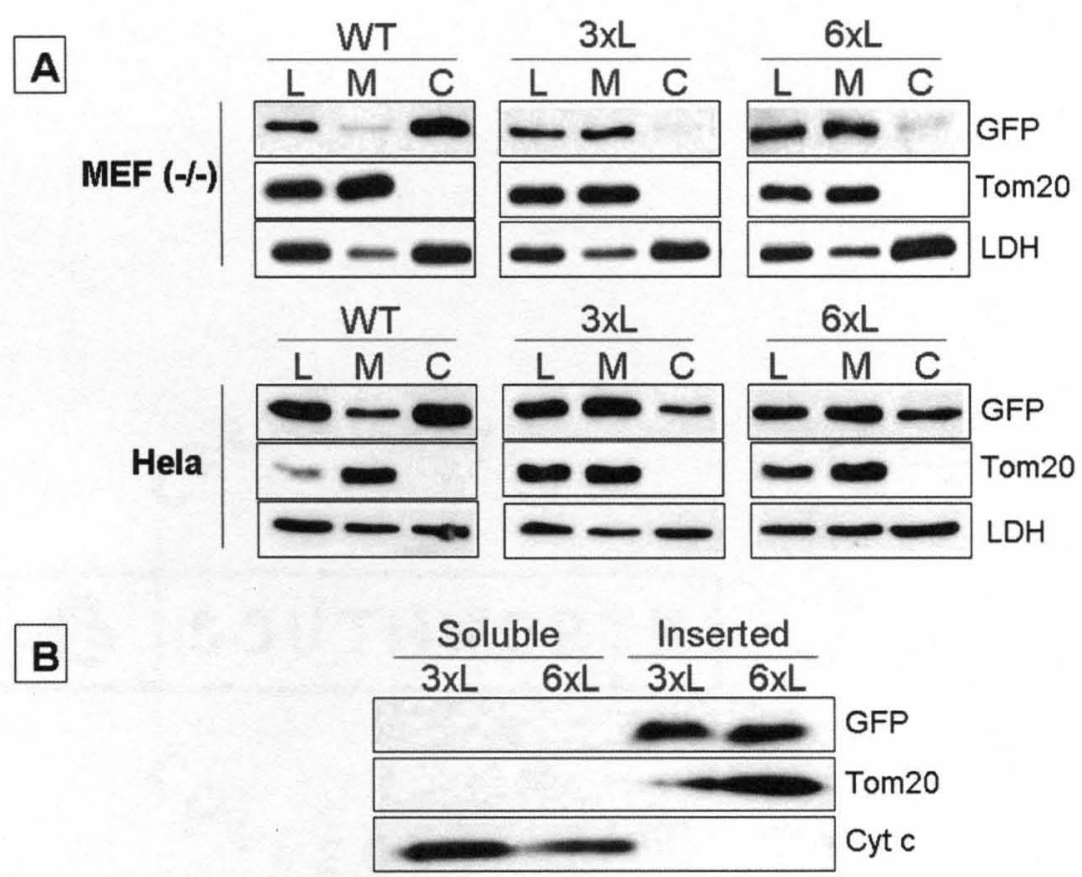


Figure 17. Mutations that increase the hydrophobicity of the Bax tail/anchor result in constitutive membrane targeting and insertion of fulllength Bax (A) The GFP-fused, full-length Bax constructs used in Figure 14 were tested. These constructs were transfected into MEF (bax-/bak-) cells and Hela cells. Subcellular fractionation was performed in order to obtain lysate, membrane, and cytosol fractions. Localization of the Bax constructs within these fractions was determined using Western analysis. $\mathrm{L}-$ lysate, $\mathrm{M}-$ membrane, $\mathrm{C}-$ cytosol. (B) Membrane fractions from the MEF (bax-/bak-) cells from (A) were treated with $0.1 \mathrm{M} \mathrm{Na} \mathrm{CO}_{3}(\mathrm{pH} 11.5)$ to observe insertion properties of the Bax mutant constructs as described in Figure 13B. 


\section{FIGURE 18.}

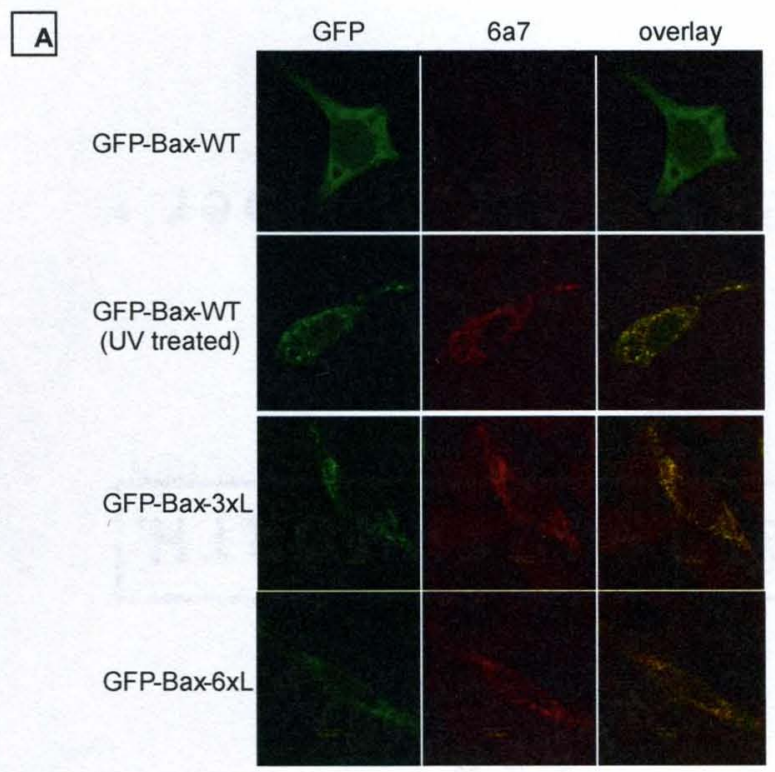

B

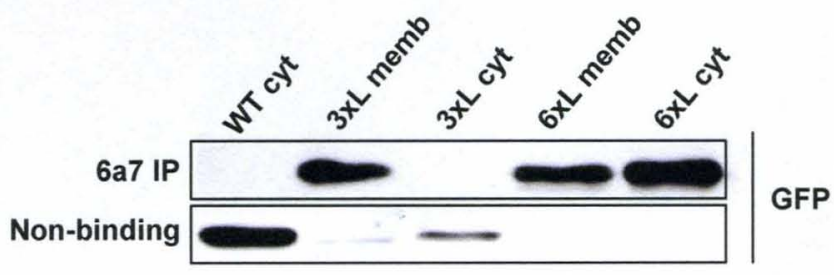


Figure 18. The mutations made in the Bax tail result in an active conformation of Bax. (A) The GFP-fused Bax constructs were transfected into MEF (bax-/bak-) cells. Wild-type transfected cells were subjected to UV treatment as described in materials and methods. Bax (6a7) antibody was used to specifically detect Bax in an active conformation. Confocal microscopy was used to visualize binding of the $6 a 7$ antibody. (B) Immunoprecipitation (IP) with the Bax (6a7) antibody was used to pull-down GFP-fused WT, 3xL, or $6 x \mathrm{~L}$ Bax that was in the active conformation. The IPs were performed on either cytosolic or membrane subcellular fractions. Probing for WT in the cytosol was used as a negative control. The IP samples, as well as the non-binding fractions, were then analyzed using Western analysis and a GFP-specific antibody to detect the Bax constructs. 
Deletion of the Bax tail results in an open/active conformation of Bax, yet Bax cannot target to the mitochondria without the tail. Studies by various groups have produced contradictory findings on the requirement of the Bax tail for Bax targeting and activity. My results indicate that the Bax tail is not the primary targeting signal for mitochondrial targeting, yet the tail plays an important role in the regulation of Bax conformational change and targeting. Therefore, I deleted the Bax tail to test whether this domain is dispensible for Bax activation and targeting. The deletion mutant $(\operatorname{Bax} \Delta \mathrm{C})$ was generated by removing residues 169-192, which includes $\alpha$-helix9 and its flanking residues, from GFP-fused full-length Bax (Figure 19A). To determine the effect of this deletion on the conformational state of Bax, I used the Bax $6 a 7$ antibody specific for the active conformation of Bax. Bax $\Delta \mathrm{C}$ was transfected into MEF (bax-/bak-) cells, and confocal microscopy was used to analyze Bax $6 a 7$ binding with or without UV treatment. The deletion of the Bax tail resulted in an open/active conformation of Bax independent of an apoptotic inducer as measured by $6 a 7$ reactivity (Figure 19B). This result supports my findings with the $3 \times \mathrm{L}$ and $6 \times \mathrm{L}$ tail mutants that the tail is an important negative regulator of Bax activation, specifically by maintaining $B a x$ in a closed/inactive conformational state. Because $B a x \Delta C$ is in an open/active conformation, it would be expected that Bax $\Delta \mathrm{C}$ would constitutively target to the mitochondria, as seen with $3 \times \mathrm{L}$ and $6 \times \mathrm{L}$. Therefore, Bax $\Delta \mathrm{C}$ was transfected into MEF (bax-/bak-) cells, and localization of this construct was assessed by confocal fluorescence with or without UV treatment. Surprisingly, despite the fact that $B a x \Delta C$ is in an active conformation, 
this construct remains predominantly in the cytosol even upon apoptotic induction by UV treatment (Figure 20A). Subcellular fractionation of Bax $\Delta$ C-transfected Hela cells reinforces these results. As previously observed, wild-type Bax becomes membrane localized after UV treatment, yet Bax $\Delta \mathrm{C}$ remains in the cytosol (Figure 20B). Therefore, while the Bax tail does not dominate the organelle-specific targeting, this sequence is essential for membrane integration of Bax. 
FIGURE 19.

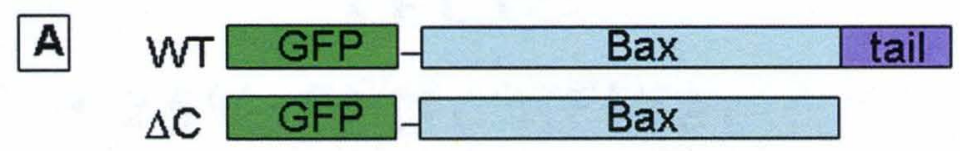

WT -GTPTWQTVTIFVAGVLTASLT IWKKMG $\triangle C-G T P$

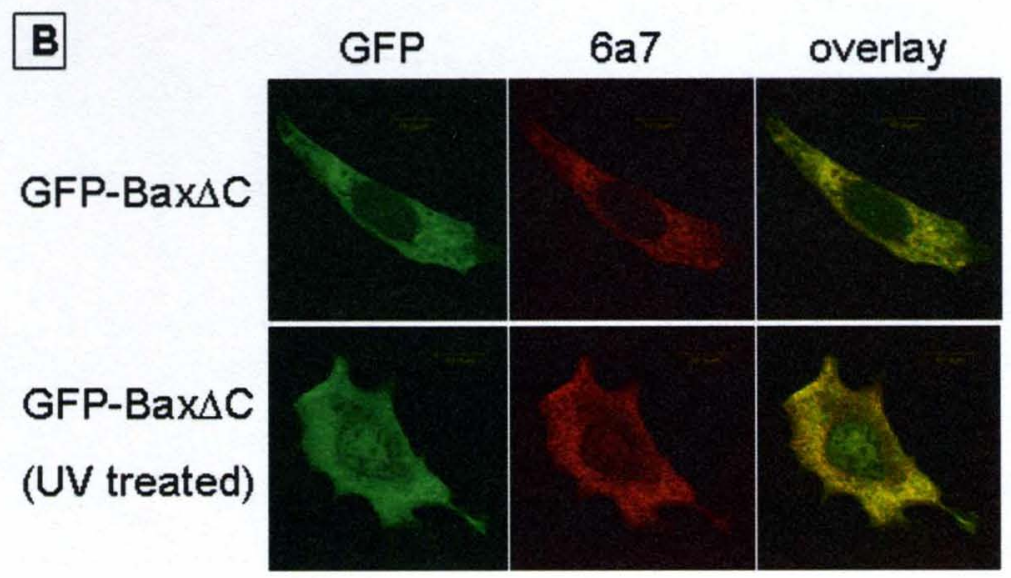


Figure 19. Deletion of the Bax tail results in an active conformation of Bax. (A) A tail-deleted form of $\operatorname{Bax}(\Delta C)$ was generated by deletion of residues 169192. The $\Delta \mathrm{C}$ mutant was fused to the C-terminus of GFP. (B) The GFP-fused Bax $\triangle \mathrm{C}$ construct was transfected into MEF (bax-/bak-) cells. The Bax (6a7) antibody was used to specifically detect Bax in an active conformation. Confocal microscopy was used to visualize binding of the $6 a 7$ antibody in the absence or presence of UV treatment. 
FIGURE 20.

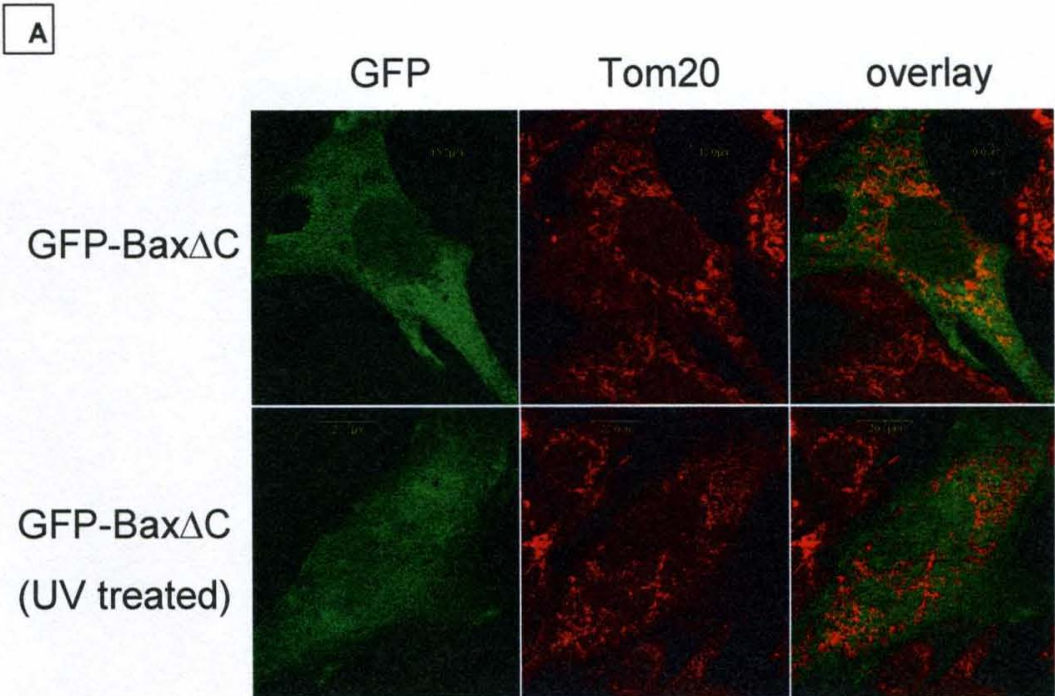

B

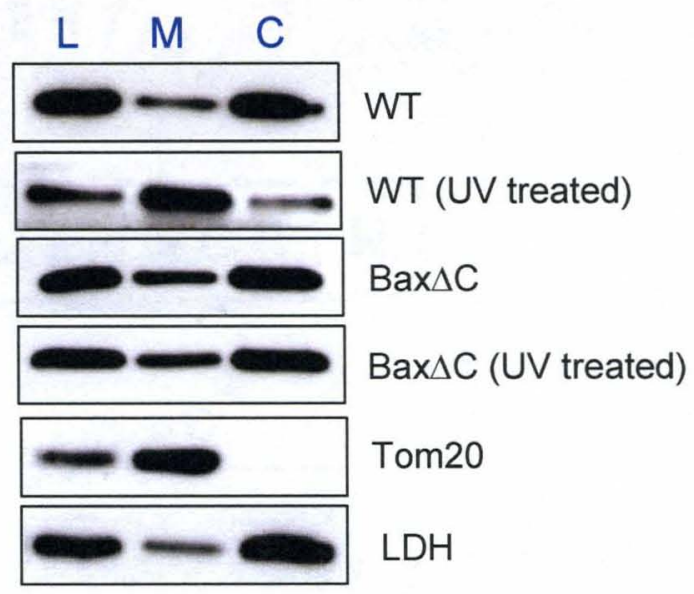


Figure 20. Deletion of the Bax tail results in a cytosolic distribution independent of apoptotic stimulus. (A) The GFP-fused Bax $\Delta C$ construct was transfected into MEF (bax-/bak-) cells. Confocal microscopy was then used to visualize the localization of this construct. An anti-Tom20 antibody was used as a mitochondrial marker. (B) BaxWT and Bax $\Delta \mathrm{C}$ were transfected into Hela cells and were either treated or not treated with UV light. Subcellular fractionation was performed to obtain lysate, membrane, and cytosol fractions. Localization of the Bax constructs within these fractions was determined using Western analysis. L-lysate, M-membrane, C—cytosol. 
FIGURE 21.

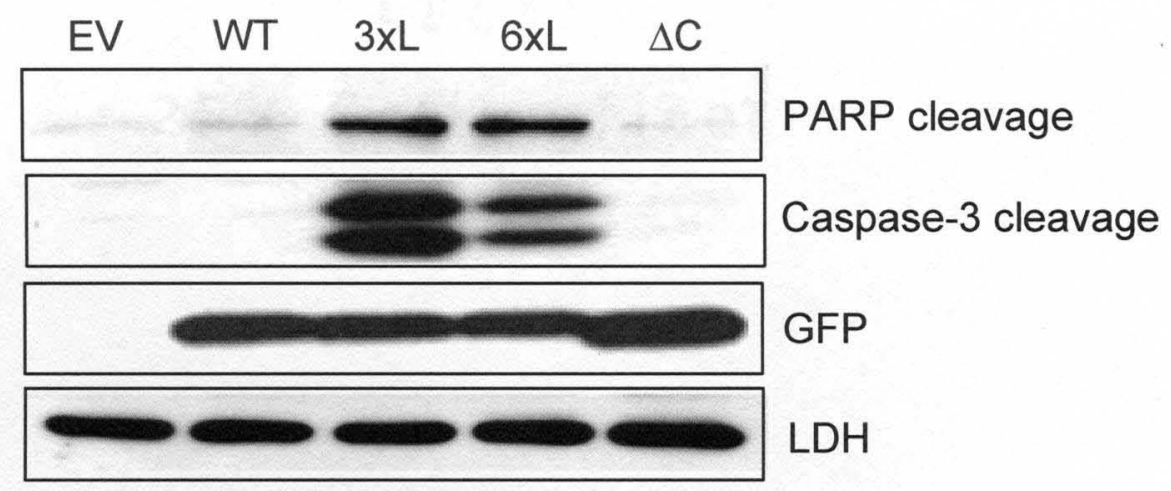




\section{The constitutively-targeted $3 \times \mathrm{L}$ and $6 \times \mathrm{L}$ Bax mutants exhibit}

enhanced apoptotic-inducing ability in comparison to wild-type and $\Delta C$ Bax. Bax $3 \times \mathrm{L}, 6 \times \mathrm{L}$, and $\Delta \mathrm{C}$ mutants are all in an open/active conformation. However, while $3 \times \mathrm{L}$ and $6 \mathrm{xL}$ are constitutively mitochondrial-targeted, Bax $\Delta \mathrm{C}$ is constitutively cytosolic. This prompted us to evaluate the subsequent apoptoticinducing ability of these Bax mutants in the absence of an apoptotic stimulus in Hela cells. These cells produce more robust apoptotic signals than the MEF cells used in the experiments depicted above. Bax wild-type, $3 x \mathrm{~L}, 6 \mathrm{xL}$, and $\Delta \mathrm{C}$ were transfected into Hela cells along with empty vector as a negative control, and apoptosis was measured without addition of an apoptotic inducer. PARP cleavage and caspase- 3 cleavage were used to measure apoptosis. As shown in Figure 21, wild-type $\operatorname{Bax}$ and $\operatorname{Bax} \Delta \mathrm{C}$ do not stimulate apoptosis and are comparable to vector alone. Conversely, $3 \times \mathrm{L}$ and $6 \mathrm{xL}$ show clear induction of apoptosis in the absence of an external apoptotic stimulus, as measured by PARP and caspase-3 cleavage. 
Figure 21. In the absence of apoptotic stimulus, the constitutively-targeted $3 \times L$ and $6 x L$ mutants of Bax exhibit enhanced apoptosis in comparison to BaxWT and Bax $\Delta C$. GFP-fused Bax constructs were transfected into Hela cells for 24 hours. Lysates from these cells were then subjected to Western analysis. An antibody that specifically recognizes cleaved PARP and an antibody that specifically recognizes cleaved caspase- 3 were used as a measure of apoptosis. LDH was used as a loading control. EV—empty vector 


\section{Inhibiting insertion of the Bax tail disrupts Bax mitochondrial-}

targeting. My results have revealed that the Bax tail does not play the addressing role in Bax mitochondrial targeting. However, I have shown that the tail is indispensable for Bax targeting. This led us to investigate whether the membrane-insertion property of the Bax tail is important for Bax mitochondrial translocation. Selected residues within the Bax hydrophobic transmembrane domain of the tail were replaced with charged residues in order to inhibit insertion of the tail into the membrane (Figure 22A). Residues G179 and T186 were chosen due to their location in the middle and end of the transmembrane segment, respectively. S184 was chosen because previous studies have identified this residue as having effects on Bax mitochondrial targeting Nechushtan A, 1999; Gardai SJ, 2004; Xin M, 2005. V180 and L185 were chosen in order to replace hydrophobic residues of the transmembrane sequence rather than polar residues. Initially, the tails in the context of GFP as a passenger protein were assessed by microscopy to confirm that these sequence changes disrupt the membrane insertion of the tail sequence (Figure 22B, first column). GFP was fused to the N-terminus of each of the mutant tails. The GFP-tail constructs were transfected into MEF (bax-/bak-) cells, and localization was visualized using confocal microscopy. Introducing a single charged residue at serine 184 (S184K, S184D, S184E) or substituting two charged residues for hydrophobic residues (V180K,L185K) resulted in a diffuse, cytosolic distribution. This contrasts sharply with the distinct mitochondrial targeting of GFP fused to the wild-type and $3 \times \mathrm{L}$ sequence or the endoplasmic reticulum targeting of the $6 \mathrm{xL}$ sequence (Figure 
12). However, T186K and G179K tails only partially inhibited the targeting of GFP to mitochondria. Although a portion of these latter constructs is localized to the mitochondria, a significant amount is diffuse throughout the cell.

The effects of these same mutations were then investigated in the context of full-length Bax. GFP was fused to the N-terminus of the full-length Bax mutants. These constructs were transfected into MEF (bax-/bak-) cells. Transfected cells were then subjected to analysis using confocal microscopy and subcellular fractionation. The introduction of charged residues within the Bax tail resulted in an open/active conformation of Bax, as detected by $6 \mathrm{a} 7$ reactivity (Figure 22B). However, even in the active conformation, Bax is not able to target to the mitochondria with a mutated tail that cannot insert. All of the mutants display a cytosolic distribution (Figures $22 \mathrm{~B}$ and $22 \mathrm{C}$ ). This is in contrast to Bax $3 \times \mathrm{L}$ and $6 \times \mathrm{L}$ mutants that are in the active conformation, yet constitutively target to the mitochondria (Figures 14 and 17, Table 2). These results indicate that inhibiting the ability of the tail sequence to insert into membranes disrupts mitochondrial targeting of Bax. 
FIGURE 22.

A

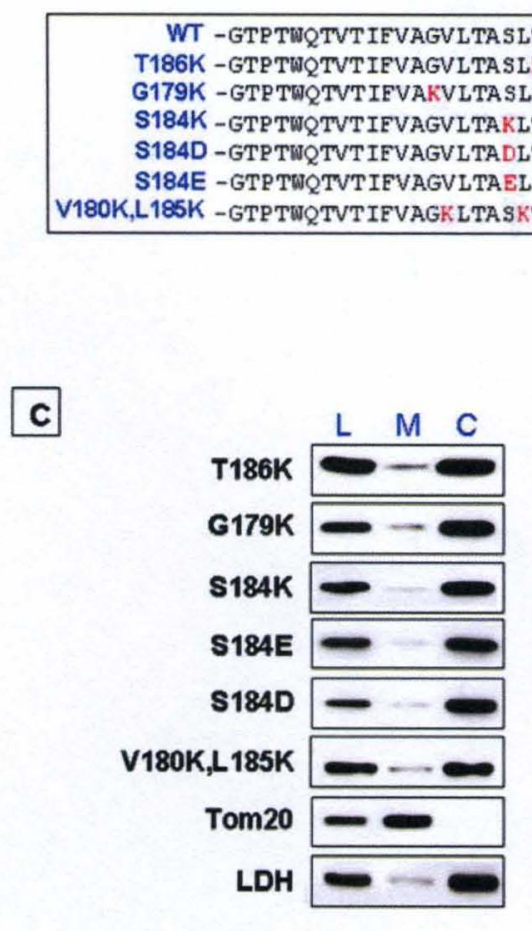

B Full-length constructs

.

erre
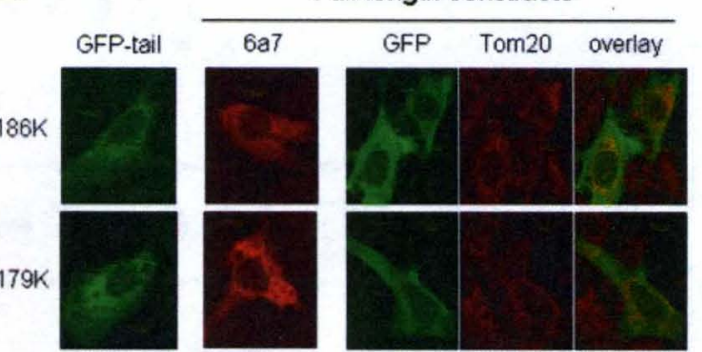

S184K
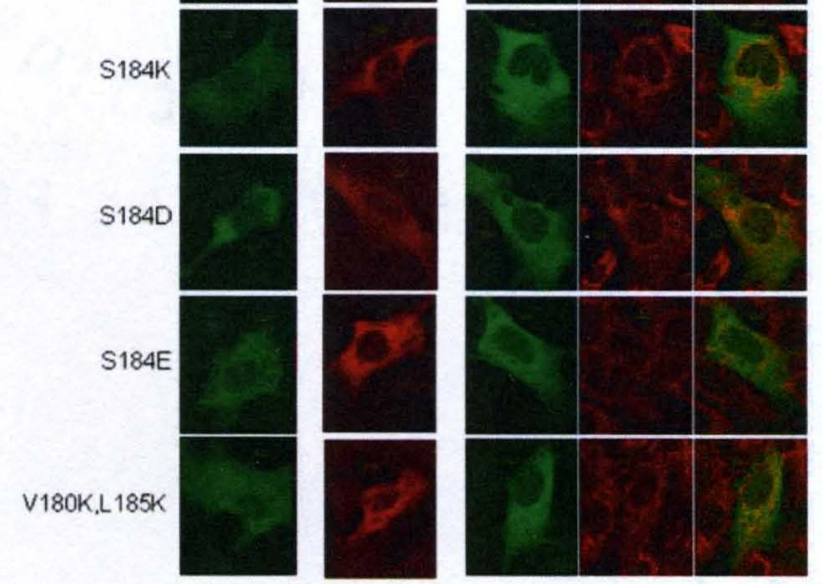
Figure 22. Inhibiting insertion of the Bax tail by introducing charged residues disrupts Bax mitochondrial-targeting. (A) Site-directed mutagenesis was used to introduce charged residues within the Bax tail. These mutations were made in both GFP-tagged full-length Bax as well as GFP fused to the tails alone (residues 166-192). The tail sequences of wild-type Bax and the Bax mutants are shown. The mutated residues are shown in red. (B) The GFP-tail and GFP-Bax (full-length) constructs were transfected into MEF (bax-/bak-) cells. Confocal microscopy was then used to visualize the localization of these constructs. An anti-Tom20 antibody and an anti-calnexin antibody were used as a mitochondrial and ER marker, respectively. Bax 6a7 antibody was used to detect the open/active conformation of full-length Bax constructs. (C) The GFPfused, full-length Bax mutants used in (B) were tested. These constructs were transfected into MEF (bax-/bak-) cells. Subcellular fractionation was performed in order to obtain lysate, membrane, and cytosol fractions. Localization of the Bax constructs within these fractions was determined using Western analysis. Llysate, $\mathrm{M}-$ membrane, $\mathrm{C}-$ cytosol. 


\section{TABLE 4.}

Table 4 Summary of conformation and localization of Bax constructs

\begin{tabular}{lccc}
\hline $\begin{array}{l}\text { Bax } \\
\text { Construct }\end{array}$ & $6 a 7$ Reactivity & $\begin{array}{c}\text { Mitochondrial } \\
\text { localization }\end{array}$ & $\begin{array}{c}\text { Cytosolic } \\
\text { localization }\end{array}$ \\
\hline WT & $\mathrm{X}$ & $\mathrm{X}$ & \\
$3 \times \mathrm{L}$ & $\mathrm{X}$ & $\mathrm{X}$ & \\
$6 \mathrm{xL}$ & $\mathrm{X}$ & $\mathrm{X}$ \\
$\Delta \mathrm{C}$ & $\mathrm{X}$ & $\mathrm{X}$ \\
T186K & $\mathrm{X}$ & $\mathrm{X}$ \\
G179K & $\mathrm{X}$ & $\mathrm{X}$ \\
S184K & $\mathrm{X}$ & $\mathrm{X}$ \\
S184D & $\mathrm{X}$ & $\mathrm{X}$ \\
S184E & $\mathrm{X}$ & $\mathrm{X}$ \\
V180K,L185K & & & \\
\hline
\end{tabular}

Shown are a list of the names given to Bax WT and the Bax mutants. An open/active conformation is indicated by $6 a 7$ reactivity. Mitochondrial or cytosolic localization is also indicated. 


\section{CHAPTER IV}

\section{DISCUSSION}

In these studies, I first show that the carboxy-terminal tail of Bax can serve as a bona-fide mitochondrial-targeting signal/anchor. Surprisingly, despite this property I demonstrate that the Bax tail does not play the primary role in addressing of full-length Bax to the mitochondria. However, I show that the Bax tail does play an important negative regulatory role in Bax activation of targeting. Deletion of the Bax tail results in an open/active conformation, yet Bax cannot localize to the mitochondria without the Bax tail. This indicates a requirement of the Bax tail for Bax mitochondrial translocation. By making mutations within the Bax tail that inhibit insertion of this domain, I illustrate that the membrane insertion of the Bax tail is crucial for Bax mitochondrial targeting.

Studies on Bax have yielded conflicting results as to whether the Bax tail functions as a targeting signal that is necessary for Bax mitochondrial translocation. There have been reports that the Bax tail cannot target a fused cytosolic passenger protein to the mitochondrial membrane, suggesting that the Bax tail does not contain a mitochondrial-targeting signal Cartron PF, 2003; Nechushtan A, 1999. Vallette's group has also presented findings in which the deletion of the Bax tail has no effect on mitochondrial targeting or apoptotic inducing ability in comparison to wild-type Bax, indicating that the Bax tail is 
dispensible for targeting and Bax activation Cartron PF, 2005 ; Cartron PF, 2003 ; Tremblais K, 1999. In addition, they have identified a potential targeting signal within the $\mathrm{N}$ terminal $\alpha$-helix1 of Bax that directly interacts with the MOM receptor Tom22.

On the other hand, several other groups have presented results that indicate a mitochondrial-targeting function of the Bax tail. Studies have shown that the Bax tail itself contains sufficient mitochondrial-targeting and anchoring information when fused to a cytosolic passenger protein Goping IS, 1998; Schinzel A 2004. Deletion of the Bax tail can prevent targeting of full-length Bax to the mitochondria as well as inhibit the apoptotic inducing ability of Bax Schinzel A. 2004; Woiter KG, 1997; Nechushtan A, 1999 . Nechushtan et al showed that even deletion of the last 5 amino acids from the Bax tail can inhibit targeting. In the same study, they demonstrated that various point mutations at residue S184 in the Bax tail either increased or inhibited Bax mitochondrial targeting, further indicating an important targeting role of the Bax tail. These localization and functional studies have established that the Bax carboxy-terminus serves a role identical to that of homologous sequences in other "tail-anchored" proteins, in which the carboxy terminus serves as both the addressing signal and membrane anchor Wolter KG, 1997; Goping IS, 1998; Hsu YT, 1998; Nguyen M, 1993.

In my hands, it is clear that the Bax tail itself can serve as a mitochondrialtargeting signal and can direct a cytosolic passenger protein specifically to the mitochondria. Moreover, the behavior of the $6 \times \mathrm{L}$ mutation demonstrates that the tail obeys the sequence rules that determine whether tail-anchors direct proteins to the mitochondria versus the endoplasmic reticulum. The varying lengths of the 
Bax tail used in previous studies may account for the differences in results. Vallette's group used residues 169-192. In contrast, I used residues 166-192 of the Bax tail, which contains the entire transmembrane domain in addition to the $\mathrm{N}$-terminal and $\mathrm{C}$-terminal flanking residues. Studies of targeting requirements for tail-anchored proteins have demonstrated that the residues flanking the hydrophobic portion of the membrane anchor are essential for targeting Isenmann $\mathrm{S}$, 1998; Kaufmann T, 2003; Masaki R, 2003; Kim PK, 1997 . Shorter portions of the Bax tail may not contain all of the essential residues for correct mitochondrial targeting, resulting in cytosolic localization. Using a shorter Bax tail segment (residues 169-192) that was used by Vallette's group, I show that although this shorter version can still target to the mitochondria to some extent, the efficiency is lower than the longer version (Figure 13C).

However, my results are in agreement with the notion of the mitochondrialtargeting signal of Bax residing in the N-terminal a-helix1 and not in the Bax tail Cartron PF, 2003. I demonstrate that replacing the C-terminal tail of Bax with an ERtargeting signal $(6 \mathrm{xL})$ has no effect on targeting of full-length Bax. This indicates that another targeting-signal exists in the structure of Bax that overrides the targeting signal within the tail, refuting the idea that the tail is the primary targeting signal within Bax. In accordance with this, when I deleted the Bax Nterminal domain including a-helix1, mitochondrial-targeting of Bax was abolished. Instead, Bax $\Delta \mathrm{N}$ localized predominantly to the ER. Additionally, translocation to the ER was observed independently of the targeting signal within the tail. This is consistent with the results of Vallette's group that indicate that the primary 
mitochondrial-targeting signal is within the $\mathrm{N}$-terminal $\alpha$-helix 1 domain. It is not clear why the $\mathrm{N}$-terminal deleted form of Bax targets to the ER. Localization of wild-type Bax to the ER is not widely studied at this point. Therefore, little is known about the mechanism of Bax targeting to this organelle. It is possible that there is another targeting signal within the Bax structure that allows for targeting to the ER.

While the Bax tail does not serve as a targeting sequence, 1 find that it is absolutely required for Bax localization to the mitochondria. What then is its function? My results suggest that the Bax tail tethers Bax to the mitochondrial membrane subsequent to or in conjunction with a targeting interaction mediated by sequences elsewhere in the protein. I come to this conclusion based on my observation that disrupting the ability of the tail sequence to insert into membranes blocks Bax mitochondrial localization. This finding provides a possible explanation for the necessity of the Bax tail for targeting, and is consistent with the results obtained when the Bax tail is deleted and mitochondrial targeting is inhibited. Interestingly, previous studies have shown that Bax mitochondrial translocation can be inhibited by phosphorylation of the tail residue S184 Gardai SJ, 2004; Xin M, 2005. My results suggest that this phoshorylation prevents the required membrane insertion of the tail, thereby inhibiting Bax targeting. My data using the phosporylation-mimicking residues $D$ and $\mathrm{E}$ at residue $\mathrm{S} 184$ are consistent with this notion. I cannot rule out that the introduction of charged residues within the tail does not have additional effects on the Bax protein. The inhibition of mitochondrial targeting that is observed with 
these tail mutants could also be due, in part, to disruption or promotion of Bax interaction with other proteins. It is also unclear why Vallette's group has described the Bax tail as being dispensible for Bax mitochondrial-targeting. Expression level differences or cell-type differences could result in suitable conditions for stable association of the tail-deleted form of Bax with the mitochondria, accounting for these discrepancies.

The Bax tail also appears to function as a negative regulator of Bax activation Suzuki M, 2000; Arokium H, 2004 . The C-terminal tail of Bax is tucked into a hydrophobic pocket in the structure of Bax, covering the $\mathrm{BH} 3$ domain and $\mathrm{\alpha}$ helices 5 and 6 . The tail is retained in the pocket by hydrophobic interactions and hydrogen bonding Suzuki M, 2000. Replacement of the Bax tail with the Cterminal tail of either $\mathrm{Bcl}-2$ or $\mathrm{Bcl}-\mathrm{xL}$ results in constitutive mitochondrial targeting of Bax Goping IS, 1998; Suzuki M, 2000; Tremblais K, 1999 . Whereas the conserved sequence of the Bax tail allows for a tight fit into the hydrophobic pocket, the imperfect fit of the alternative tails into the hydrophobic groove allows for an open/active conformation of Bax. This would result in the constitutive exposure of the tail sequence and the activation of Bax. My results have demonstrated a comparable phenomenon, where mutations within the Bax tail result in an open/active conformation of Bax, constitutive mitochondrial targeting, and enhanced apoptotic-inducing ability. Moreover, mutation of six residues within the tail, rather than three, had a greater effect on Bax conformation, reiterating the idea that increased disruption of the interactions between the tail and the hydrophobic groove results in dissocation of the Bax tail. The complete deletion 
of the tail also results in an open conformation of Bax, illustrating that the specific positioning of the tail within the hydrophobic pocket is important in maintaining Bax in a closed/inactive conformation. This negative regulatory role of the Bax tail is comparable to that of the ART (apoptotic regulation of targeting) domain in the N-terminal portion of Bax Goping IS, 1998; Cartron PF, 2005; Cartron PF, 2003.

Taken together, my findings have presented possible explanations for the conflicting results describing the function of the Bax tail. My results support previous findings that the Bax tail serves as a negative regulator of the initial conformational change that leads to Bax mitochondrial translocation. While my data contradict the notion that the Bax tail serves as the primary targeting signal for mitochondrial targeting, I suggest an important anchoring/tethering role of the Bax tail that is required for mitochondrial targeting of Bax. I propose a model where after the initial addressing of Bax to the MOM, the Bax tail functions to stabilize Bax at the membrane (Figure 23). This would then allow for complete integration of Bax into the membrane where helices 5 and 6 can be inserted. Consistent with this model, Andrews and colleagues also suggest a stepwise process of transient to stable interaction of Bax with the membrane Yethon JA, 2003: Leber B, 2007. Further studies will be needed to elucidate greater detail of this insertion process.

It is well accepted that translocation of Bax to the mitochondria is essential for Bax-induced apoptosis. The numerous studies on Bax have uncovered various mechanisms involved in Bax activation and mitochondrial translocation. I believe that Bax activation and translocation are achieved through a stepwise 
process that consists of these various mechanisms that have been identified. Bax is retained in an inactive state in the cytosol due to a specific conformation of Bax. The N-terminal ART sequence and the carboxy-terminal tail of Bax serve to keep Bax in an inactive/closed conformation. By sitting in the hydrophobic groove, the Bax tail also functions to cover the $\mathrm{Bax} \mathrm{BH} 3$ domain that can interact with activating proteins such as tBid. Inhibitory proteins, such as $14-3-3$ and Ku70, can also bind to Bax and maintain Bax in an inactive conformation.

Interactions with the inhibitory proteins must be disrupted and Bax must undergo a conformational change before it can translocate to the mitochondrial outer membrane (MOM). It is unclear what triggers this conformational change of Bax, though addition of cytosolic extract stimulates translocation of recombinant Bax. Therefore, it is likely that activating proteins are involved. These proteins may induce a conformational change by competing with the Bax tail for the $\mathrm{BH} 3$ domain in the hydrophobic pocket. The best described example of a Bax activating protein is the $\mathrm{Bcl}-2 \mathrm{BH} 3$-only protein, Bid. The truncated form of Bid, tBid, induces Bax conformational change and mitochondrial translocation. tBid has been shown to interact with the $\mathrm{BH} 3$ domain of Bax, hence this interaction could facilitate release of the Bax tail and the subsequent activating conformational change. In addition, other factors may serve as indirect activators by blocking the inhibitory actions of the inhibitory proteins. This is exemplified by the action of the $\mathrm{BH} 3-$ only proteins that block the Bax-inhibitory proteins $\mathrm{Bcl}-2$ and $\mathrm{Bcl}-\mathrm{xL}$. 
I believe that the conformational change of Bax allows for exposure of a mitochondrial signal, possibly $\alpha$-helix1 of the $\operatorname{Bax~} \mathrm{N}$-terminus. This mitochondrial-targeting signal interacts loosely with a factor at the surface of the mitochondria and does not insert into the MOM. The interaction of the Bax mitochondrial-targeting signal with the mitochondria is transient until the Bax Cterminal tail inserts into the membrane. Insertion of the Bax tail is essential for tethering of Bax to the mitochondrial membrane. The insertion of the Bax tail then stabilizes Bax for complete integration of Bax a-helices 5 and 6 into the MOM. Once the Bax tail is inserted, I believe that the subsequent integration of a-helices 5 and 6 occurs rapidly.

This proposes a complex model that involves a stepwise process of Bax activation. This sequential activation allows for a tight regulation of Bax due to the number of steps that are required for complete activation. Tight control is vital to keep Bax from aberrantly being activated, since Bax is such a potent stimulus of cell death. Future studies need to focus on verifying each step. However, it is difficult to isolate intermediate steps in order to show it is in a stepwise fashion. Identifying all of the steps of Bax activation will provide more points of intervention in the context of potential therapeutic targets. 


\section{FIGURE 23.}

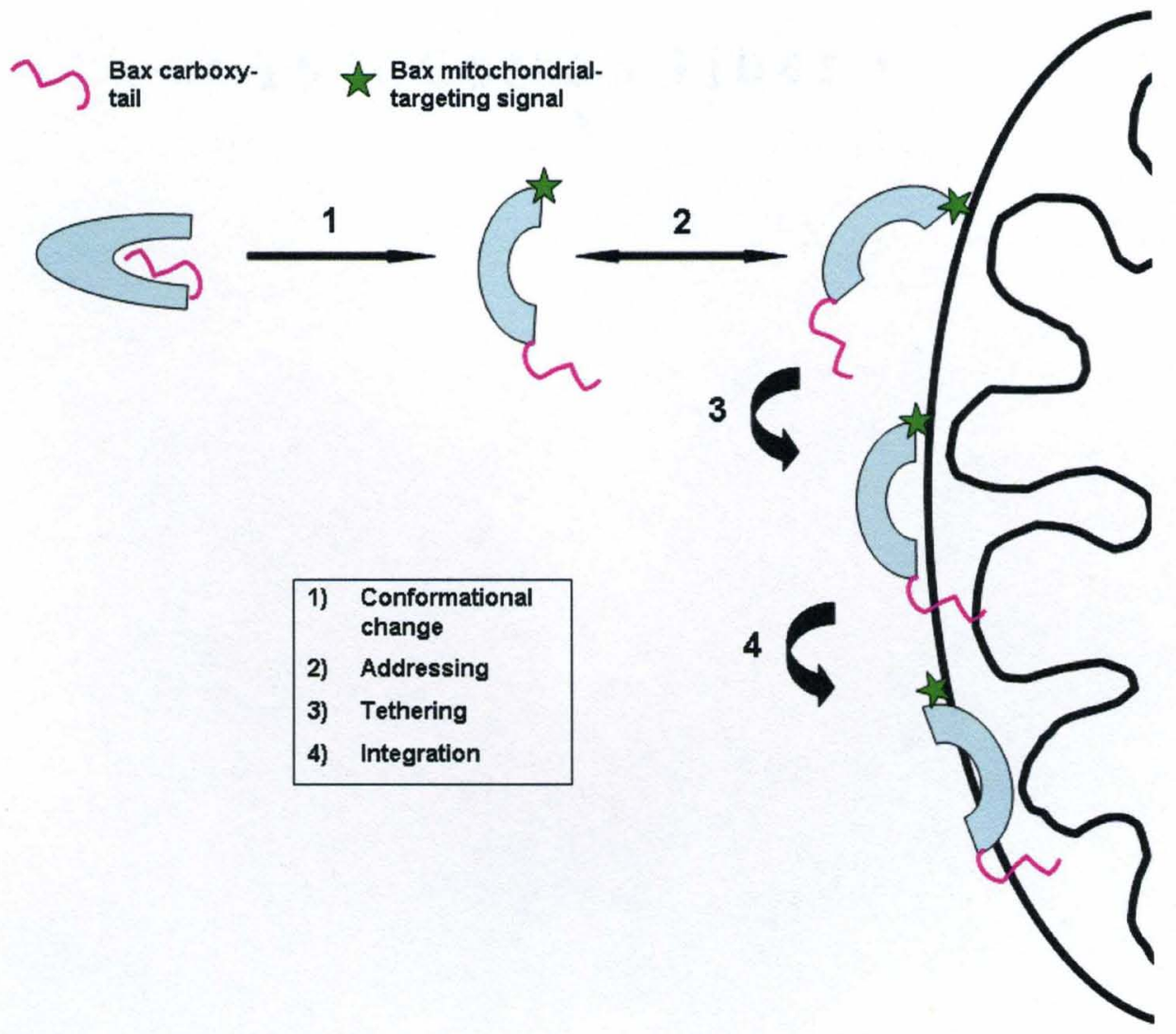


Figure 23. Model of Bax targeting to the mitochondria. Bax is found in a closed/inactive state in the cytosol. The correct orientation of the tail in the hydrophobic pocket keeps Bax in a closed/inactive conformation. 1) An apoptotic trigger induces a conformational change into an open conformation of Bax, thereby exposing a mitochondrial-addressing signal. 2) The exposed addressing signal interacts with the mitochondrial membrane in a loose fashion whereby Bax can attach and detach from the membrane. 3) The Bax tail must insert into the MOM, tethering Bax to the membrane and 4) allowing for complete integration of Bax into the bilayer. 


\section{CHAPTER V}

\section{RELATED PROJECT:}

\section{A PEPTIDE DERIVED FROM A MITOCHONDRIAL TAIL-ANCHOR SHOWS AN INCREASED PROPENSITY FOR HELIX FORMATION AS COMPARED TO A PEPTIDE DERIVED FROM AN ER-DIRECTED SEQUENCE}

\section{Introduction}

Tail-anchored proteins consist of an $\mathrm{N}$-terminal cytosolic globular domain that is tethered to an intracellular membrane by a C-terminal hydrophobic transmembrane domain, or tail-anchor Wattenberg BW, 2001; Borgese N, 2003; Habib SJ, 2003; Borgese $\mathrm{N}, 2003$. The $\mathrm{C}$-terminal transmembrane domain serves as the addressing signal as well as the anchor that tethers the protein to the correct membrane Wattenberg BW, 2001; Habib SJ, 2003; Borgese $\mathrm{N}, 2003$. Because the C-terminal sequence is the final portion of the protein to exit the ribosome during translation, targeting to the destination membrane is post-translational. Tail-anchored proteins localize initially to the endoplasmic reticulum or the mitochondria, and to a lesser extent at peroxisomal membranes Borgese N, 2003. The targeting signal within the Cterminal tail that differentiates between membranes does not consist of specific amino acid sequences. Instead, distinctive structural characteristics of the tail allow for differential targeting (Table 2). These characteristics include hydrophobicity, polarity, charged flanking-residues, and spacing of residues Borgese N, 2001; Horie C, 2002; Isenmann S, 1998; Habib SJ, 2003. ER-targeted tail-anchored 
proteins contain relatively hydrophobic transmembrane sequences. Alternatively, mitochondrial-targeted tail-anchored proteins contain less hydrophobic transmembrane domains due to the presence of polar residues or due to containing shorter transmembrane segments. The mitochondrial-targeting tail anchors also contain positively-charged residues that flank the transmembrane sequence. A relevant example of these properties can be described with two splice isoforms, $A$ and $B$, of the tail-anchored protein VAMP1 Isenmann S, 1998. VAMP1A targets specifically to the ER. The tail anchor of VAMP1B differs from the tail anchor of VAMP1A only by shortening of the hydrophobic transmembrane domain and the addition of positively charged residues at the end of the tailanchor sequence. These slight changes allow for targeting of VAMP1B specifically to the mitochondria. Although these general structural characteristics have been established, the mechanism by which these differing structures selectively target to destination membranes is poorly understood. To shed more light on the differences in biophysical properties of mitochondrial- versus ERtargeted tail anchors, I investigated differences in secondary structure formation of representative artificial tail-anchor sequences.

\section{Materials and Methods}

\section{Circular dichroism of tail-anchor peptides}

The following synthetic peptides (Invitrogen) were examined by circular dichroism: MOA-tail (KSGSGSRIIGFSTSVTALGFVLYRYRLLPRS) and $L_{16}$ (KSGSGSRLLLLLLLLLLLLLLLLRYRLLPRS). Differing concentrations of 
trifluoroethanol (TFE) or dodecylphosphocholine (DPC; Avanti Polar Lipids) in $10 \mathrm{mM}$ phosphate buffer, or $4 \mathrm{mM}$ SDS in $5 \mathrm{mM}$ Tris $\mathrm{pH} 7.6$ were used to solubilize the peptides. Peptide concentrations were determined using absorbance readings at a wavelength of 220 . Concentrations corresponding to an absorbance reading of $0.7-0.8$ were found to be optimal for CD readings. Spectra were collected on a Jasco J-800 spectropolarimeter equipped with a thermoeclectric temperature control unit. Parameters for the $C D$ analysis are as follows: temperature $-20^{\circ} \mathrm{C}$, sensitivity—standard (100mdeg), start-260nm, end- $178 \mathrm{~nm}$, data pitch-0.2nm, scan mode-continuous, scan speed$50 \mathrm{~nm} / \mathrm{min}$, response $-2 \mathrm{~s}$, bandwidth $-1 \mathrm{~nm}$, accumulation-10. The spectra resulting from the $C D$ analysis were analyzed using CONTINLL software to determine the percent of helical conformation Provencher SW, 1981.

\section{Results and Discussion}

Tail-anchors direct targeting based on distinct structural characteristics rather than specific sequence requirements. By measuring the formation of secondary structure, I determined differing biophysical properties of a mitochondrial- versus an ER-targeted tail-anchor peptide. The mitochondrialtargeted tail-anchor peptide was derived using sequence from the tail-anchor of

the mitochondrially-targeted protein monoamine oxidase: KSGSGSRIIGFSTSVTALGFVLYRYRLLPRS. A poly-leucine sequence was used to represent an ER-targeted tail-anchor peptide, based on the high hydrophobicity characteristics of ER-targeted tail-anchors. This poly-leucine 
sequence was substituted into the tail-anchor sequence of monoamine oxidase: KSGSGSRLLLLLLLLLLLLLLLLRYRLLPRS. Both of these sequences were confirmed to target to the specified membrane (Table 2). Two conditions were used to measure the propensity of these peptides to form secondary structure. First, I wanted to test increasing concentrations of trifluoroethanol (TFE), a solvent that promotes helix formation. Secondly, dodecyl phosphocholine (DPC) was used as a membrane-mimetic zwitterionic detergent.

Peptides were first dissolved in aqueous buffer containing increasing concentrations of TFE. Circular dichroism was used to determine secondary structure at the various concentrations. Figure $24 \mathrm{~A}$ shows the delta epsilon measurements versus wavelength for the mitochondrial tail-anchor peptide, MOA, at the increasing TFE concentrations. The corresponding curves for the ER-targeted tail-anchor peptide, $\mathrm{L}_{16}$, are displayed in Figure 24B. Both peptides exhibit $\alpha$-helical formation upon increasing concentrations of TFE. This is shown by the characteristic spectrum indicative of $\alpha$-helical secondary structure, a maximum peak around $195 \mathrm{~nm}$ and two minimum peaks around $209 \mathrm{~nm}$ and $222 \mathrm{~nm}$. In aqueous buffer and at a lower concentration of TFE, the spectra are indicative of random coil structure. Random coil secondary structure is depicted by a minimum peak around $195-200 \mathrm{~nm}$. In buffer containing $25 \%$ TFE, the MOA-tail peptide appears to have more helical formation than the $\mathrm{L}_{16}$-tail peptide (Figure 24C). This is evident from the increase in delta epsilon for the MOA-tail peptide at $192 \mathrm{~nm}$, characteristic of alpha helix formation. This is also illustrated in Figure 24D where the calculated percentage of alpha helix was graphed 
FIGURE 24.

A

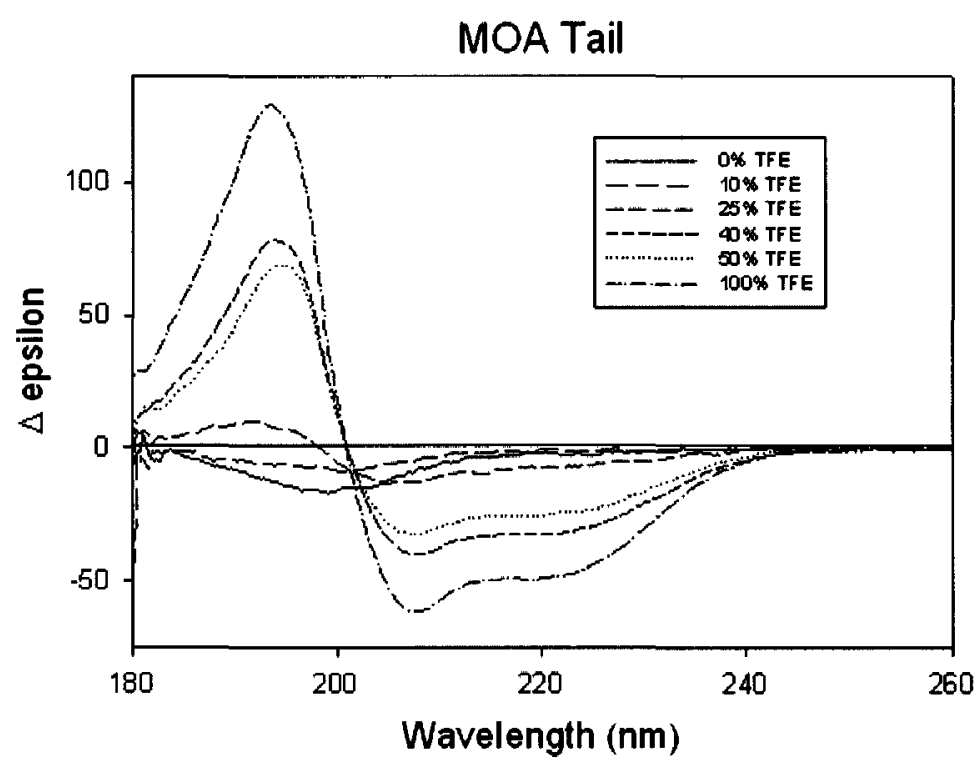

B

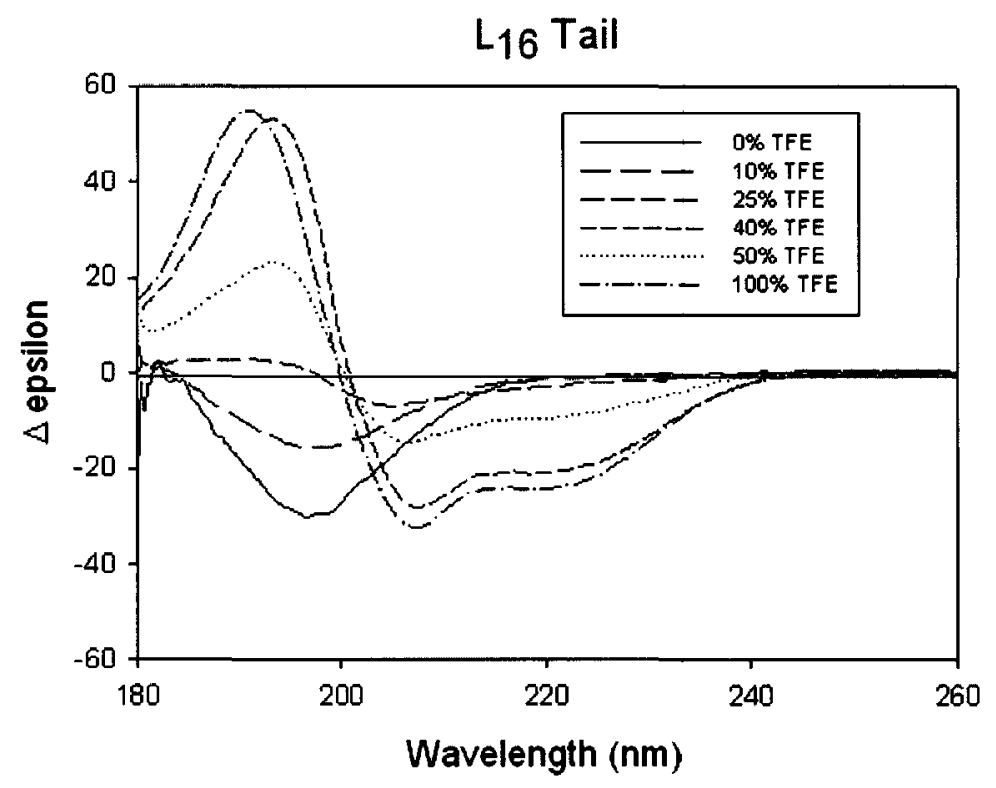


c

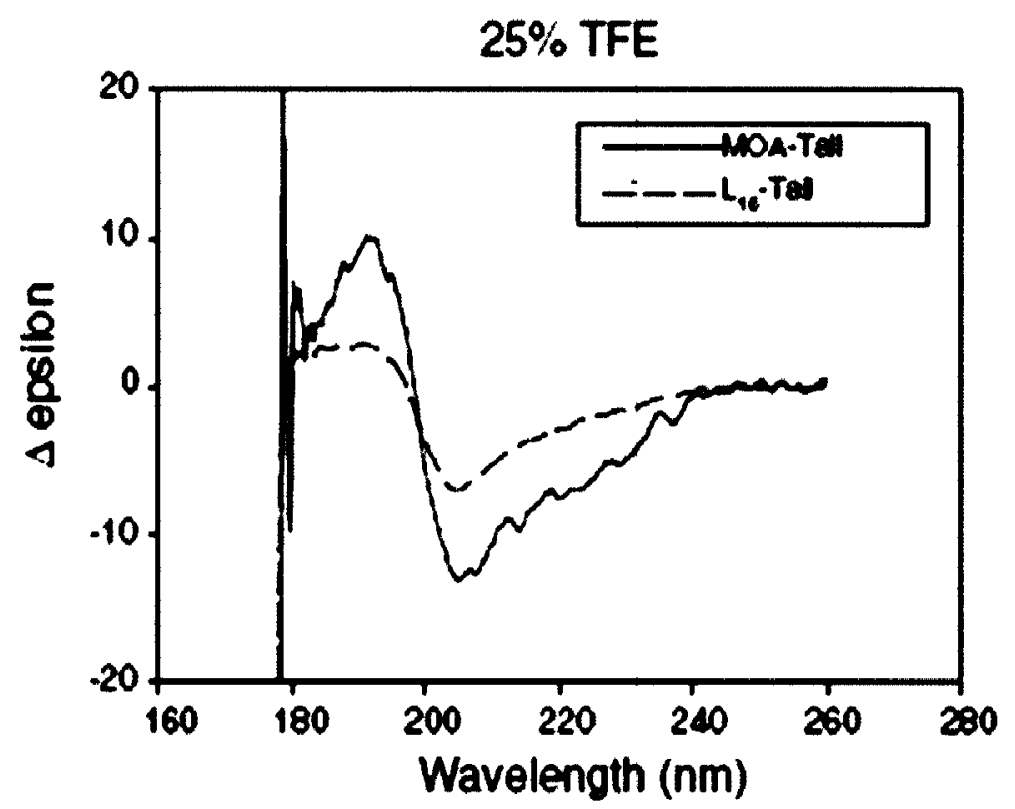

D

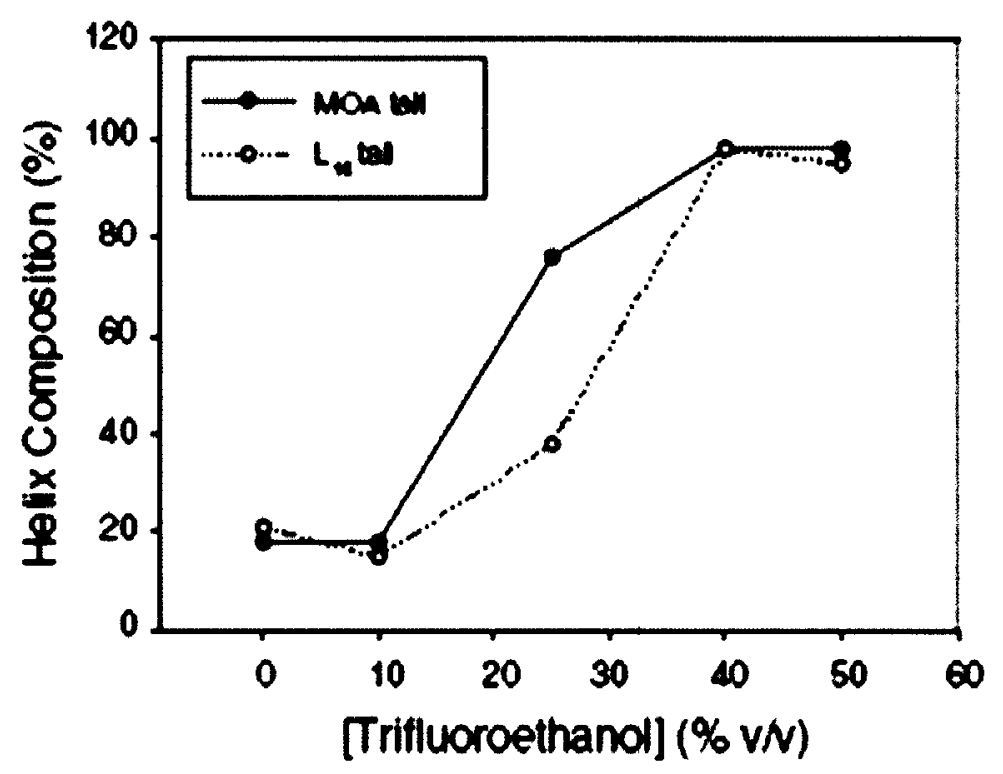


Figure 24. The mitochondrially targeted MOA-tail peptide has a higher propensity for TFE-induced $\alpha$-helix formation than the ER-targeted peptide L16. Synthetic peptides were dissolved in aqueous buffer containing the indicated amounts of TFE. Circular dichroism was measured as described in Materials and Methods. (A) MOA-tail peptide was measured with $0,10 \%, 25 \%$, $40 \%, 50 \%$, and $100 \%$ TFE. Results are reported as delta epsilon. (B) L16 peptide was measured as in panel (A). (C) The spectra for $25 \%$ TFE are shown in greater detail for comparison of MOA-tail peptide and the L16 peptide. (D) The percent helical content, calculated as described in Materials and Methods, is plotted for the two peptides versus TFE concentration. 
versus TFE concentration. Both peptides reached maximum helix formation in $40 \%$ TFE. However, while MOA-tail peptide was highly helical $(76 \%)$ in $25 \%$ TFE, $L_{16}$-tail peptide was only slightly more helical (38\%) than in completely aqueous buffer. This indicates that the mitochondrial-targeted tail-anchor peptide has a greater propensity to form helical structure in a helix-promoting solvent.

These peptides exhibited similar behavior in DPC. The MOA-tail peptide exhibited helical formation even at the lowest concentration of $0.8 \mathrm{mM}$ DPC (Figure 25A). In contrast, the $L_{16}$-tail peptide did not display helical formation until a higher concentration of $30 \mathrm{mM}$ DPC was used (Figure 25B). Percent helical content of these peptides at the various DPC concentrations is graphed in Figure 25C. As shown above, the MOA-tail peptide shows a higher propensity to form a helix in increasing concentrations of DPC, in comparison to the $\mathrm{L}_{16}$-tail peptide. It should be noted that the concentrations of DPC were chosen in terms of the amount of micelle that is formed. The critical micelle concentration of DPC is $1.1 \mathrm{mM}$ Stafford RE, 1989 . At $0.8 \mathrm{mM}$, DPC is entirely monomeric. At $3 \mathrm{mM}$, there is more or less an even distribution of DPC in monomeric versus micelle form. At $30 \mathrm{mM}, \mathrm{DPC}$ is predominantly in micelles. Therefore, while the MOA-tail peptide exhibits a tendency to form helix in the presence of monomeric DPC, the $\mathrm{L}_{16}$-tail peptide does not. However, both peptides display helical formation in the presence of micellar DPC. A summary of these data are represented in Table 3. Comparisons of the percent helicity in the various solutions demonstrate an increased propensity of the MOA-tail peptide to form helix compared to the $L_{16^{-}}$ tail peptide. 
As the data indicate, the mitochondrial-targeted tail-anchor peptide more readily forms $\alpha$-helical secondary structure in comparison to the ER-targeted tailanchor peptide. This illustrates divergent biophysical properties that could account for the differential targeting of these tail-anchor sequences. In the context of physiological tail-anchored proteins, the translocation to differential membranes could depend partly on the helix-forming propensity of the various tail anchors. Future studies should expand this analysis by looking at larger subsets of mitochondrial- versus ER-targeted tail anchors. 
FIGURE 25.

A

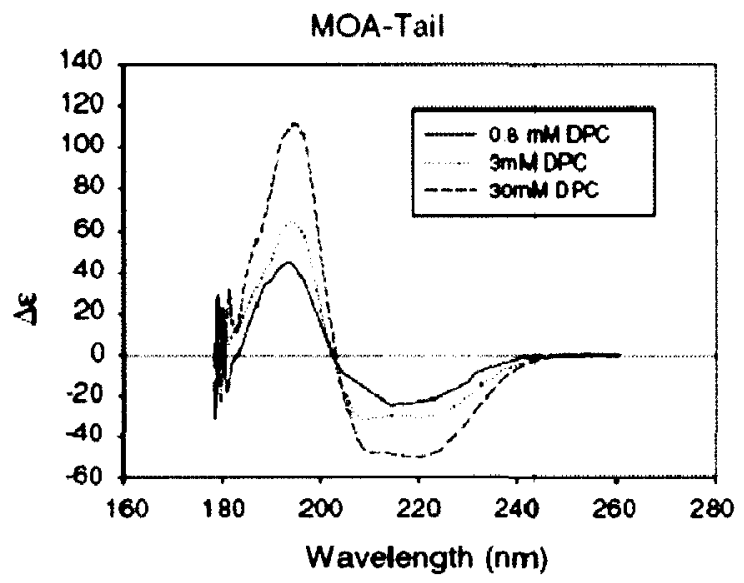

B

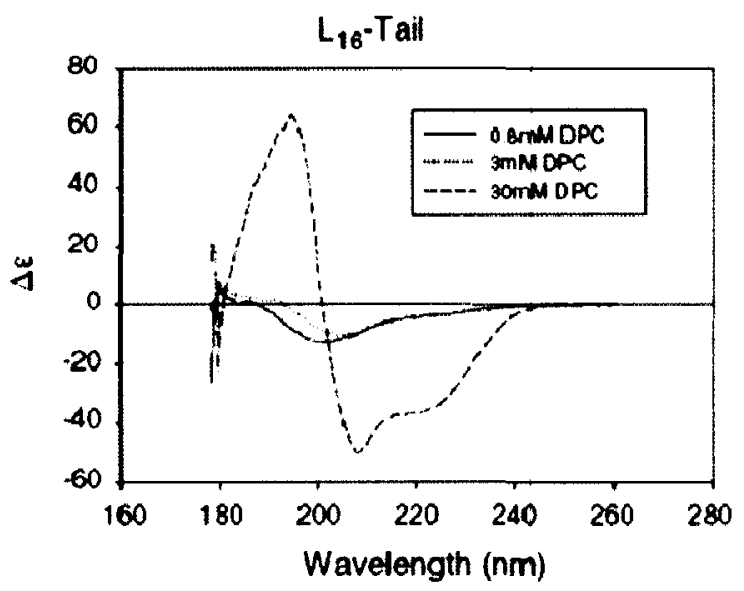

c

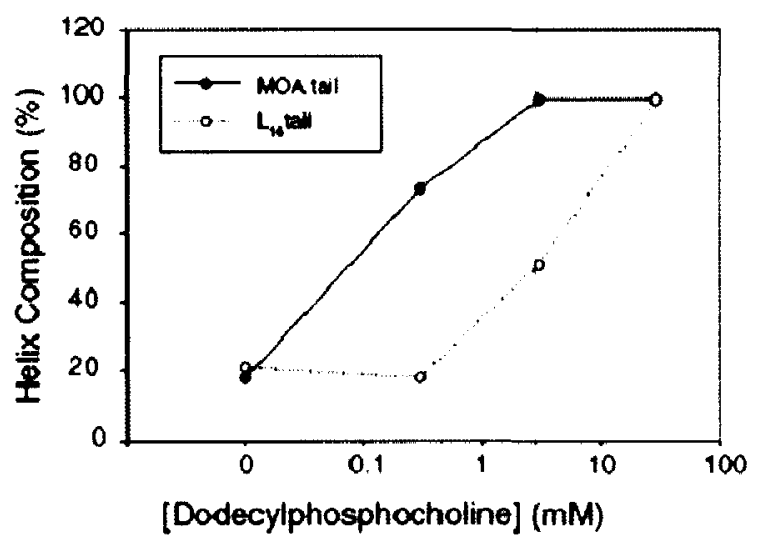


Figure 25. The mitochondrially targeted MOA-tail peptide has a higher propensity for a-helix formation in the membrane mimetic DPC than the ER-targeted peptide L16. Synthetic peptides were dissolved in aqueous buffer containing the indicated amounts of DPC. Circular dichroism was measured as described in Materials and Methods. (A) MOA-tail peptide was measured with $0.3 \mathrm{mM}, 3 \mathrm{mM}$, and $30 \mathrm{mM}$ DPC. Results are reported as delta epsilon. (B) L16 peptide was measured as in panel (A). (C) The percent helical content, calculated as described in Materials and Methods, is plotted for the two peptides versus DPC concentration. 


\section{TABLE 5.}

Table 5 Summary of alpha helix content of the indicated peptides in the solutions shown

\begin{tabular}{lcc}
\hline Solution & MOA-tail \% helix & $\mathrm{L}_{16}$-tail \% helix \\
\hline Phosphate Buffer & 18 & 21 \\
$10 \%$ TFE & 18 & 15 \\
$25 \%$ TFE & 76 & 38 \\
$40 \%$ TFE & 98 & 98 \\
$50 \%$ TFE & 98 & 95 \\
$0.8 \mathrm{mM} \mathrm{DPC}$ & 73 & 18 \\
$3 \mathrm{mM} \mathrm{DPC}$ & 99 & 51 \\
$30 \mathrm{mM} \mathrm{DPC}$ & 99 & 99
\end{tabular}

Alpha helix content was calculated from the curves shown in Figs 12 and 13 as described in

Materials and Methods. The remainder of the structure was almost exclusively random coil. 


\section{REFERENCES}

1. Adams JM and Cory S. The Bcl-2 protein family: Arbiters of cell survival. Science 1998; 281: 1322-1326.

2. Ahting U, Waizenegger T, Neupert $\mathbf{W}$, and Rapaport D. Signalanchored proteins follow a unique insertion pathway into the outer membrane of mitochondria. J Biol Chem 2005; 280: 48-53.

3. Annis MG, Soucie EL, Dlugosz PJ, Cruz-Aguado JA, Penn LZ, Leber $B$, and Andrews DW. Bax forms multispanning monomers that oligomerize to permeabilize membranes during apoptosis. EMBO J 2005; 24: 2096-2103.

4. Antonsson B, Conti F, Ciavatta A, Montessuit S, Lewis S, Martinou I, Bernasconi L, Bernard A, Mermod JJ, Mazzei G, Maundrell K, Gambale F, Sadoul R, and Martinou JC. Inhibition of Bax channel-forming activity by Bcl-2. Science 1997; 277: 370-372.

5. Antonsson B, Montessuit S, Lauper S, Eskes R, and Martinou JC. Bax oligomerization is required for channel-forming activity in liposomes and to trigger cytochrome $\mathrm{c}$ release from mitochondria. Biochem J 2000; 345: 271-278.

6. Antonsson B, Montessuit S, Sanchez B, and Martinou JC. Bax is present as a high molecular weight oligomer/complex in the mitochondrial membrane of apoptotic cells. J Biol Chem 2001; 276 : 11615-11623.

7. Arokium H, Camougrand N, Vallette FM, and Manon S. Studies of the interaction of substituted mutants of Bax with yeast mitochondria reveal that the C-terminal hydrophobic alpha-helix is a second ART sequence and plays a role in the interaction with anti-apoptotic BclxL. J Biol Chem 2004; 279: 52566-52573.

8. Ashkenazi A and Dixit VM. Death receptors: Signaling and modulation. Science 1998; 281: 1305-1308.

9. Balch WE and Rothman JE. Characterization of protein transport between successive compartments of the Golgi apparatus: 
asymmetric properties of donor and acceptor activities in a cell-free system. Arch Biochem Biophys 1985; 240: 413-425.

10. Bargou RC, Daniel PT, Mapara MY, Bommert K, Wagener C, Kallinich B, Royer HD, and Dorken B. Expression of the bcl-2 gene family in normal and malignant breast tissue: low bax-alpha expression in tumor cells correlates with resistance towards apoptosis. Int J Cancer 1995; 60: 854-859.

11. Beerheide $\mathbf{W}$, Tan $Y J$, Teng $E$, Ting $A E$, Jedpiyawongse $A$, and Srivatanakul P. Downregulation of proapoptotic proteins Bax and $\mathrm{Bcl}-\mathrm{X}(\mathrm{S})$ in p53 overexpressing hepatocellular carcinomas. Biochem Biophys Res Commun 2000; 273: 54-61.

12. Bellot G, Cartron PF, Er E, Oliver L, Jin P, Armstrong LC, Bornstein, P, Mihara K, Manon S, and Vallette FM. TOM22, a core component of the mitochondria outer membrane protein translocation pore, is a mitochondrial receptor for the proapoptotic protein Bax. Cell Death Differ 2007; 14: 785-794.

13. Belzacq AS, Vieira HL, Verrier F, Vandecasteele G, Cohen I, Prevost MC, Larquet E, Pariselli F, Petit PX, Kahn A, Rizzuto R, Brenner $\mathrm{C}$, and Kroemer G. Bcl-2 and Bax modulate adenine nucleotide translocase activity. Cancer Res 2003; 63: 541-546.

14. Billen LP, Kokoski CL, Lovell JF, Leber B, and Andrews DW. Bcl-xL inhibits membrane permeabilization by competing with Bax. PLoS Biol 2008; 6: e147.

15. Borgese N, Brambillasca S, and Colombo S. How tails guide tailanchored proteins to their destinations. Curr Opin Cell Biol 2007; 19: $368-375$.

16. Borgese N, Brambillasca S, Soffientini P, Yabal M, and Makarow M. Biogenesis of tail-anchored proteins. Biochem Soc Trans 2003; 31: 1238-1242.

17. Borgese N, Colombo S, and Pedrazzini E. The tale of tail-anchored proteins: coming from the cytosol and looking for a membrane. $J$ Cell Biol 2003; 161: 1013-1019.

18. Borgese N, Gazzoni I, Barberi M, Colombo S, and Pedrazzini E. Targeting of a tail-anchored protein to endoplasmic reticulum and mitochondrial outer membrane by independent but competing pathways. Mol Biol Cell 2001; 12: 2482-2496. 
19. Brenner C, Cadiou H, Vieira HL, Zamzami N, Marzo I, Xie Z, Leber B, Andrews D, Duclohier H, Reed JC, and Kroemer G. Bcl-2 and Bax regulate the channel activity of the mitochondrial adenine nucleotide translocator. Oncogene 2000; 19: 329-336.

20. Capano $M$ and Crompton $M$. Bax translocates to mitochondria of heart cells during simulated ischaemia: involvement of AMP-activated and p38 mitogen-activated protein kinases. Biochem $J$ 2006; 395: 57-64.

21. Capano $M$ and Crompton M. Biphasic translocation of Bax to mitochondria. Biochem J 2002; 367: 169-178.

22. Cartron PF, Arokium H, Oliver L, Meflah K, Manon S, and Vallette FM. Distinct domains control the addressing and the insertion of Bax into mitochondria. J Biol Chem 2005; 280: 10587-10598.

23. Cartron PF, Priault M, Oliver L, Meflah K, Manon S, and Vallette FM. The N-terminal end of Bax contains a mitochondrial-targeting signal. J Biol Chem 2003; 278: 11633-11641.

24. Cheng EH, Wei MC, Weiler S, Flavell RA, Mak TW, Lindsten T, and Korsmeyer SJ. Bcl-2, Bcl-xL sequester $\mathrm{BH} 3$ domain-only molecules preventing Bax-and Bak-mediated mitochondrial apoptosis. Mol Cell 2001; 8(3): 705-711.

25. Cory $\mathbf{S}$ and Adams JM. The $\mathrm{Bcl}-2$ family: regulators of the cellular lifeor-death switch. Nat Rev Cancer 2002; 2(9): 647-656.

26. Desagher S, Osen-Sand A, Nichols A, Eskes R, Montessuit $S$, Lauper S, Maundrell K, Antonsson B, and Martinou JC. Bidinduced conformational change of Bax is responsible for mitochondrial cytochrome $\mathrm{c}$ release during apoptosis. J Cell Biol 1999; 144: 891-901.

27. Dlugosz PJ, Billen LP, Annis MG, Zhu W, Zhang Z, Lin J, Leber B, and Andrews DW. Bcl-2 changes conformation to inhibit Bax oligomerization. EMBO J 2006; 25: 2287-2296.

28. Eskes R, Antonsson B, Osen-Sand A, Montessuit S, Richter C, Sadoul R, Mazzei G, Nichols A, and Martinou JC. Bax-induced cytochrome $c$ release from mitochondria is independent of the permeability transition pore but highly dependent on Mg2+ ions. $J$ Cell Biol 1998; 143: 217-224. 
29. Eskes R, Desagher S, Antonsson B, and Martinou JC. Bid induces the oligomerization and insertion of Bax into the outer mitochondrial membrane. Mol Cell Biol 2000; 20: 929-935.

30. Finucane DM, Bossy-Wetzel E, Waterhouse NJ, Cotter TG, and Green DR. Bax-induced caspase activation and apoptosis via cytochrome $c$ release from mitochondria is inhibitable by Bcl-xL. $J$ Biol Chem 1999; 274: 2225-2233.

31. Gardai SJ, Hildeman DA, Frankel SK, Whitlock BB, Frasch SC, Borregaard N, Marrack P, Bratton DL, and Henson PM. Phosphorylation of Bax Ser184 by Akt regulates its activity and apoptosis in neutrophils. J Biol Chem 2004; 279: 21085-21095.

32. Gil J, Yamamoto H, Zapata JM, Reed JC, and Perucho M. Impairment of the proapoptotic activity of Bax by missense mutations found in gastrointestinal cancers. Cancer Res 1999; 59: 2034-2037.

33. Goping IS, Gross A, Lavoie JN, Nguyen M, Jemmerson R, Roth K, Korsmeyer SJ, and Shore GC. Regulated targeting of Bax to mitochondria. J Cell Biol 1998; 143: 207-215.

34. Green DR and Reed JC. Mitochondria and apoptosis. Science 1998; 281: $1309-1312$.

35. Guo B, Zhai D, Cabezas E, Welsh K, Nouraini S, Satterthwait AC, and Reed JC. Humanin peptide suppresses apoptosis by interfering with Bax activation. Nature 2003; 423: 456-461.

36. Gupta S and Knowlton AA. HSP60, Bax, apoptosis and the heart. $J$ Cell Mol Med 2005; 9: 51-58.

37. Habib SJ, Vasiljev A, Neupert W, and Rapaport D. Multiple functions of tail-anchor domains of mitochondrial outer membrane proteins. FEBS Lett 2003; 555: 511-515.

38. Haunstetter A and lzumo S. Apoptosis: basic mechanisms and implications for cardiovascular disease. Circ Res 1998; 82: 11111129.

39. Haunstetter A and lzumo S. Toward antiapoptosis as a new treatment modality. Circ Res 2000; 86: 371-376.

40. Hetz C, Bernasconi P, Fisher J, Lee AH, Bassik MC, Antonsson B, Brandt GS, Iwakoshi NN, Schinzel A, Glimcher LH, and Korsmeyer SJ. Proapoptotic Bax and Bak modulate the unfolded 
protein response by a direct interaction with IRE1alpha. Science 2006; 312: 572-576.

41. Hochhauser E, Cheporko Y, Yasovich N, Pinchas L, Offen D, Barhum Y, Pannet $H$, Tobar A, Vidne BA, and Birk E. Bax deficiency reduces infarct size and improves long-term function after myocardial infarction. Cell Biochem Biophys 2007; 47: 11-20.

42. Hochhauser E, Kivity S, Offen D, Maulik N, Otani H, Barhum Y, Pannet H, Shneyvays V, Shainberg A, Goldshtaub V, Tobar A, and Vidne BA. Bax ablation protects against myocardial ischemiareperfusion injury in transgenic mice. Am J Physiol Heart Circ Physiol 2003; 284: H2351-2359.

43. Horie C, Suzuki H, Sakaguchi M, and Mihara K. Characterization of signal that directs $\mathrm{C}$-tail-anchored proteins to mammalian mitochondrial outer membrane. Mol Biol Cell 2002; 13: 1615-1625.

44. Hou Q and Hsu YT. Bax translocates from cytosol to mitochondria in cardiac cells during apoptosis: development of a GFP-Bax-stable $\mathrm{H} 9 \mathrm{c} 2$ cell line for apoptosis analysis. Am J Physiol Heart Circ Physiol 2005; 289: H477-H487.

45. Hsu YT, Wolter KG, and Youle RJ. Cytosol-to-membrane redistribution of Bax and Bcl-X(L) during apoptosis. Proc Natl Acad Sci U S A 1997; 94: 3668-72.

46. Hsu YT and Youle RJ. Bax in murine thymus is a soluble monomeric protein that displays differential detergent-induced conformations. $J$ Biol Chem 1998; 273: 10777-10783.

47. Hsu YT and Youle RJ. Nonionic detergents induce dimerization among members of the Bcl-2 family. J Biol Chem 1997; 272: 13829-13834.

48. Isenmann S, Khew-Goodall Y, Gamble J, Vadas M, and Wattenberg BW. A splice-isoform of vesicle-associated membrane protein-1 (VAMP-1) contains a mitochondrial targeting signal. Mol Biol Cell 1998; 9: 1649-1660.

49. Jin $Z$ and EI-Diery WS. Overview of cell death signaling pathways. Cancer Biol Ther 2005; 4(2): 139-163.

50. Jurgensmeier JM, Xie Z, Deveraux Q, Ellerby L, Bredesen D, and Reed JC. Bax directly induces release of cytochrome $\mathrm{c}$ from isolated mitochondria. Proc Natl Acad Sci U S A 1998; 95: 49975002. 
51. Kagawa S, Gu J, Swisher SG, Ji L, Roth JA, Lai D, Stephens LC, and Fang $B$. Antitumor effect of adenovirus-mediated Bax gene transfer on p53-sensitive and p53-resistant cancer lines. Cancer Res 2000; 60: 1157-1161.

52. Kalbfleisch T, Cambon A, and Wattenberg BW. A bioinformatics approach to identifying tail-anchored proteins in the human genome. Traffic 2007; 8: 1687-1694.

53. Kaufmann T, Schlipf S, Sanz J, Neubert K, Stein R, and Borner C. Characterization of the signal that directs $\mathrm{Bcl}-\mathrm{x}(\mathrm{L})$, but not $\mathrm{Bcl}-2$, to the mitochondrial outer membrane. J Cell Biol 2003; 160: 53-64.

54. Kerr JF, Wyllie AH, and Currie AR. Apoptosis: a basic biological phenomenon with wide-ranging implications in tissue kinetics. $\mathrm{Br} \mathrm{J}$ Cancer 1972; 26(4): 239-257.

55. Kim PK, Janiak-Spens F, Trimble WS, Leber B, and Andrews DW. Evidence for multiple mechanisms for membrane binding and integration via carboxyl-terminal insertion sequences. Biochemistry 1997; 36: 8873-8882.

56. Kuwana T, Bouchier-Hayes L, Chipuk JE, Bonzon C, Sullivan BA, Green DR, and Newmeyer DD. BH2 domains of BH3-only proteins differentially regulate Bax-mediated mitochondrial membrane permeabilization both directly and indirectly. Mol Cell 2005; 17 : 525-535.

57. Lan L, Isenmann S, and Wattenberg BW. Targeting and insertion of Cterminally anchored proteins to the mitochondrial outer membrane is specific and saturable but does not strictly require ATP or molecular chaperones. Biochem J 2000; 349: 611-621.

58. Leber B, Lin J, and Andrews DW. Embedded together: the life and death consequences of interaction of the $\mathrm{Bcl}-2$ family with membranes. Apoptosis 2007; 12: 897-911.

59. LeBlanc H, Lawrence D, Varfolomeev E, Totpal K, Morlan J, Schow P, Fong S, Schwall R, Sinicropi D, and Ashkinazi A. Tumor-cell resistance to death receptor-induced apoptosis through mutational inactivation of the proapoptotic Bcl-2 homolog Bax. Nat Med 2002; 8: 274-281.

60. Li X, Marani M, Yu J, Nan B, Roth JA, Kagawa S, Fang B, Denner L, and Marcelli M. Adenovirus-mediated Bax overexpression for the 
induction of therapeutic apoptosis in prostate cancer. Cancer Res 2001; 61: 186-191.

61. Lowe SL, Rubinchik S, Honda T, McDonnell TJ, Dong JY, and Norris JS. Prostate-specific expression of Bax delivered by an adenoviral vector induces apoptosis in LNCaP prostate cancer cells. Gene Ther 2001; 8: 1363-1371.

62. Lundberg KC and Szweda LI. Initiation of mitochondrial-mediated apoptosis during cardiac reperfusion. Arch Biochem Biophys 2004; 432: $50-57$.

63. Marani M, Tenev T, Hancock D, Downard J, and Lemoine NR. Identification of novel isoforms of the $\mathrm{BH} 3$ domain protein Bim which directly activate Bax to trigger apoptosis. Mol Cell Biol 2002; 22: 3577-3589.

64. Marzo I, Brenner C, Zamzami N, Jurgensmeier JM, Susin SA, Vieira HL, Prevost MC, Xie Z, Matsuyama S, Reed JC, and Kroemer G. Bax and adenine nucleotide translocator cooperate in the mitochondrial control of apoptosis. Science 1998; 281: 2027-2031.

65. Masaki R, Kameyama K, and Yamamoto A. Post-translational targeting of a tail-anchored green fluorescent protein to the endoplasmic reticulum. $J$ Biochem 2003; 134: 415-426.

66. Meijerink JP, Mensink EJ, Wang K, Sedlak TW, Sloetjes AW, de Witte T, Waksman G, and Korsmeyer SJ. Hematopoietic malignancies demonstrate loss-of-function mutations of Bax. Blood 1998; 91: 2991-2997.

67. Mikhailov V, Mikhailova M, Pulkrabek DJ, Dong Z, Venkatachalam MA, and Saikumar P. Bcl-2 prevents Bax oligomerization in the mitochondrial outer membrane. J Biol Chem 2001; 276: 1836118374.

68. Murphy KM, Streips UN, and Lock RB. Bcl-2 inhibits a Fas-induced conformational change in the Bax $\mathrm{N}$ terminus and Bax mitochondrial translocation. J Biol Chem 2000; 275: 17225-17228.

69. Narita M, Shimizu S, Ito T, Chittenden T, Lutz RJ, Matsuda H, and Tsujimoto $Y$. Bax interacts with the permeability transition pore to induce permeability transition and cytochrome $c$ release in isolated mitochondria. Proc Natl Acad Sci U S A 1998; 95: 14681-14686. 
70. Nechushtan A, Smith CL, Hsu YT, and Youle RJ. Conformation of the Bax C-terminus regulates subcellular location and cell death. EMBO J 1999; 18: 2330-2341.

71. Nguyen M, Millar DG, Yong VW, Korsmeyer SJ, and Shore GC. Targeting of $\mathrm{Bcl}-2$ to the mitochondrial outer membrane by a COOH-terminal signal anchor sequence. J Biol Chem 1993; 268: 25265-25268.

72. Nomura M, Shimizu S, Ito T, Narita M, Matsuda $H$, and Tsujimoto $Y$. Apoptotic cytosol facilitates Bax translocation to mitochondria that involves cytosolic factor regulated by Bcl-2. Cancer Res 1999; 59: $5542-5548$.

73. Nomura M, Shimizu S, Sugiyama $T$, Narita $M$, Ito $T$, Matsuda $H$, ad Tsujimoto Y. 14-3-3 interacts directly with and negatively regulates pro-apoptotic Bax. J Biol Chem 2003; 278: 2058-2065.

74. Nutt LK, Chandra J, Pataer A, Fang B, Roth JA, Swisher SG, O'Neil RG, and McConkey DJ. Bax-mediated $\mathrm{Ca} 2+$ mobilization promotes cytochrome $\mathrm{c}$ release during apoptosis. $\mathrm{J} \mathrm{Biol} \mathrm{Chem}$ 2002; 277: 20301-20308.

75. Nutt LK, Pataer A, Pahler J, Fang B, Roth J, McConkey DJ, and Swisher SG. Bax and Bak promote apoptosis by modulating endoplasmic reticular and mitochondrial $\mathrm{Ca} 2+$ stores. J Biol Chem 2002; 277: 9219-9225.

76. Oakes SA, Scorrano L, Opferman JT, Bassik MC, Nishino M, Pozzan $\mathrm{T}$, Korsmeyer SJ. Proapoptotic Bax and Bak regulate the type 1 inositol trisphosphate receptor and calcium leak from the endoplasmic reticulum. Proc Natl Acad Sci U S A 2005; 102: 105110.

77. Oltvai ZN, Milliman CL, and Korsmeyer SJ. Bcl-2 heterodimerizes in vivo with a conserved homolog, Bax, that accelerates programmed cell death. Cell 1993; 74(4): 609-619.

78. Ouyang H, Furukawa T, Abe T, Kato Y, and Horii A. The Bax gene, the promoter of apoptosis, is mutated in genetically unstable cancers of the colorectum, stomach, and endometrium. Clin Cancer Res 1998; 4: 1071-1074.

79. Paradis E, Douillard H, Koutroumanis M, Goodyer C, and LeBlanc A. Amyloid beta peptide of Alzheimer's disease downregulates Bcl- 
2 and upregulates bax expression in human neurons. $J$ Neurosci 1996; 16: 7533-7539.

80. Perier C, Bove J, Wu DC, Dehav B, Choi DK, Jackson-Lewis V, Rathke-Hartlieb S, Bouillet P, Strasser A, Schulz JB, Przedborski S, and Vila M. Two molecular pathways initiate mitochondria-dependent dopaminergic neurodegeneration in experimental Parkinson's disease. Proc Natl Acad Sci U S A 2007; 104: 8161-8166.

81. Provencher SW and Glockner J. Estimation of globular protein secondary structure from circular dichroism. Biochemistry 1981; 20:33-37.

82. Rampino N, Yamamoto H, lonov Y, Li Y, Sawai H, Reed JC, and Perucho M. Somatic frameshift mutations in the Bax gene in colon cancers of the microsatellite mutator phenotype. Science 1997; 275: 967-969.

83. Roucou X, Montessuit S, Antonsson B, and Martinou JC. Bax oligomerization in mitochondrial membranes requires tBid (caspase-8-cleaved Bid) and a mitochondrial protein. Biochem $J$ 2002; 368: 915-921.

84. Ruffolo SC, Breckenridge DG, Nguyen M, Goping IS, Gross A, Korsmeyer SJ, Li H, Yuan J, and Shore GC. BID-dependent and BID-independent pathways for Bax insertion into mitochondria. Cell Death Differ 2000; 7: 1101-1108.

85. Saito M, Korsmeyer SJ, and Schlesinger PH. Bax-dependent transport of cytochrome $c$ reconstituted in pure liposomes. Nat Cell Biol 2000; 2: 553-555.

86. Sakakura C, Sweeney EA, Shirahama T, Igarashi Y, Hakomori S, Nakatani H, Tsujimoto H, Imanishi T, Ohgaki M, Ohyama T, Yamazaki J, Hwagiwara A, Yamaguchi T, Sawai K, and Takahashi T. Overexpression of Bax sensitizes human breast cancer MCF-7 cells to radiation-induced apoptosis. Int $\mathrm{J}$ Cancer 1996; 67: 101-105.

87. Sawada M, Sun W, Hayes P, Leskov K, Boothman DA, and Matsuyama S. Ku70 suppresses the apoptotic translocation of Bax to mitochondria. Nat Cell Biol 2003; $5: 320-329$. 
88. Schinzel A, Kaufmann T, and Borner C. Bcl-2 family members: integrators of survival and death signals in physiology and pathology. Biochim Biophys Acta 2004; 1644(2-3): 95-105.

89. Schinzel A, Kaufmann T, Schuler M, Martinalbo J, Grubb D, and Borner C. Conformational control of Bax localization and apoptotic activity by Pro168. J Cell Biol 2004; 164: 1021-1032.

90. Schlesinger PH, Gross A, Yin XM, Yamamoto K, Saito M, Waksman $G$, and Korsmeyer SJ. Comparison of the ion channel characteristics of proapoptotic Bax and antiapoptotic Bcl-2. Proc Natl Acad Sci U S A 1997; 94: 11357-11362.

91. Scorrano L, Oakes SA, Opferman JT, Cheng EH, Sorcinelli MD, Pozzan T, and Korsmeyer SJ. Bax and Bak regulation of endoplasmic reticulum $\mathrm{Ca} 2+$ : a control point for apoptosis. Science 2003; 300: 135-139.

92. Sharpe JC, Arnoult D, and Youle RJ. Control of mitochondrial permeability by Bcl-2 family members. Biochim Biophys Acta 2004; 1644: 107-113.

93. Stafford RE, Fanni, T, and Dennis EA. Interfacial properties and critical micelle concentration of lysophospholipids. Biochemistry 1989; 28: 5113-5120.

94. Stefanovic $\mathbf{S}$ and Hegde RS. Identification of a targeting factor for posttranslational membrane protein insertion into the ER. Cell 2007; 128: 1147-1159.

95. Strasser A, O'Connor L, and Dixit VM. Apoptosis signaling. Annu Rev Biochem 2000; 69: 217-245.

96. Su JH, Deng G, and Cotman CW. Bax protein expression is increased in Alzheimer's brain: correlations with DNA damage, $\mathrm{Bcl}-2$ expression, and brain pathology. J Neuropathol Exp Neurol 1997; 56: 86-93.

97. Suzuki M, Youle RJ, and Tjandra N. Structure of Bax: coregulation of dimmer formation and intracellular localization. Cell 2000; 103: 645654.

98. Takeuchi O, Fisher J, Suh H, Harada H, Malynn BA, and Korsmeyer SJ. Essential role of Bax,Bak in B cell homeostasis and prevention of autoimmune disease. Proc Natl Acad Sci U S A 2005; 102: 11272-11277. 
99. Teles AV, Rosenstock TR, Okuno CS, Lopes GS, Bertoncini CR, Smaili SS. Increase in bax expression and apoptosis are associated in Huntington's disease progression. Neurosci Lett 2008; 438: 59-63.

100. Theodorakis $P$, Lomonosova $E$, and Chinnadurai $G$. Critical requirement of Bax for manifestation of apoptosis induced by multiple stimuli in human epithelial cancer cells. Cancer Res 2002; 62: 3373-3376.

101. Tortosa A, Lopez E, and Ferrer I. Bcl-2 and Bax protein expression in Alzheimer's disease. Acta Neuropathol 1998; 95: 407-412.

102. Tremblais K, Oliver L, Juin P, Le Cabellec TM, Meflah K, and Vallette FM. The C-terminus of bax is not a membrane addressing/anchoring signal. Biochem Biophys Res Commun 1999; 260: 582-591.

103. Tsujimoto Y, Finger LR, Yunis J, Nowell PC, and Croce CM. Cloning of the chromosome breakpoint of neoplastic $B$ cells with the $t(14 ; 18)$ chromosome translocation. Science 1984; 226: 1097-1099.

104. Vila M, Jackson-Lewis V, Vukosavic S, Djaldetti R, Liberatore G, Offen D, Korsmeyer SJ, and Przedborski S. Bax ablation prevents dopaminergic neurodegeneration in the 1-methyl-4phenyl-1,2,3,6-tetrahydropyridine mouse model of Parkinson's disease. Proc Natl Acad Sci U S A 2001; 98: 2837-2842.

105. Wagener C, Bargou RC, Daniel PT, Bommert K, Mapara MY, Royer $H D$, and Dorken $B$. Induction of the death-promoting gene baxalpha sensitizes cultured breast-cancer cells to drug-induced apoptosis. Int J Cancer 1996; 67: 138-141.

106. Wang K, Gross A, Waksman G, and Korsmeyer SJ. Mutagenesis of the $\mathrm{BH} 3$ domain of Bax identifies residues critical for dimerization and killing. Mol Cell Biol 1998; 18: 6083-6089.

107. Wattenberg BW, Clark D, and Brock S. An artificial mitochondrial tail signal/anchor sequence confirms a requirement for moderate hydrophobicity for targeting. Biosci Rep 2007; 27: 385-401.

108. Wattenberg BW and Lithgow T. Targeting of C-terminal (tail)-anchored proteins: understanding how cytoplasmic activities are anchored to intracellular membranes. Traffic 2001; 2: 66-71. 
109. Wei MC, Zong WX, Cheng EH, Lindsten T, Panoutsakopoulou V, Ross AJ, Roth KA, MacGregor GR, Thompson CB, and Korsmeyer SJ. Proapoptotic Bax and Bak: a requisite gateway to mitochondrial dysfunction and death. Science 2001; 292: 727-730.

110. Wolter KG, Hsu YT, Smith CL, Nechushtan A, Xi XG, and Youle RJ. Movement of Bax from the cytosol to mitochondria during apoptosis. J Cell Biol 1997; 139: 1281-1292.

111. Wu $Y$, Xing $D$, Chen WR, and Wang $X$. Bid is not required for Bax translocation during UV-induced apoptosis. Cell Signal 2007; 19: 2468-2478.

112. Xin $\mathbf{M}$ and Deng $\mathbf{X}$. Nicotine inactivation of the proapoptotic function of Bax through phosphorylation. J Biol Chem 2005; 280: 1078110789.

113. Xu ZW, Friess H, Buchler MW, and Solioz M. Overexpression of Bax sensitizes human pancreatic cancer cells to apoptosis induced by chemotherapeutic agents. Cancer Chemother Pharmacol 2002; 49: 504-510.

114. Yamamoto H, Sawai $\mathbf{H}$, and Perucho M. Frameshift somatic mutations in gastrointestinal cancer of the microsatellite mutator phenotype. Cancer Res 1997; 57: 4420-4426.

115. Yethon JA, Epand RF, Leber B, Epand RM and Andrews DW. Interaction with a membrane surface triggers a reversible conformational change in Bax normally associated with induction of apoptosis. J Biol Chem 2003; 278: 48935-48941.

116. Yi X, Yin X-M, and Dong Z. Inhibition of Bid-induced apoptosis by Bcl-2. $J$ Biol Chem 2003; 278: 16992-16999.

117. Yin C, Knudson CM, Korsmeyer SJ, and Van Dyke T. Bax suppresses tumorigenesis and stimulates apoptosis in vivo. Nature 1997; 385 : 637-640.

118. Zha H, Aime-Sempe C, Sato T, and Reed JC. Proapoptotic protein Bax heterodimerizes with $\mathrm{Bcl}-2$ and homodimerizes with $\mathrm{Bax}$ via a novel domain $(\mathrm{BH} 3)$ distinct from $\mathrm{BH} 1$ and $\mathrm{BH} 2$. J Biol Chem 1996; 271: 7440-7444.

119. Zhang H, Kim JK, Edwards CA, Xu Z, Taichman R, and Wang $C Y$. Clusterin inhibits apoptosis by interacting with activated Bax. Nat Cell Biol 2005; 7: 909-915. 
120. Zhang L, Yu J, Park BH, Kinzler KW, and Vogelstein B. Role of Bax in the apoptotic response to anticancer agents. Science 2000; 290: 989-992.

121. Zong WX, Li C, Hatzivassiliou G, Lindsten T, Yu QC, Yuan J, and Thompson CB. Bax and Bak can localize to the endoplasmic reticulum to initiate apoptosis. J Cell Biol 2003; 162: 59-69.

122. Zong WX, Lindsten T, Ross AJ, MacGregor GR, and Thompson CB. $\mathrm{BH} 3-o n l y$ proteins that bind pro-survival $\mathrm{Bcl}-2$ family members fail to induce apoptosis in the absence of Bax and Bak. Genes Dev $2001 ; 15(12): 1481-1486$. 


\section{CURRICULUM VITAE}

NAME: Stephanie Erin Brock

EMAIL: sebroc01@gwise.louisville.edu

DOB: $\quad$ Louisville, Ky-July 8,1980

\section{EDUCATION:}

Doctorate of Philosophy, Biochemistry and Molecular Biology, July 2009 University of Louisville, Louisville, Ky

Dissertation: Mitochondrial targeting of the pro-apoptotic protein Bax: Role of the Bax carboxy-terminal tail

Advisor: Dr. Binks Wattenberg

GPA 3.99

Bachelor of Science, Biotechnology; Double Major: Biology, Dec 2002 University of Kentucky, Lexington, Ky

GPA 3.97

\section{HONORS/AWARDS:}

2006 Southeastern Regional Lipid Conference (SERLC) Travel Award 2006 American Society for Biochemistry and Molecular Biology (ASBMB) Travel Award 2005-2007 American Heart Association (AHA) Predoctoral Scholarship 2002 Graduated Summa Cum Laude 1998-2002 (all semesters) Dean's List 2000 Kentucky Millers Association Scholarship 2000 Agriculture Phone-a-thon Scholarship 1999-2001 University of Kentucky Panhellenic Academic Excellence Award 1998-2002 University of Kentucky Academic Scholarship 1998 Bellarmine College Academic Scholarship (declined)

\section{RESEARCH INTERESTS:}

- Cancer biology

- Huntington's Disease

- Regulation of cell apoptosis

- Regulation of protein localization within the cell

- Protein structure and function 
- Signal transduction

\section{TEACHING INTERESTS:}

- Cell Biology, Biochemistry, Molecular Biology

\section{RELATED EXPERIENCE:}

\section{Research}

Pre-Doctoral Fellow/Ph.D. Research, Department of Biochemistry and Molecular Biology, University of Louisville, Louisville, Ky

August 2003 - July 2009

- Designed and conducted experiments for determining cellular localization of wild-type Bax and Bax mutant constructs

- Focused on the role of the C-terminal tail of Bax in regulating Bax localization

- Performed structural studies on artificial peptides

- Investigated the role of the tail-anchor in a tail-anchored protein, Fis 1, using functional studies in yeast

Skills gained:

- Cell culture and transfection

- Measurement of apoptosis

- Confocal microscopy

- Subcellular fractionation

- Gel electrophoresis (DNA and protein)

- Immunoblotting

- DNA vector construction and mutagenesis

- Circular dichroism analysis of peptides

- Flow cytometry

- Yeast DNA transformation using integrated plasmids and circular plasmids

- Functional mitochondria assays in yeast

- Growth property studies in yeast

- In vitro translation

- In vitro mitochondrial import assays

Independent Research Project, Department of Physiology, University of Kentucky, Lexington, Ky

Fall 2002

- Participated in the verification of primary culture conditions of lobster olfactory sensory neurons (OSNs)

- Used immunocytochemistry to identify OSNs within primary cell cultures and olfactory tissue sections

Pharmaceutical Sciences Research Program, College of Pharmacy, University of Kentucky, Lexington, Ky

Summer 2001 
- Determine if electrical stimulation conditions could elicit $[3 \mathrm{H}] \mathrm{NE}$ release from rat hypothalamus tissue using superfusion chambers

- Determine the effect of AngiotensinIl on [3H]NE release

- Analyze the effect of the AngiotensinII inhibitor, Losartan, on this release

\section{Teaching}

Teaching Assistant, Department of Biochemistry and Molecular Biology, University of Louisville, Louisville, Ky

Fall 2004

- Advised undergraduate/graduate biochemistry students during office hours

- Graded quizzes and assignments

\section{PUBLICATIONS:}

Stepanyan R, Hollins B, Brock SE, McClintock TS (2004) Primary culture of lobster (Homarus americanus) olfactory sensory neurons. Chem Senses. 29(3): 179-87

Wattenberg BW, Clark D, Brock S (2007) An artificial mitochondrial tail signal/anchor sequence confirms a requirement for moderate hydrophobicity for targeting. Biosci Rep. 27:385-401

Yalcin A, Clem BF, Simmons A, Lane A, Nelson K, Clem AL, Brock E, Siow D, Wattenberg B, Telang S, and Chesney J (2009) Nuclear targeting of 6phosphofructo-2-kinase (PFKFB3) increases proliferation via cyclin-dependent kinases. J Biol Chem. (in press)

Brock SE and Wattenberg BW. The Bax carboxy-terminal hydroophobic helix does not determine organelle-specific targeting but is essential for maintaining Bax in an inactive state and for stable mitochondrial membrane insertion. (submitted)

\section{ABSTRACTS AND PRESENTATIONS:}

Brock SE, Wattenberg BW (2005) Controlling apoptosis through protein targeting to mitochondria. A yeast system to elucidate activation of the proapoptotic protein Bax. Poster \#6. James Graham Brown Cancer Center Fourth Annual Retreat, Louisville, KY

Brock SE, Wattenberg BW (2006) Mitochondrial targeting of the pro-apoptotic protein Bax and other tail-anchored proteins. Poster. American Society for Biochemistry and Molecular Biology (ASBMB) 2006 Annual Meeting, San Francisco, CA

Brock SE, Wattenberg BW (2006) Membrane targeting of the pro-apoptotic protein Bax. Presentation. The $41^{\text {st }}$ Annual Southeastern Regional Lipid Conference, Cashiers, NC 
Brock SE, Wattenberg BW (2006) Membrane targeting of the pro-apoptotic protein Bax. Poster \#6. James Graham Brown Cancer Center Fifth Annual Retreat, Louisville, KY

Brock SE, Wattenberg BW (2007) Membrane targeting of the pro-apoptotic protein Bax. Poster \#13. James Graham Brown Cancer Center Sixth Annual Retreat, Louisville, KY

Brock SE, Wattenberg BW (2008) Membrane targeting of the pro-apoptotic protein Bax. Poster \#111 Keystone Symposia: Cell Death and Cellular Senescence, Breckenridge, $\mathrm{CO}$

\section{REFERENCES:}

Binks Wattenberg, Ph.D.

Associate Professor

Brown Cancer Center

University of Louisville

Tel. (502) 8527762

bowatt01@gwise.louisville.edu

Thomas Geoghegan, Ph.D.

Associate Professor

Department of Biochemistry and Molecular Biology

University of Louisville

Tel. (502) 8527824

tegeog01@gwise.louisville.edu 